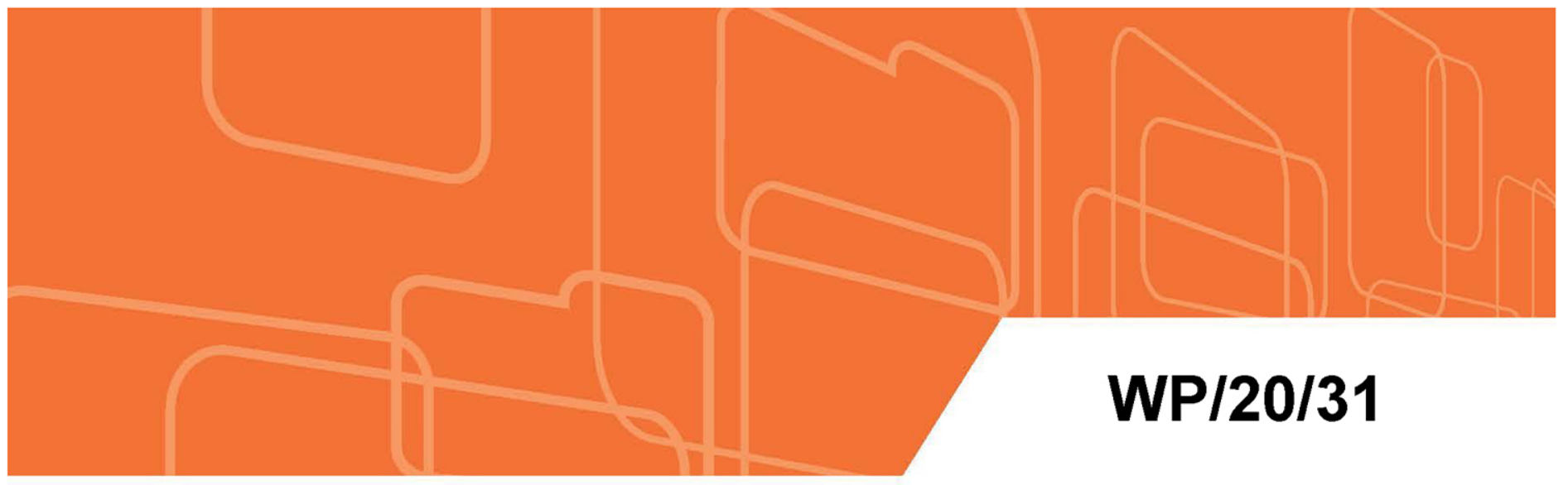

IMF Working Paper

\title{
Judge Bias in Labor Courts and Firm Performance
}

by Pierre Cahuc, Stephane Carcillo, Berengere Patault, and Flavien Moreau

IMF Working Papers describe research in progress by the author(s) and are published to elicit comments and to encourage debate. The views expressed in IMF Working Papers are those of the author(s) and do not necessarily represent the views of the IMF, its Executive Board, or IMF management. 


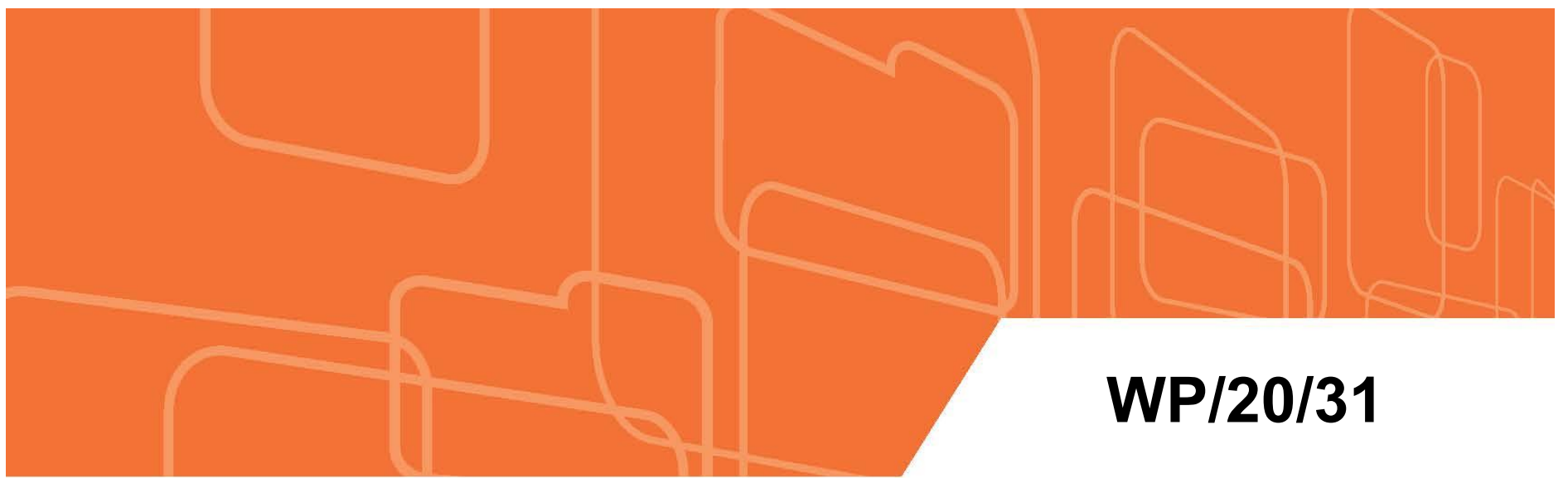

\section{IMF Working Paper}

\section{Judge Bias in Labor Courts and Firm Performance}

by Pierre Cahuc, Stephane Carcillo, Berengere Patault, and Flavien Moreau

IMF Working Papers describe research in progress by the author(s) and are published to elicit comments and to encourage debate. The views expressed in IMF Working Papers are those of the author(s) and do not necessarily represent the views of the IMF, its Executive Board, or IMF management.

I N T E R N A T I O N A L M O N E T A R Y F U N D 


\title{
IMF Working Paper
}

\author{
African Department \\ Judge Bias in Labor Courts and Firm Performance \\ Prepared by Pierre Cahuc, Stephane Carcillo, Berengere Patault, and Flavien Moreau \\ Authorized for distribution by Amine Mati
}

February 2021

\begin{abstract}
IMF Working Papers describe research in progress by the author(s) and are published to elicit comments and to encourage debate. The views expressed in IMF Working Papers are those of the author(s) and do not necessarily represent the views of the IMF, its Executive Board, or IMF management.
\end{abstract}

\begin{abstract}
Does labor court uncertainty and judge subjectivity influence firms' performance? We study the economic consequences of judge decisions by collecting information on more than 145,000 Appeal court rulings, combined with administrative firm-level records covering the whole universe of French firms. The quasi-random assignment of judges to cases reveals that judge bias has statistically significant effects on the survival, employment, and sales of small low-performing firms. However, we find that the uncertainty associated with the actual dispersion of judge bias is small and has a non-significant impact on their average outcomes.
\end{abstract}

JEL Classification Numbers: J33, J63, J65.

Keywords: Dismissal compensation, judge bias, firm survival, employment Author's E-Mail Address: fmoreau@imf.org 


\title{
Judge Bias in Labor Courts and Firm Performance
}

\author{
Pierre Cahuc \\ Sciences Po, IZA, CEPR
}

\author{
Stéphane Carcillo \\ $O E C D$
}

Bérengère Patault

CREST

\author{
Flavien Moreau
}

$I M F$

October 2020

\begin{abstract}
Does labor court uncertainty and judge subjectivity influence firms performance? We study the economic consequences of judge decisions by collecting information on more than 145,000 Appeal court rulings, combined with administrative firm-level records covering the whole universe of French firms. The quasi-random assignment of judges to cases reveals that judge bias has statistically significant effects on the survival, employment, and sales of small low-performing firms. However, we find that the uncertainty associated with the actual dispersion of judge bias is small and has a non-significant impact on their average outcomes.
\end{abstract}

Key words: Dismissal compensation, judge bias, firm survival, employment. JEL Codes: J33, J63, J65.

Acknowledgements We thank the Chaire Sécurisation des Parcours Professionnels for its financial support. We thank Camille Hebert for providing invaluable help in retrieving firm identifiers. We also thank Andrea Ichino, Yanos Zylberberg and seminar participants at CREST and Sciences Po for their comments. The views expressed in this document are those of the authors and do not necessarily represent those of the IMF or its Executive Board or Management. This paper has benefited from the IAAE travel grant for the 2019 IAAE Conference in Nicosia. This work is supported by a public grant overseen by the French National Research Agency (ANR) as part of the 'Investissements d'avenir' program (reference : ANR-10-EQPX-17 - Centre d'accès sécurisé aux données - CASD). 


\section{Introduction}

Outcome unpredictability, the fear of a differentiated treatment, and judges' alleged pro-worker biases are frequent worries. In order to limit economic uncertainty and guard against dramatic outcomes, many advanced economies have recently enacted reforms that restrict judge latitude in awarding compensations. ${ }^{1}$ However, none of these regulations has been grounded on rigorous fact-based analysis, partly for lack of appropriate data.

To shed light on this issue, this paper presents the first systematic evidence of the impact of labor court judge bias on firms economic performance. We use text analysis to extract rich information from about 145,000 decisions made by French Appeals court over the period 2006-2016. This allows us to identify judge bias - i.e. the effects of judgespecific differences on compensations for wrongful dismissals - from the quasi-random allocation of cases to judges.

We find that some judges are more pro-worker than others, meaning that conditional on observables, they are more likely to i) consider more often that dismissals are wrongful and ii) set higher compensation levels conditional on characteristics of cases. The difference between the compensation set by the most pro-worker and the most pro-employer judges is significant: moving from the bottom decile to the top decile of judge bias increases expected compensation payments by about two months of salary, or 20 percent of the average compensation.

We then explore the impact of judge bias on firms. We rely on administrative firm-level records covering the whole universe of French firms and we focus on small firms, below 100 employees at the date of the judgment, which are likely to provide an upper-bound of the uncertainty effect we seek to estimate. From reduced-form regressions, we find that the judge bias has a significant impact on firm survival, sales and employment for firms which are small and low-performing, i.e. which have less than 10 employees and whose return on assets is below the median. There are no significant effects for other firms, either with at least 10 employees or whose return on assets is above the median. This indicates that the judge bias does matter for small, low-performing firms, but not for other firms. From instrumental variable regressions, in which the compensation for wrongful dismissal is instrumented by the judge bias, we find that an increase in the amount of compensation of

\footnotetext{
${ }^{1}$ In the U.S., judges of the National Labor Relation Board are denounced as being influenced by partisan ideology (Turner (2006), Semet (2016)). In Italy, the Jobs Act, adopted under the Renzi government in December 2014, aimed at reducing uncertainty due to excessive litigation and the unpredictability of judges' decisions (Boeri and Garibaldi (2018)). In France, the 2017 Ordonnances reforming the labor code introduced a ceiling to the level of compensation granted by judges, which depends on firm size and worker seniority. Actually, the power of judges in compensating the individual damages following wrongful dismissals is capped in a majority of European countries (see Annex A).
} 
1 percent of the payroll of the firm reduces employment at 3 years horizon by 3 percent for small firms whose returns on assets is below the median, but has no employment effects for other firms. ${ }^{2}$

Special attention is paid to establishing the credibility of our identification strategy. Appeals cases for wrongful dismissal are decided by three-judge panels composed of a president and their two assessors in a section of the court called "social chamber". We focus on the presidents, who oversee all the rulings and accordingly play a key role in deciding the case, and leverage their rotations across courts. To identify the effects of judge-specific differences on compensations for wrongful dismissals, we compare the compensations decided by subsequent presidents of social chambers within the same social chamber of the same Appeal court within the same year. More precisely, we estimate for each judgment the president bias using a leave-one-out difference between the average compensations for all other cases that a president has handled and the average compensations handled in the same social chamber within the worker and firm characteristics of the cases they judge. We verify that the allocation of judges is unrelated to the observable worker and firm characteristics of the cases they judge. We therefore interpret the differences between leave-one-out mean compensations set by subsequent judges in the same social chamber of the same Appeal court in a given year as reflecting the influence of judges' subjectivity.

Our results should nevertheless be interpreted cautiously as the dispersion of judge biases is an endogenous object, which may influence the decisions of firms and workers to go to court, even if the matching between judges and cases were random. More uncertainty about judge decisions raises the litigation rate and changes the type of cases going to litigation (Priest and Klein, 1984a; Lee and Klerman, 2016). Therefore, to evaluate the presence of potential selection effects, we compute the risk premium associated with the dispersion of judge bias. We find that the risk premium is at most equal to 1.5 percent of the expected amount of compensation conditional on observable worker and firm characteristics, meaning that it is likely that the dispersion of judge bias has negligible effects on the selection of cases that go to Appeal courts in our sample.

Given these negligible selection effects, what, then, would be the impact of reducing the dispersion of judge bias on firms' average outcomes? We consider three thought experiments, assuming either i) that the bias of all judges is set to zero, or ii) that the bias of pro-worker judges is set to zero while that of pro-employer judges is unchanged, or iii) that the bias of all pro-employer judges is set to zero while that of pro-worker judges is unchanged. In each case we find small statistically non-significant effects even for small,

\footnotetext{
${ }^{2}$ This corresponds to a labor demand elasticity of 3 percent, which is in the high part of the range of labor demand elasticity estimates. This order of magnitude looks relevant for small and low performing firms at 3-year horizon (Lichter et al. (2015)).
} 
low-performing firms. Hence, we conclude that the actual dispersion of judge bias has no significant effects on the average performance of firms in our context. An important open question that our study cannot address, however, is the possibility that all judges are biased, meaning that setting all biases to the mean does not ensure the absence of bias of all judges in the interpretation of labor laws (Ash et al., 2018).

This paper is related to several strands of research. First, there is a large strand of research on the consequences of judge disparities. Posner (2005) and Gennaioli and Shleifer (2008) show how the judicial policy preferences and the aversion of judges to reversal of their decisions by superior courts can influence judge biases from a theoretical perspective. The empirical literature provides evidence about differentiated treatment by judges in a wide spectrum of domains, including criminal sentencing (Scott (2010), Dobbie et al. (2018), Yang (2015), Bhuller et al. (2020)), bankruptcies (Bernstein et al. (2018a), Bernstein et al. (2018b)), decisions related to disability benefits (Autor et al. (2015), Dahl et al. (2014), French and Song (2014), Kostol et al. (2017), Maestas et al. (2013), Autor et al. (2019)). Relying on the quasi-random or random allocation of judges to cases, these contributions generally find that differentiated treatment by judges is significant, but that it can be mitigated by sentencing guidelines (Scott (2010), Yang (2015), Cohen and Yang (2019)). Bamieh (2016) uses this approach to document the behavior of judges in labor courts. Using random assignment of judges to cases in Italy, he shows that some judges are systematically slower, which leads to random variation in the trial length. Semet (2016) finds that the propensity of a panel of the US National National Labor Relation Board to reach a decision favoring labor increases with each additional Democrat judge added to the panel. We add to this literature by documenting for the first time the differentiated treatment by judges on the qualification of dismissals and on the amount of compensation when the dismissal is deemed wrongful.

Another strand of research deals with the impact of extraneous factors on the qualification of dismissals as unfair by judges. Ichino et al. (2003), Marinescu (2011) and Jimeno et al. (2020) show that the local unemployment and bankruptcy rates influence the probability that judges deem dismissals unfair. Our findings are coherent with these contributions, which show that the interpretation of labor law by judges is quite flexible. They are also in line with Jimeno et al. (2020) who show that despite the reforms of 2010 and 2012, which widened the definition of fair economic dismissals in Spain, the proportion of economic redundancies being ruled as fair by labor courts has not substantially increased. This discrepancy between the evolution of the legal rules and the "effective" (after resolution) rules is interpreted as arising from the opposition of judges to the change in the legal definition of fair dismissals, suggesting that judges have significant margin for interpreting legal rules. 
Our contribution is also related to the very large literature which analyzes the labor market impact of dismissal costs (see Cahuc et al. (2014) for a survey). We add to the part of this literature which analyzes the effects of court decisions regarding unfair dismissals on firms' outcomes (Autor (2003), Autor et al. (2006), Autor et al. (2007), Bamieh (2016), Boeri and Garibaldi (2018), Fraisse et al. (2015), Gianfreda and Vallanti (2017), Martins (2009)). Those papers typically use the implementation of reforms of Employment Protection Legislation to assess the effects of dismissal costs on employment or productivity. Autor et al. (2007) use the adoption of wrongful discharge protections by U.S. State courts and find that higher employment protection leads to lower employment flows, lower firm entry rates and lower total factor productivity. In France, Fraisse et al. (2015) use an instrumental strategy and estimate that an increase in dismissal costs leads to a decline in employment fluctuations. In Italy, Bamieh (2016) shows that longer trials induced by specific differences in judges randomly assigned to firms reduce the labor turnover and increase employment. Our paper differs from previous studies in several crucial aspects. First, we analyze the impact of the differentiated treatment by judges concerning the qualification of dismissals and the compensation for wrongful dismissal on firm performance. This is the first contribution exploiting such information at the firm level. Second, we identify the causal impact of dismissal costs exploiting the quasi-random allocation of judges to cases. Third, our contribution looks at the impact of dismissal costs on the survival of small firms, an issue which has been overlooked by the literature so far. From this perspective, it is related to the corporate finance literature that assesses the effect of exogenous cash flow shocks, positive or negative, on firms (Blanchard et al. (1994), Giroud and Mueller (2017), Rauh (2006)) and the effects of labor market regulation on access to credit (Simintzi et al. (2014), Favilukis et al. (2020).

The paper is organized as follows. Section 2 describes the French institutional setting and Section 3 the data. Section 4 presents evidence about judge bias. Section 5 documents the impact of judge bias on firm survival and employment. Section 6 concludes. 


\section{Institutional background}

This section starts by presenting the regulation of termination of open-ended employment contracts, which represent about 85 percent of ongoing contracts in France, before providing an overview of the organization of courts and describing the assignment of judges to cases.

\subsection{Legal framework}

Following the termination of an open-ended contract, employees with a tenure longer than one year and who did not commit any serious or gross misconduct (faute grave or faute lourde) are granted a minimum legal severance payment calculated as one fifth of monthly salary per year of tenure, plus an additional two fifteenths after ten-year tenure. These amounts can be topped up if the professional branch to which the firm belongs has signed a collective agreement setting higher payouts.

Under French law, terminations of open-ended employment contracts are lawful if they are justified by a "real and serious cause", either economic or personal. Dismissals for economic reasons are lawful only to "safeguard" firms, but not to improve their profitability. Dismissals for personal reasons are lawful only in case of misconduct or lack of adaptation to the job. For both types of dismissal, the burden the proof is on the side of employers. Furthermore, employers have to prove that there is no other position available in the firm (worldwide in the period we are studying) for dismissed employees when the dismissal is motivated by economic reasons or by lack of adaptation to the job.

When the employee deems her dismissal wrongful, she can file a complaint before the Prud'hommes councils, which are courts of first instance. While most European countries have specialized labor tribunals to deal with dismissal cases (OECD, 2013), in France judges in Prud'hommes councils are employee and employer representatives, with an exact equality between the numbers of councilors representing employers and those representing employees.

Serverin and Valentin (2009) calculate that for economic dismissals in 2006, the rate of employee recourse to Prud'hommes in case of dismissal is between $1 \%$ and $2 \%$ while for disciplinary dismissals it is between $17 \%$ and $25 \% .{ }^{3}$ According to Desrieux and Espinosa (2019), among claims that reached the judicial stage at Prud'hommes council from 1998 to $2012,62 \%$ resulted in the acceptance of the employee's claims. Similarly Fraisse et al.

\footnotetext{
${ }^{3}$ Economic dismissals are therefore very rarely challenged, one reason being that their conditions are usually negotiated between social partners at the firm level. Another reason is that these layoffs only account for $2 \%$ of all exiters, since employers prefer to have recourse to personal motives given the complexity of their procedure (when more than one person is laid off) and the absence of a legal or conventional definition of a lawful separation for economic reason (at least until a 2016 law which clarified this notion).
} 
(2015) estimate that in the 1996-2003 period, "60\% of cases end up with a trial, among which $75 \%$ lead to a worker's victory".

The decisions of the Prud'hommes council are appealed in most of the cases: the appeal rates are, according to Guillonneau and Serverin (2015), between $60 \%$ and $67 \%$ in the 2004-2013 period. From 2006 to 2016, we find that only 45\% of Prud'hommes councils decisions about compensations for dismissal were confirmed by Appeal courts. Insofar as appeal rates are very high and the appeal suspends the application of the decisions of Prud'hommes councils which are frequently not fully confirmed, the compensation for wrongful dismissals decided at the Appeal court level is a better measure of the compensation to be paid by the firm than that decided by Prud'hommes councils. ${ }^{4}$ Therefore, in what follows, we use the compensation for wrongful dismissals decided by Appeal courts.

\subsection{Overview of Appeal court's organization}

There are 36 Appeal courts and 210 Prud'hommes councils. Each French Appeal court has different chambers, among which at least one social chamber treats cases coming from the Prud'hommes council. Some Appeal courts have several social chambers, such as the Paris court which has fourteen of them. There is one president for each social chamber. This chamber president has administrative responsibilities within the court, and is in charge of presiding over all the chamber's trails. She can nevertheless be replaced whenever needed, for instance during holidays. For each judgment, the chamber president is assisted by two councillor-judges.

The status of judges and their mobility is determined by the Ordonnance Organique of 22 December 1958. This regulation states that judges in Appeal courts are "placed judges", i.e. assigned to a given Court or a given Chamber in a specific position according to decisions made every year by the First President of the Court of Cassation (the highest civil jurisdiction) and the First President of the Appeal court. Promotions are based on merit and decided every year by a National Commission of Advancement. The First President of the Appeal court herself is placed by a decree signed by the President of the Republic following the recommendation of the independent National Council of the Judiciary. Besides, mobility requirements are enforced through several regulations, such as promotions awarded only to judges in a given position for less than 5 years in a same jurisdiction (7 years from 2017), the prohibition to stay in the same specialized function in the same jurisdiction more that ten years altogether, or geographical mobility requirements

\footnotetext{
${ }^{4}$ In any case, data about Prud'hommes councils decisions are not available.
} 
to achieve the first grade of the remuneration schedule (organic law 2001-539 of June 25 th, 2001). The turnover that follows is substantial: every year $20 \%$ of positions are re-assigned among judges (Conseil de la Magistrature, rapport d'activité 2016).

Importantly, the First President of the Appeal court sets objective criteria driving the distribution of the cases between the various chambers of the Appeal court, independently of the judges' identity, under the control of the assembly of judges (articles R312-42 and R312-42-1 of the Judiciary Organisation Code).

\subsection{Assignment of judges to cases}

To identify judge bias, the allocation of cases to judges must be independent of judges observable and non-observable characteristics. Therefore, our identification strategy relies on the quasi-randomness of the allocation of cases to judges. Two aspects of the organization of the judicial system imply that the allocation of judges to cases has important random components, i.e. does not depend on the identity of judges.

First, it takes a judge on average two years from the time of her appointment to rule on all the cases assigned to the social chamber prior to her arrival. The composition of the court cannot be changed by plaintiffs and judges cannot select their cases, except for conflict of interest. The presence of this backlog and the fact that cases cannot be re-allocated imply that it is almost impossible to assign a case to a specific judge, because the average spell of a judge in a social chamber is equal to about 2.5 years, meaning that the identity of the president that will judge a case assigned to a social chamber is generally unknown when the case is allocated to the social chamber. Moreover, when a president is absent, for vacation, sickness, vocational training or any other reason, she is replaced by the president of another chamber who judges the cases which are scheduled.

Second, the selection of cases settled before going to court can be influenced by the judge in charge of the case. However, employers, workers and lawyers do not know with certainty the identity of the president until the day of the judgment for several reasons: a new judge may be appointed, the judge may be absent and replaced by another one. In addition, in the case of larger Appeal courts, the existence of several social chambers in the same court implies that the social chamber that will judge the case is not known before the judgment. ${ }^{5}$

These institutional features imply that the assignment of judges to cases has important random components that we will leverage to identify the judge bias as explained in Section 4.2 .

\footnotetext{
${ }^{5}$ Our main analysis relies on all Appeal courts, but we show that our results hold when the sample of cases is limited to large Appeal courts with several social chambers (see Section 5.5).
} 


\section{Data}

\subsection{Compensation data}

The empirical analysis draws on a newly created dataset of French Appeal court rulings from 2006 to 2016 bringing together, for the first time, detailed information on compensation amounts decided in court along with a rich set of firm characteristics. From the court rulings, we extract a wide array of variables related to each case, as well as the firm's name and address. Then, using the firm's name and address, we are able to retrieve the firm's unique administrative identifier (SIREN), which allows us to link our compensation dataset to comprehensive, matched employer-employee data as well as to financial variables. This section highlights the key steps in the construction of this dataset and the main features of the data. Appendix E provides additional and technical details.

First, we gather 145, 638 Appeal court rulings published by the Ministry of Justice Each of these text documents contains a lot of information in a semi-structured format. Court rulings usually provide a description of the history of the contractual relationship between the employee and the employer. This presentation of facts also includes the claims of the parties and the decision of the Prud'hommes council. Court rulings then describe the reasons for the Appeal court decision and end with the compensation for dismissal if the dismissal is deemed wrongful. Figure 2 shows an extract of a typical ruling.

When her dismissal is ruled wrongful, an employee may receive additional compensations on top of the compensation for wrongful dismissal. Tracking and accounting for these different forms of compensation is important because even though the legal bases for granting them are distinct in principle, judges' full understanding of the case at hand might in practice create correlation patterns between these amounts. In other words, it is possible that a judge's appreciation of the case might color not only the amount granted for unfair dismissal but also the other forms of compensation. Possible additional compensations include: moral and financial damages, compensation for unpaid wages, etc. ${ }^{6}$

We extract all these variables automatically from the Appeal court rulings using a Python program based on keywords extraction and natural language processing techniques. In order to control the quality of the process, we assessed the accuracy of the results on a manually-filled dataset forming a subsample of about 2,500 observations, selected at random. We find that the correlation between the compensation amount of the manuallyfilled and the automatically-filled datasets is equal to $94 \%$, which is in the upper range of

\footnotetext{
${ }^{6}$ See Appendix E for a more complete list of the dozens of possible additional compensations.
} 
seminal papers using this type of approach (Baker et al. (2016)).

Finally, we also retrieve the unique administrative firm identifier known as SIREN, either directly from the text when it is displayed, or, using the firm's name and address, after an automatic search on online companies registries such as societe.com and bodacc.fr. The SIREN identifier, assigned by France's statistical agency to each company, then allows us to merge our rulings compensation dataset with French administrative social security and tax data. In some cases where the company is very small or when the cases were launched a long time ago, we were not able to retrieve the SIREN.

\subsection{Social security and tax data}

In order to analyze the impact of judge decisions on firm performance, we combine our novel rulings data with two comprehensive administrative datasets. Because both have been used in the literature we only briefly highlight their main characteristics

Matched employer-employee data. We merge the compensation data with social security data thanks to the firm identifier. We use the comprehensive matched employeremployee dataset called DADS Postes Déclarations Administratives de Données Sociales from 2002 to 2015, which reports detailed payroll information about each employee working for a French private firm. This dataset allows us to track the evolution over time of the wage bill and of the number of employees of the firms in our rulings dataset.

Tax data. We rely on tax data, FICUS-FARE, that contain the full company accounts, including for instance sales, net income, EBITDA. From these files we are able to construct a wide array of indicators for the firm's financial health such as the firm's leverage ratio, the return on assets, etc. These data are available from 2002 to 2016.

\subsection{Sample restriction}

From our initial sample of 145,638 rulings, we select those for which it is indicated that the firm was not in liquidation at the judgment date, because dismissal compensations of liquidated firms are paid by a public insurance agency (Agence de Garantie des Salaires). Since the parties involved in these cases are no longer the employer and the employee, but the employee and the public agency, these cases are not suitable to identify judge bias in situations where employers are directly involved. Then, we eliminate cases for which the relevant information about the presiding judge's name and surname, the total amount of compensation, and the monthly wage was either not retrieved or is not available. While the most important information is often retrievable - the identity of the Appeal court, compensation amounts for wrongful dismissal, worker's wage and seniority, location of the Prud'hommes council, whether the worker or the firm was the appellant, etc. - there 
are sizeable variations in the amount of available information from one ruling to the next. This heterogeneity reduces the size of the useable sample by about a half. Finally, we eliminate cases in which the employer belongs to the public sector and those judged by judges who have judged less than 50 cases. We end up eventually with 37,149 cases and 159 presidents $^{7}$ (See Table 1 ). The 159 presidents who judged more than 50 cases cover 93.3\% of cases among the universe of cases that we analyze. Each of these presidents judged 450 cases on average with a median equal to 339 .

\section{Judge biases}

This section is devoted to the analysis of judge bias. We start by reporting descriptive statistics about judgments before presenting the empirical strategy used to identify judge bias and showing the results.

\subsection{Descriptive statistics}

Table 2 presents descriptive statistics of judgments at the case-level. Our sample comprises only cases that are judged in Appeal courts. The average amount of compensation for wrongful dismissal granted by Appeal courts is equivalent of 4.3 months of salary, while the total amount, including other possible indemnities for unpaid leave, unpaid (overtime) hours worked, unpaid notice, or (more rarely) compensation for damages in case of harassment or discrimination, represents 10.5 months of salary. The worker appeals in $58 \%$ of cases.

Figure 3 displays the histogram of the compensation for wrongful dismissal in monthly wages, conditional on being positive. There is a mass around six months of salary: this stems from French legislation that institutes a minimal threshold of six months of salary for workers with more than 24 months of seniority employed in firms with more than 11 workers, when the dismissal is deemed wrongful.

Table 2 also provides information about differences between decisions of Appeal courts and Prud'hommes. The amount given at Appeal court is the same as the amount decided at Prud'hommes in $45 \%$ of cases, while it is higher in $38 \%$ of cases and lower in $17 \%$ of cases. The average compensation for unfair dismissal set by Appeal courts is much higher $(12.288 €)$ than that of Prud'hommes $(7.236 €) .{ }^{8}$ All in all, Appeal courts are more

\footnotetext{
${ }^{7}$ Let us remind readers that the court is composed of a president and two councillor-judges. The president, who is in charge of supervising the writing of the judgments, plays the key role in the judgment.

${ }^{8}$ Note that we consider here only Prud'hommes judgments which are appealed and reach the Appeal court, as the information about other Prud'hommes judgments is not available
} 
favorable to workers than Prud'hommes. Figure 4 shows the scatter plot of the amount of compensation in monthly wages depending on seniority set by Appeal courts (right panel) and by Prud'hommes (left panel). It is apparent that there is an important dispersion of the amount of compensation conditional on seniority in both tribunals. Table 2 shows that the variance of the compensations of Appeal courts is larger than that of Prud'hommes.

Obviously, the variance of compensations conditional on seniority originates from the diversity of situations specific to each case. Nevertheless, the subjective interpretation of judges might exert an important influence, as suggested by the difference between the judgments of Prud'hommes and Appeal courts, which is significant at all amounts of compensation (Figure 5). Only a small share of the variance of compensations is explained by observable case characteristics: for instance, only $13.6 \%$ of the variance is explained by salary and seniority. Adding many other covariates ${ }^{9}$ makes this share jump to $32.9 \%$. In other words, $67 \%$ of the variance of dismissal compensation is still left unexplained when controlling for a wide range of covariates.

We use two types of variable to evaluate a judge's bias: i) the frequency at which the judge grants a positive compensation to the worker (for unfair dismissal or any other motive), and ii) the amount of compensation. ${ }^{10}$ First, Figure 6 displays the histogram of the frequency at which the judge grants a positive compensation. Figure 7 shows that amounts granted for unfair dismissal are positively correlated with the amounts granted under other motives. On average one month of salary granted for unfair dismissal is associated with one third of additional monthly wage granted for other motives. In other words, judges' decisions not only bear on amounts granted for unfair dismissal, but also on other compensations related to contract breach, like unpaid hours of work, compensation for non-respect of the dismissal procedure and other reasons enumerated in Section 3.1. Therefore, the main variable of interest we use throughout our analysis is the total compensation for contract breach (for unfair or any other motive), the histogram of which is exhibited in Figure 8.

In order to identify the judge bias, the allocation of judges to cases must be random. We devise in the following section our strategy to consistently identify judges biases.

\footnotetext{
${ }^{9}$ i.e. controlling for the amount granted at Prud'hommes, the amount claimed by the worker, the firm's number of workers, whether it was the worker who appealed, whether it is an economic dismissal and the time elapsed between the dismissal and the appeal judgment

${ }^{10}$ Our measures of Appeal courts judges bias do not rely on the difference between the outcome of the Appeal court and the outcome of Prud'hommes insofar as Prud'hommes' decisions are influenced by the potential bias of Prud'hommes counselors.
} 


\subsection{Empirical strategy}

Our empirical strategy rests on the assumption that the allocation of judges to cases is random. As argued in Section 2.3 this is supported by three key institutional features: i) judges inherit a large backlog, ii) judges are mobile and iii) defendants and plaintiffs have limited information about the identity of the judge which ensures that the personality of judges does not unduly generate case selection through pre-trial settlement. In this context, the random component of the allocation we use is the allocation of cases across different judges within court, social chamber and year. Hence, we rely on differences between decisions of presidents belonging to the same social chamber within the same year.

In a given year, the president of a social chamber may move to another job, either to another Appeal court or to another position within the same court, and is then replaced by a new president. The initial judge and the new judge may have different interpretations of labor laws influencing the amount of compensation in case of dismissal. For instance, in year 2014 and social chamber 1 of the Paris Appeal court, a case may be either allocated to president $A$ in the first part of the year, or to president $B$ in the second part of the year, as shown by Figure 9. Although unlikely, a non-random assignment of cases to judges is still possible. For instance, it is possible that judge $A$ is specialized in sexual harassment cases and that all those cases allocated this year are systematically assigned to this judge. However, what makes such an allocation of cases highly implausible is the large backlog in each social chamber - the average waiting time before judgments is about two years (667 days), and only 10\% of cases are judged in less than 300 days. In this context, insofar as the cases are allocated to the social chambers at the start of the appeal procedure, it is very unlikely that cases can be specifically allocated to presidents whose seniority in the chamber is less than one year. Thus, since we rely on differences between decisions of presidents belonging to the same social chamber within the same year to identify judge specific differences, it is unlikely that this identification strategy is burdened by non-random allocation of cases to judges.

Moreover, if the judge is absent the day of the judgment, he can be replaced by another judge without notice to the plaintiff and the defendant. Regardless, the presence of several social chambers implies that the plaintiff and the defendant do not know which social chamber will judge their case before the judgment. This implies that it is very unlikely that the identity of the judge in charge of the case influences the settlements before the judgment.

We implement this strategy by computing, for each social chamber $\times$ year pair $(k, t)$ in which we observe judge $j$, the difference between the average of judge $j$ outcomes $^{11}$ in

\footnotetext{
${ }^{11}$ The outcome is either the amount of compensation or the indicator variable equal to one if the
} 
this chamber this year and the average of all outcomes in this chamber this year:

$$
\bar{\varepsilon}_{j k t}=\left(\frac{1}{n_{j k t}} \sum_{i \in(j, k, t)} y_{i}\right)-\left(\frac{1}{n_{k t}} \sum_{i \in(k, t)} y_{i}\right)
$$

where $i \in(j, k, t)$ means that case $i$ is judged by judge $j$ in chamber $k$ and year $t$ and $i \in(k, t)$ means that case $i$ is judged in chamber $k$ and year $t ; y_{i}$ is the outcome of case $i$; $n_{j k t}$ the number of judgments of judge $j$ in chamber $k$ during year $t$ and $n_{k t}$ is the number of judgments in chamber $k$ during year $t$.

Judges move across social chambers during the period. Our measure of the bias of judge $j$ is thus the weighted average of $\bar{\varepsilon}_{j k t}$, where the weight of social chamber $k$ in year $t$ is the share of judgments of judge $j$ in this chamber this year in all judgments of judge $j$ :

$$
\bar{\varepsilon}_{j}=\sum_{(k, t) \in(K, T)(j)} \frac{n_{j k t}}{n_{j}} \bar{\varepsilon}_{j k t}
$$

where $(K, T)(j)$ is the set of all chamber $\times$ year pairs $(k, t)$ observed for judge $j ; \bar{\varepsilon}_{j}$ is the bias of judge $j$.

When we analyze the correlation between judge $j$ bias and the outcome of case $i$, the bias of judge $j$ is measured by the leave-one-out mean of case $i$, meaning that it is judge specific and case specific. To put it differently, the bias of judge $j$ for case $i$ is ${ }^{12}$

$$
\bar{\varepsilon}_{i j}=\sum_{(k, t) \in(K, T)(j)} \sum_{i^{\prime}, i^{\prime} \neq i} \frac{n_{j k t}}{n_{j}-1} \bar{\varepsilon}_{i^{\prime} j k t}
$$

where

$$
\bar{\varepsilon}_{i j k t}=\left(\frac{1}{n_{j k t}-1} \sum_{i^{\prime} \in(j, k, t), i^{\prime} \neq i} y_{i^{\prime}}\right)-\left(\frac{1}{n_{k t}-1} \sum_{i^{\prime} \in(k, t), i^{\prime} \neq i} y_{i^{\prime}}\right)
$$

Obviously, by definition: $\sum_{i \in j} \bar{\varepsilon}_{i j}=\bar{\varepsilon}_{j}$.

It is clear that our measure of judge bias relies on their mobility across social chambers which is crucial for comparing all judges. This measure allows us to rank judges according to their bias. The higher the degree of judge mobility, the higher the probability to achieve a perfect ranking (see Appendix C). We document the extent of judge mobility in Figure 10, where each dot represents a judge, and where a line connects two dots if the two judges shared the same social chamber at least once. As is apparent, the network of judges is dense, thus indicating a high mobility of judges across social chambers. ${ }^{13}$

To further confirm the randomness of the allocation of cases to judges, we conduct randomization tests in which we regress our measure of judge specific differences on

\footnotetext{
dismissal is deemed wrongful.

${ }^{12}$ Note that our definition of the bias can be obtained by regressing the outcome for all cases on chamber $\times$ year fixed effects as in the contributions of Dahl et al. (2014) and Dobbie et al. (2018). See appendix B.

${ }^{13}$ If judges were not mobile whatsoever, one would observe perfectly distinct judge clusters, each cluster representing one social chamber.
} 
worker and firm characteristics of corresponding cases. The absence of correlation between observable characteristics of case and judge specific differences indicates that there is no selection on observable variables. Though we obviously cannot test the correlation between judge specific differences and unobserved variables, such randomization tests are reassuring for our identification strategy.

\subsection{Results}

Judge subjectivity can influence both the qualification of the dismissal - either wrongful or lawful - and the compensation amount granted by the judge to the worker. In what follows, we examine these two aspects of judges' decisions and we look at how they are related.

\subsubsection{Qualification of dismissals}

We first construct a judge specific pro-worker bias with respect to the dismissal qualification. Figure 11 presents the histogram of the judges' pro-worker bias among the population of cases defined by equation (3). It sheds light on the variability of biases.

Relation between judge bias and the qualification of dismissals

Our measure of judge bias is relevant only if it is significantly correlated with the qualification of dismissal in each specific case. To check whether our measure of judge bias is indeed related to the actual qualification of dismissals, Figure 11 displays the local polynomial fit of the probability that dismissals are deemed wrongful explained by the judge pro-worker bias. The judge pro-worker bias is indeed positively related to the probability that dismissals are deemed wrongful. Being assigned to one of the $10 \%$ most pro-worker judges as compared to one of the $10 \%$ least pro-worker judges increases the probability that the dismissal is deemed wrongful by about 4 percentage points, which corresponds to an increase of $7 \%$ in the probability that the dismissal is deemed wrongful.

Table 3 further documents the relation between the qualification of dismissals and judge pro-worker bias. This table displays the OLS estimator of the regression of the indicator variable equal to one if the dismissal is deemed wrongful on the judge's pro-worker bias. All standard errors are clustered at the judge level. Column (1) includes Appeal court and year fixed effects. Column (2) adds control variables comprising the worker's salary, seniority and whether the dismissal is economic or for personal reasons. The coefficients, which are significant at $1 \%$ level of confidence, are consistent with those obtained from the polynomial fit without any control, displayed on Figure 11. Indeed, according to Table 3, 
being assigned to one of the $10 \%$ most pro-worker judges as compared to one of the $10 \%$ least pro-worker judges increases the probability that the dismissal is deemed wrongful by 4.1 percentage points ${ }^{14}$ which is very close to the prediction of the polynomial fit.

Contribution of judge biases to the dispersion of qualification of dismissals

Table 4 shows nevertheless that the dispersion of judge fixed effects only explains a small share of the variance of the qualification of dismissal: column (4) exhibits that the adjusted $R^{2}$ only increases from $2.7 \%$ to $3.0 \%$ when controlling for judge bias, once case controls, court fixed effects and year fixed effects are accounted for. One may note that the qualification of the dismissal is barely predicted by fixed effects, case controls and judge bias, indicating that a large share of the variation of the qualification is left unexplained when these variables are taken into account.

\section{Analysis of the allocation of cases to judges}

If judges are randomly assigned, the addition of control variables in the regression of the qualification of dismissal reported in Column (1) of Table 3 should not significantly change the estimates of the coefficient of the judge bias, as case characteristics should be uncorrelated with judge bias. The assumption that judges are randomly assigned is not rejected insofar as the coefficients are not significantly different ( $\mathrm{p}$-value $=0.25$ ) across specifications reported in Columns (1) and (2) of Table 3.

To further check that the measure of judge bias is not the consequence of a non-random allocation of judges to cases, we examine whether judge fixed effects are correlated to the observable characteristics of cases. Tables 5 and 6 display such tests. The main finding is that no variable is correlated to judge bias. Table 5, first column displays the regression of the qualification of the dismissal on several characteristics of the case, with Appeal court and year fixed effects and standard errors clustered at the judge level. The amount granted by Prud'hommes and an economic ground for the dismissal are positively correlated with the probability of the dismissal to be deemed wrongful, while the seniority and the fact that the worker appealed are negatively correlated. The second column of Table 5 thus offers a stark contrast to its first column: when regressing the judge fixed effect on the same characteristics, one finds no significant relationship. Furthermore, the F-test rejects the hypothesis of joint significance of explanatory variables. We replicate the exact same

\footnotetext{
${ }^{14}$ The computation is performed as follows: we multiply the point estimate given in column (3) of Table 3 by the difference of pro-worker bias when going from the 1 st to the 9 th decile of the pro-worker bias, respectively equal to -0.46 and 0.36 .
} 
methodology for the characteristics of the firm. Results reported in Table 6 show that judge bias is not correlated to characteristics of firms.

\subsubsection{Compensation for wrongful dismissal}

The amount of the full compensation package granted by the judge provides another dimension along which to analyze judges' heterogeneity. In the following, we perform the same exercise as before by computing the pro-worker bias based on the amount granted by the judge as a proportion of monthly wage. Figure 12 presents the histogram of the judge bias among the population of cases. The judge bias displays a significant heterogeneity.

Relation between the judge bias and the amount of compensation for wrongful dismissal

The judge bias computed from the amount of compensation is highly correlated to the compensation granted by the judges. This correlation is illustrated by Figure 12 which displays the polynomial fit of the compensation explained by judge pro-worker bias. Being assigned to on of the $10 \%$ most pro-worker judges rather than one of the $10 \%$ least pro-worker judges increases the amount by about 2 months of salary. ${ }^{15}$

Table 7 provides further evidence about the relation between the compensation granted by the judges and their bias computed with the amount of compensation. Table 7 displays the OLS estimators of the regression of the compensation for wrongful dismissal in monthly wages on the judge's pro-worker bias. Column (1) reports the result with Appeal court and sector $\times$ year fixed effects. Column (2) adds control variables comprising the worker's salary, seniority and whether the dismissal is economic or for personal reasons. Controlling for case characteristics, an increase in the judge pro-worker bias by one point increases the amount of compensation in months of salary by 0.8 points. This implies that being assigned to one of the $10 \%$ most pro-worker biased judges as compared to one of the least $10 \%$ pro-worker judges increases the compensation amount by 2.1 months of salary. This prediction is in line with that obtained from the polynomial fit, displayed on Figure 12.

Contribution of judge biases to the dispersion of compensation for wrongful dismissal

Although judge biases are strongly correlated with the amount of compensation, Table 4 shows that the dispersion of judge bias only explains a small share of the variance of compensations for wrongful dismissals: Column (8) exhibits that the adjusted $R^{2}$ only increases from $10.8 \%$ to $11.1 \%$ when controlling for the judge bias once case controls, court fixed effects and year fixed effects are accounted for. This suggests that the judge

\footnotetext{
${ }^{15}$ The judge bias of the 1 st decile is equal to -1.28 and that of the 9 th decile to 1.25 .
} 
bias may explain a limited share of the large dispersion of compensation conditional on several observable characteristics of cases.

\section{Analysis of the allocation of cases to judges}

As before, if judges are randomly assigned, the addition of control variables in the regression of the amount of compensation reported in Column (1) of Table 7 should not significantly change the estimates of the coefficient of the judge bias, as cases characteristics should be uncorrelated with judge bias. The assumption that judges are randomly assigned is not rejected insofar as the coefficients are not significantly different ( $\mathrm{p}$-value $=0.71$ ) across specifications reported in Columns (1) and (2) of Table 7.

Furthermore, judge biases are not correlated with the observable characteristics of cases or firms. Tables 8 and 9 display respectively the correlation between pro-worker biases and the characteristics of the case, and the correlations between pro-worker biases and the characteristics of the firm. The amount received at Prud'hommes, the seniority of the worker, and the worker's salary are all positively correlated to the compensation granted at Appeal court. The second column of Table 8 therefore offers a sharp contrast to its first column: when regressing the pro-worker bias on the same characteristics, one finds no significant relationship. The second column of Table 9 displays the regression of the judge's severity on the firm's characteristics the year before the judgment, ie in $t-1$. No significant relationship is found.

Judges who often qualify the dismissal as wrongful are also those who, conditional on granting a positive compensation, grant the highest compensations. In other words, our two indices of pro-worker bias are highly and positively correlated. We display this correlation in Figure 13, which presents the scatter plot of the pro-worker bias with respect to the compensation granted, conditional on being positive, ${ }^{16}$ and the pro-worker bias with respect to the dismissal qualification.

All in all, our analysis of Appeal court rulings points to the existence of significant biases on the part of judges which influence the probability that dismissals are deemed wrongful and the amount of compensation for wrongful dismissal. However, the dispersion of judge biases only explains a very limited share of the dispersion of the qualification of dismissal and of the amount of compensation, conditional on observable characteristics of the cases, suggesting that judges interpret in a similar way many specific features of cases which are not observable without very detailed information about each specific case. The

\footnotetext{
${ }^{16}$ Note that Figure 12 reports judges biases for the average compensation unconditional on being positive.
} 
next section analyzes the consequence of judge bias on firms performance.

\section{The effects of judge bias on firm performance and firm survival}

This section is devoted to the analysis of the impact of judge bias on firms' performance. We start by providing some descriptive statistics on firms before proceeding to the presentation of the empirical strategy and of the results. Then, we exploit the results to explore the consequences of reducing the dispersion of judge bias before proceeding to several robustness checks.

\subsection{Descriptive statistics}

The analysis is focused on firms with fewer than 100 employees the year before the Appeal judgment, because the decisions of judges should in principle have stronger effects on small firms. We consider for-profit firms in the private sector, excluding the agricultural sector. Among the sample of appeal court rulings going from 2006 to 2016, we select firms going to court no later than 2012 in order to analyze outcome variables up to three years after the judgment. ${ }^{17}$ We drop firms going to court several times during the period in order to drop collective dismissals. The description of sample restrictions is presented in Table 10 .

Table 11 provides descriptive statistics at the firm-level level, i.e. the level of analysis for our sample. Because we restrict the analysis to firms under 100 employees, the average number of workers is about 20 employees. The firms are relatively young as $24 \%$ are less than 10 years old. $52 \%$ of firms end up paying a positive compensation for wrongful dismissal. For firms paying a positive compensation amount, which corresponds on average to $10.7 \%$ of firms' annual payroll, the median is equal to $4.1 \%$. Their probability to survive one year after the judgment is equal to $99 \%$ and to $92 \%$ three years after.

For very small firms below 10 employees (see Table 12), for which the judge bias will be shown to have more impact, the probability of wrongful dismissal is identical but the share of compensation for wrongful dismissal (conditional on being positive) in the annual payroll is much higher; it is equal to about $20.9 \%$ for very small firms versus $10.7 \%$ for the others. Very small firms are younger than larger firms as 35\% have less than 10 years versus $25 \%$, and their survival probability is significantly smaller: $89 \%$ three years after the judgment versus $92 \%$.

\footnotetext{
${ }^{17}$ Matched employer-employee data are available from 2002 to 2015.
} 


\subsection{Empirical strategy}

We estimate the causal impact of judge pro-worker bias on an array of firm performance indicators: firm survival, growth of total, temporary and permanent employment and sales. To that end, we regress the outcome of interest of each firm on the pro-worker bias of the judge in charge of its case. The benchmark equation is the following:

$$
Y_{i j(i) t}=\alpha_{0}+\alpha_{1} \operatorname{bias}_{i j(i)}+\alpha_{2} X_{i t}+\eta_{i j(i) t}
$$

where $Y_{i j(i) t}$ is the outcome of interest for firm $i$ assigned to judge $j, t \geq 0$ years after the judgment; $\operatorname{bias}_{i j(i)}=\left(\bar{\varepsilon}_{i j}-\bar{\varepsilon}\right) / \sigma_{\varepsilon}$ denotes judge $j$ 's normalized bias (i.e., the difference between the judge's bias and the average judge bias $(\bar{\varepsilon})$ scaled in standard deviation $\left(\sigma_{\varepsilon}\right)$ units of the judge bias distribution), where $\bar{\varepsilon}_{i j}$, defined in Section 4.2 , is the leave-one-out mean of the residuals for all the other cases than $i$ judged by the corresponding judge $j$. $X_{i t}$ includes Appeal court fixed effects, year fixed effects, the leave-one-out average industry annual growth rate of sales and an indicator variable for economic dismissals.

We estimate Equation (5) with OLS and the condition for $\alpha_{1}$ to be unbiased is that the error term $\eta_{i j(i) t}$ is mean-independent of $b_{i a s_{i j(i)}}$. A necessary condition for unbiasedness is random assignment of judges to case. Although this condition is fundamentally nontestable, the random nature of the assignment of judges to cases has been documented above in Sections 2.3 and 4.

Equation (5) allows us to analyze the average impact of the bias of judges on all firms. However, it is probable that firms which do not perform well are more impacted by the high compensations set by pro-worker judges. To deal with this issue, we examine how the impact of judge bias depends on the return on assets. More precisely, we estimate the following equation:

$$
Y_{i j(i) t}=\beta_{0}+\beta_{1} \operatorname{bias}_{i j(i)} \times \operatorname{low}_{i}+\beta_{2} \operatorname{bias}_{i j(i)} \times h i g h_{i}+\beta_{3} X_{i t}+\nu_{i j(i) t}
$$

where $l o w_{i}$ is an indicator variable equal to 1 if the financial variable (i.e. the return on assets or the leverage) of firm $i$ the year before the judgment is below the median; high is an indicator variable equal to 1 if the financial variable of firm $i$ the year before the judgment is above the median. $X_{i t}$ includes the same variables as before plus the indicator variables $l_{\text {low }}$ and $h i g h_{i}$.

Our dependent variables include indicator variables equal to one for firms which survive within $t=1,2,3$ years after the judgment and symmetric growth rates for a set of variables, namely total, temporary and permanent employment and sales. ${ }^{18}$ All standard errors are

\footnotetext{
${ }^{18}$ For instance, the symmetric growth rate between $t-1$ and $t+1$ is computed as follows:

$$
\Delta Y_{i j(i) t}=2 \frac{Y_{i j(i) t+1}-Y_{i j(i) t-1}}{Y_{i j(i) t+1}+Y_{i j(i) t-1}}
$$
}


clustered at the judge level, following Abadie et al. (2017) who state that the standard errors clustering must be decided according to the level at which either the sampling or the randomization is performed. In our case, the randomization occurs primarily at the judge-level.

Moreover, in order to quantify the impact of the shock on the amount of compensation induced by judge bias on the performance of firms, we regress the performance indicators on the share of the compensation for wrongful dismissal in the firm payroll, which is instrumented by the judge's bias. This allows us to evaluate the impact of unexpected shocks on the amount of compensation, expressed in payroll share, on firms.

\subsection{Results}

\subsubsection{Reduced form estimates}

We start by presenting the results of the effects of judge bias on all firms below 100 employees before looking at the differential impact of judge bias according to firm size, and especially small firms, below 10 employees.

\section{All firms below 100 employees}

Tables 13, 14 and 15 present the results of the estimation of equations (5) and (6) for the firm's outcomes respectively 1 year, 2 years and 3 years after the Appeal court judgment.

Table 13 shows that the pro-worker bias of judges has a significant negative impact on employment growth the first year after the judgment only for firms with low return on assets. The drop is economically significant: a one standard deviation increase in judge pro-worker bias reduces employment growth by 1.8 percentage points. Low-performing firms also face a drop in their sales growth of the same order of magnitude. By contrast, the overall employment and the sales of high-performing firms defined as those whose returns on assets are above the median, are not significantly impacted by judge bias.

The effects of judge bias become stronger two and three years after the judgment, as shown by Tables 14 and 15 . They are statistically significant for firms taken as a whole, but they are still entirely driven by low-performing firms which are more seriously affected by judge pro-worker bias as time elapses. The impact on low-performing firms employment is approximately doubled in the third year, compared with the first year. It is striking that the employment effects are induced by the drop in permanent jobs only.

This growth rate measure has become standard in analysis of establishment and firm dynamics because it shares some useful properties of log differences and accommodates entry and exit. It is a second-order approximation of the log difference for growth rates around 0 and it ensures that growth rates range from -2 to 2 , thus preventing outliers from complicating the analysis. See Tor and Davis et al. (1996) 
Temporary jobs are not affected. All in all, pro-worker bias on the part of judges reduces employment growth and raises its instability.

The effect of judge bias on sales is also more important 3 years after the judgment than one year after. The difference is significant: a one standard deviation increase in judge pro-worker bias reduces sales growth by 1.4 percentage points one year after the judgement and by 4.7 percentage points 3 years after.

Two years after the judgement, judge pro-worker bias has a significant impact on the survival rate of low-performing firms, which drops by 0.7 percentage points two years after the judgment and by 1 percentage point three years after, when the pro-worker judge bias increases by one standard deviation. High-performing firms are not impacted at any time horizon. Interestingly, the employment effects of the judge pro-worker bias within a 3 -year horizon are not solely driven by firm death. Table 16 shows that judge pro-worker bias has a significant negative impact on the growth rate of employment and sales of low-performing firms which survive 3 years after the judgment. Though the selection of this sub-sample is endogenous, it is still informative about the channels at play.

The effects of judge bias on the number of entries and exits are non significant for either type of firms at any time horizon, as shown by Tables 13, 14 and 15. The absence of significant impact is the consequence of two counteracting effects. First, the pro-worker bias reduces employment, which negatively affects the entries and exits. Second, the pro-worker bias decreases the share of permanent jobs, which increases the job turnover. The composition of these two effects induces no significant change in entries and exits in our empirical context.

Small firms, below 10 employees, versus medium-sized firms

One might expect small firms to be more impacted than medium-sized firms by judge bias because the dismissal compensations represent a larger share of the payroll of small firms, and small firms might also be more financially fragile. This is what clearly arises in our context. Table 17 shows that firms with less than 10 employees are very strongly impacted if their return on assets is below the median at the judgment date. For those firms, a one standard deviation increase in the judge's pro-worker bias reduces employment growth and sales by 6 percentage points at the 3-year horizon. This impact is about twice as high as for all low-performing firms below 100 employees. All employment effects are driven by the drop in permanent jobs, while the number of temporary jobs does not change significantly. High-performing firms, even if they have less than 10 employees, are not significantly impacted by judge bias.

Table 18 shows that the employment of firms with 10 employees and more is not significantly impacted by judge bias even if they are low-performing firms. The judge bias 
has an impact of their sales if their return of assets is below the median, which is about half of that estimated for small low-performing firms.

The survival of small low-performing firms is also strongly impacted by the judge pro-worker bias. A one standard deviation increase in the judge pro-worker bias reduces the survival rate by 3 percentage points for low-performing firms at the 3 -year horizon. The survival rate of high performing firms, even if they have fewer than 10 employees, is not significantly impacted by judge bias.

Overall, it is clear that judge bias has a significant impact on small and low-performing firms, below 10 employees. The judge bias has no significant effects on the employment of larger firms. Firms with return on assets above the median are not significantly impacted by judge bias.

\subsubsection{IV estimates}

In order to quantify the effect of the amount of compensation for wrongful dismissal induced by judge bias on the outcomes of firms, it is useful to regress the firm outcomes on the amount of compensation for wrongful dismissal, expressed in share of the payroll in the year preceding the judgment, and to instrument this variable by the judge bias. The exclusion restriction is satisfied if the allocation of cases to judges is random, which is arguably the case in our context, as shown above. Table 19, which reports the results of the first stage of IV estimations, confirms that judge bias is strongly correlated with the share of compensation for wrongful dismissal in the firm payroll.

Table 20, which reports the results of the second stage of the IV estimations for all firms below 100 employees, shows that an increase in the amount of compensation of one percent of the payroll reduces employment by 3 percentage points at the 3 -year horizon for low-performing firms. The effect arises from the growth of permanent employment, while temporary employment is not significantly impacted. Sales growth is significantly impacted: an increase in the amount of compensation of one percent of the payroll reduces sales growth by 4 percentage points at the 3-year horizon for low-performing firms. High performing firms are not impacted by the shock on their revenue induced by judge bias.

Table 21 shows that the point estimates reported for all firms below 100 employees are the same as for firms below 10 employees. This means that a transitory shock on the revenue of firms equal to one percent of their payroll has a similar impact on small and medium-sized firms. Hence, the stronger employment impact of pro-worker judges on

small low-performing firms found in the reduced form estimates is merely the consequence of the fact that dismissal compensations represent a higher share of the payroll for small firms, below 10 employees, than for medium-sized firms, as shown by Tables 11 and 12 . This indicates that the same amount of compensation for wrongful dismissal has effects 
which are very different according to the financial capacity of firms, which is determined by their size and their return on assets. Smaller low-performing firms are likely to be more impacted because of a weaker financial capacity.

In these circumstances, it can be argued that pro-worker bias on the part of judges has cleansing effects by destroying the structurally weakest firms. It cannot be excluded that judge bias improves overall efficiency, since the jobs destroyed by pro-worker judges in low-performing firms might be reallocated at low cost to high performing firms. Addressing this question is left for future research.

\subsection{The effects of the dispersion of judges bias}

So far, we have uncovered the effects of judge bias on firms survival, employment and sales. A natural question that arises is what would the outcomes be if the dispersion of biases was reduced. Because our measure of bias is relative, setting all our bias estimates to the mean produces the effect of eliminating any judge-related dispersion in dismissal compensation.

It is well known that less uncertainty about judge decisions reduces the litigation rate but also affects the composition of the set of cases going to litigation (Priest and Klein (1984b), Lee and Klerman (2016)). Accordingly, the set of cases going to Appeal courts would change if the dispersion of judge bias changed. However, to the extent that the dispersion of judge bias explains less than $0.3 \%$ of the variance of compensations conditional on observable worker and firm characteristics, as shown by Table 4, it is likely that the dispersion of judge bias has negligible effects on the selection of cases that go to Appeal court. Indeed, an approximation of the relative risk premium associated with the dispersion of judge bias implies that an upper bound of the cost of the risk associated with the dispersion of judge bias is at most equal to $1.5 \%$ of the average compensation, depending on the degree of risk aversion (see Appendix D). This means that the actual dispersion of judge bias has a very limited impact on the selection of cases going to the Appeal courts. Hence, in what follows, we evaluate the consequences of reductions in the dispersion of judge bias for our sample of firms which go to Appeal courts assuming that such changes in the dispersion of judge bias have negligible selection effects.

First, changes in the mean-preserving spread of judges biases can have an effect on the mean outcome of firms only if the bias of judges has non-linear effects on firm outcomes. Therefore, we start by analyzing whether judge bias has non-linear effects on firm outcomes. It is indeed plausible that judges with a strong pro-worker bias who set very high compensation for wrongful dismissal have a disproportionately strong impact, especially on small, low-performing firms.

Focusing on small firms below 10 employees whose return on assets is below the median, 
which are the only firms for which judge bias has a significant impact, we do not find any evidence of non-linearity, either from visual inspection of augmented component-plusresidual plots (see Figure 14), or from the introduction of quadratic terms in the reduced form equations (see Table 22). This means that mean-preserving spread changes in judge bias have no significant impact on the average outcome of firms potentially impacted by judge bias.

Then, we perform counterfactual exercises in which we cap judge bias at several percentiles of the distribution of bias. To do so, we first estimate, based on 1,000 bootstrap replications, the predicted outcomes for small low-performing firms from equation (5) on samples featuring counterfactual distributions of bias to obtain the counterfactual distributions of predicted outcomes. We perform similar bootstrap replications based on our initial sample of small low-performing firms, to obtain a distribution of predicted outcomes with the actual distribution of judge bias. Figure 15 reports the mean and the 95\% confidence interval of the differences between those predicted outcomes three years after the judgments for different counterfactual distributions. It is clear that reducing the dispersion of judge bias has very small and non-significant effects on firm survival and employment growth. Confirming our observation of absence of non-linear effects of judge bias on firm outcomes, Figure 15 shows that setting all biases to the mean yields points estimates for the difference between the actual and the counterfactual outcomes very close to zero, and these point estimates are not significantly different from zero at any standard confidence level. Capping the bias of pro-worker judges to the mean has a larger impact, but one which remains small and far from statistically significant. The same result arises when the bias of pro-employer judges is capped to zero.

These findings clearly indicate that capping or reducing the dispersion of judge bias has very limited effects on firms, even for small, low-performing firms which are the most impacted by judge bias. An open question that our study cannot address, however, is the possibility that all judges are biased, meaning that setting all biases to the mean does not ensure the absence of bias in the interpretation of labor laws (see: Ash et al. (2018)).

\subsection{Robustness checks}

We conduct a range of checks both to test the robustness of the previous results and to investigate the mechanisms at play.

First, we conduct placebo tests for the significance of the effect of judge bias on firm performance before the judgment. By definition, we cannot proceed to placebo tests on firm survival before the judgment since all firms which are judged by Appeal courts necessarily survive until the date of the judgment. In this context, placebo tests are similar to regressions run on surviving firms, presented in Table 16, which reports negative 
significant correlations between the pro-worker bias of judges and employment and sales growth. Table 23 documents the absence of significant correlation between judge bias and the growth rates of these variables between two years and one year before the judgment for all firms and for small firms, whether their are high-performing or low performing firms. This means that the effects of judge bias on firm performance after the judgment year which are identified by our empirical strategy are not driven by selection of firms due to the anticipation of judge bias.

Second, the effects of judge bias we find are significant only for low-performance firms - defined as firms with a below-median return on assets. One may wonder whether this result would hold for different measures of the financial situation of firms. In order to investigate this issue, Table 24 contrasts the effect of judge bias according to the level of return on equity. By definition, the return on equity of high performing firms is above the median and that of low-performing firms is below the median. The bias of judges has a significant impact on low-performing firms only and the effect is larger for small low-performing firms, which confirms the results obtained when the performance of firms is measured with the return on assets.

Third, we examine the results for the sub-sample of cases which go to large Appeal courts that contain several social chambers, because, as explained above in Section 5.2, it is even more likely that the parties do not know until the day of the judgment the identity of the president who will be in charge of the case when there are several social chambers. These large Appeal courts, located at Aix-en-Provence, Paris and Versailles, have 4, 14 and 7 social chambers respectively. Although the number of observations is about half that of the whole sample, Table 25 shows that we get similar results when the sample is restricted to large Appeal courts. This confirms that our results are not driven by non-random allocation of cases to judges.

\section{Conclusion}

Using new data on Appeal court rulings about dismissals merged with firm data, this paper provides the first systematic analysis of the impact of judge bias on dismissal compensation and on firm performance. It shows that the subjective opinion of judges influences the amount of dismissal compensation: some judges appear more likely to rule in favor of the employer and others in favor of dismissed workers. We find that the bias of judges has a significant impact on employment, sales and survival of small, low-performing firms, hence partly confirming the intuition of policy makers who implemented reforms to limit the power of judges in the setting of dismissal compensation. However, the actual dispersion of judge bias, before the implementation of such reforms in France, does not 
seem to have had significant detrimental effects on the average performance of firms going to Appeal courts, even the weakest and the smallest ones. The main reason is that the risk premium associated with the dispersion of judge bias is very small compared with the expected amount of dismissal compensation.

It is worth stressing that our paper does not fully address the question of the impact of judge bias on overall employment. It may be that the publicity around several extreme cases, with very high compensations, has a strong impact on the beliefs of employers and thus on hiring behavior and firm entry. It is also possible that cases judged by Appeal courts are not representative of all cases. From this perspective, our paper must be completed by future research to better understand the effects of judge bias on employment, firm creation and destruction. 


\section{References}

Alberto Abadie, Susan Athey, Guido W Imbens, and Jeffrey Wooldridge. When should you adjust standard errors for clustering? Technical report, National Bureau of Economic Research, 2017.

Elliott Ash, Daniel L Chen, and Suresh Naidu. Ideas have consequences: The impact of law and economics on american justice. Technical report, working paper, 2018.

David Autor, William Kerr, and Adriana Kugler. Do employment protections reduce productivity? evidence from us states. Economic Journal, 117:F189-F217, 2007.

David Autor, Nicole Maestas, Kathleen J Mullen, and Alexander Strand. Does delay cause decay? the effect of administrative decision time on the labor force participation and earnings of disability applicants. Technical report, National Bureau of Economic Research, 2015.

David Autor, Andreas Kostøl, Magne Mogstad, and Bradley Setzler. Disability benefits, consumption insurance, and household labor supply. American Economic Review, 109 (7):2613-54, July 2019.

David H Autor. Outsourcing at will: The contribution of unjust dismissal doctrine to the growth of employment outsourcing. Journal of labor economics, 21(1):1-42, 2003.

David H Autor, John J Donohue III, and Stewart J Schwab. The costs of wrongful-discharge laws. The Review of Economics and Statistics, 88(2):211-231, 2006.

Scott R. Baker, Nicholas Bloom, and Steven J. Davis. Measuring Economic Policy Uncertainty*. The Quarterly Journal of Economics, 131(4):1593-1636, 072016.

Omar Bamieh. Firing costs, employment and misallocation. 2016.

Shai Bernstein, Emanuele Colonnelli, Xavier Giroud, and Benjamin Iverson. Bankruptcy spillovers. Journal of Financial Economics, Forthcoming, 2018a.

Shai Bernstein, Emanuele Colonnelli, and Ben Iverson. Asset allocation in bankruptcy. Journal of Finance, Forthcoming, 2018b.

Manudeep Bhuller, Løken Katrine V. Dahl, Gordon B., and Magne Mogstad. Incarceration, Recidivism, and Employment,. Journal of Political Economy, 128(4):1269-1324, 04 2020. 
Olivier Jean Blanchard, Florencio Lopez-de Silanes, and Andrei Shleifer. What do firms do with cash windfalls? Journal of financial economics, 36(3):337-360, 1994.

Tito Boeri and Pietro Garibaldi. Graded security and labor market mobility clean evidence from the italian jobs act. 2018.

Pierre Cahuc, Stéphane Carcillo, and André Zylberberg. Labor economics. MIT press, 2014.

Raj Chetty. A new method of estimating risk aversion. The American Economic Review, 96(5):1821-1834, 2006.

Alma Cohen and Crystal S. Yang. Judicial politics and sentencing decisions. American Economic Journal: Economic Policy, 11(1):160-91, February 2019.

Gordon B Dahl, Andreas Ravndal Kostøl, and Magne Mogstad. Family welfare cultures. The Quarterly Journal of Economics, 129(4):1711-1752, 2014.

Steven J. Davis, John C. Haltwanger, and Scott Schuh. Job Creation and Destruction. MIT press, 1996.

Claudine Desrieux and Romain Espinosa. Case selection and judicial decision-making: evidence from french labor courts. European Journal of Law and Economics, 47(1): 57-88, 2019.

Will Dobbie, Jacob Goldin, and Crystal S Yang. The effects of pretrial detention on conviction, future crime, and employment: Evidence from randomly assigned judges. American Economic Review, 108(2):201-40, 2018.

Louis Eeckhoudt, Christian Gollier, and Harris Schlesinger. Economic and Financial Decisions under Risk. Princeton University Press, 2005.

Jack Favilukis, Xiaoji Lin, and Xiaofei Zhao. The elephant in the room: The impact of labor obligations on credit markets. American Economic Review, 110(6):1673-1712, June 2020.

Henri Fraisse, Francis Kramarz, and Corinne Prost. Labor disputes and job flows. ILR Review, 68(5):1043-1077, 2015.

Eric French and Jae Song. The effect of disability insurance receipt on labor supply. American Economic Journal: Economic Policy, 6(2):291-337, 2014. 
Nicola Gennaioli and Andrei Shleifer. Judicial fact discretion. The Journal of Legal Studies, 37(1):1-35, 2008. ISSN 00472530, 15375366. URL http://www.jstor.org/ stable/10.1086/588266.

Giuseppina Gianfreda and Giovanna Vallanti. Institutions' and firms' adjustments: Measuring the impact of courts' delays on job flows and productivity. The Journal of Law and Economics, 60(1):135-172, 2017.

Xavier Giroud and Holger M. Mueller. Firm leverage, consumer demand, and employment losses during the great recession*. The Quarterly Journal of Economics, 132(1):271-316, 2017. doi: 10.1093/qje/qjw035. URL http://dx.doi.org/10.1093/qje/qjw035.

Maud Guillonneau and Evelyne Serverin. Les litiges individuels du travail de 2004à 2013: des actions moins nombreuses mais toujours plus contentieuses. 2015.

Nathaniel Hendren. Knowledge of future job loss and implications for unemployment insurance. American Economic Review, 107(7):1778-1823, 2017.

Andrea Ichino, Michele Polo, and Enrico Rettore. Are judges biased by labor market conditions? European Economic Review, 47(5):913-944, 2003.

Juan F. Jimeno, Marta Martínez-Matute, and Juan S. Mora-Sanguinetti. Employment protection legislation, labor courts, and effective firing costs. IZA Journal of Labor Economics, 9(1):20200002, 2020.

Andreas Ravndal Kostol, Magne Mogstad, Bradley Setzler, et al. Disability benefits, consumption insurance, and household labor supply. Technical report, National Bureau of Economic Research, 2017.

Yoon-Ho Alex Lee and Daniel Klerman. The priest-klein hypotheses: Proofs and generality. International Review of Law and Economics, 48:59 - 76, 2016.

Andreas Lichter, Andreas Peichl, and Sebastian Siegloch. The own-wage elasticity of labor demand: A meta-regression analysis. European Economic Review, 80:94 - 119, 2015.

Nicole Maestas, Kathleen J Mullen, and Alexander Strand. Does disability insurance receipt discourage work? using examiner assignment to estimate causal effects of ssdi receipt. American Economic Review, 103(5):1797-1829, 2013.

Ioana Marinescu. Are judges sensitive to economic conditions? evidence from uk employment tribunals. ILR Review, 64(4):673-698, 2011. 
Pedro S Martins. Dismissals for cause: The difference that just eight paragraphs can make. Journal of Labor Economics, 27(2):257-279, 2009.

OECD. Protecting jobs, enhancing flexibility: a new look at employment protection legislation, 2013.

Richard Posner. Judicial behavior and performance: An economic approach. Florida State University Law Review, 32(1):1259-79, 2005.

George L. Priest and Benjamin Klein. The selection of disputes for litigation. The Journal of Legal Studies, 13(1):1-55, 1984a.

George L Priest and Benjamin Klein. The selection of disputes for litigation. The Journal of Legal Studies, 13(1):1-55, 1984b.

Joshua D Rauh. Investment and financing constraints: Evidence from the funding of corporate pension plans. The Journal of Finance, 61(1):33-71, 2006.

Ryan W Scott. Inter-judge sentencing disparity after booker: A first look. Stan. L. Rev., $63: 1,2010$.

Amy Semet. Political decision-making at the national labor relations board: An empirical examination of the board's unfair labor practice decisions through the clinton and bush ii years. Berkeley Journal of Employment and Labor Law, 37(2):223-292, 2016.

Evelyne Serverin and Julie Valentin. Licenciement et recours aux prud'hommes, questions de mesure. In Bernard Gomel, Dominique Meda, and Evelyne Serverin, editors, L'emploi en ruptures, pages 121-138. Dalloz, Paris, 2009.

Elena Simintzi, Vikrant Vig, and Paolo Volpin. Labor Protection and Leverage. The Review of Financial Studies, 28(2):561-591, 082014.

Ronald Turner. Ideological voting on the national labor relations board. University of Pennsylvania Journal of Labor and Employment Law, 8(2):707-764, 2006.

Crystal S Yang. Free at last? judicial discretion and racial disparities in federal sentencing. The Journal of Legal Studies, 44(1):75-111, 2015. 
Table 1 - From the initial to the final number of observations used to estimate judge bias

\begin{tabular}{lcc} 
& \# of cases & \# of judges \\
\hline Initial severance pay data & 145,638 & - \\
(a) Cases for firms not already liquidated & 123,304 & - \\
(b) Cases with non-missing president name and surname & 117,989 & 1,039 \\
(c) Cases with non-missing total amount of compensation & 84,151 & 878 \\
(d) Cases with non-missing monthly wage & 61,728 & 731 \\
(e) Elimination of cases in the public sector & 39,843 & 652 \\
(f) Cases restricted to judges with at least 50 cases & 37,149 & 159 \\
\hline
\end{tabular}

Note: This table presents the selection process to obtain the sample of cases on which we estimate the judge fixed effects. Starting from the initial set of all Appeal court rulings from 2006 to 2016 published by the Ministry of Justice which covers all Appeal court rulings, we apply successive filters in order to retain (a) only those firms that we know were not liquidated at the judgment date, otherwise dismissal compensations of liquidated firms would be incurred by a public insurance agency (Agence de Garantie des salaires). Then, we eliminate cases for which we do not have the relevant information about either (b) the president's name and surname, (c) the total amount of compensation, or (d) the monthly wage was either. Finally, we eliminate cases (e) in which the employer belongs to the public sector, and (f) those decided by judges who covered less than 50 cases, our threshold for the calculation of judge fixed-effects. We eventually end up with 37,149 cases and 159 judges. Source: Authors' Appeal court rulings database. 
Table 2 - Summary main variables of case-level data

\begin{tabular}{lcccccc} 
& mean & min & med & max & sd & count \\
\hline Total amount in euro & 29,794 & 0 & 15,724 & 963,154 & 50,056 & 37,149 \\
Total amount in months of salary & 10.47 & 0 & 7.84 & 76.26 & 11.12 & 37,149 \\
Positive total amount & 0.89 & 0 & 1 & 1 & 0.31 & 37,149 \\
Amount for unfair dismissal in euro & 12,288 & 0 & 3,000 & 530,000 & 24,193 & 37,149 \\
Amount for unfair dismissal in months of salary & 4.32 & 0 & 1.55 & 73,17 & 6.10 & 37,149 \\
Positive amount for unfair dismissal & 0.58 & 0 & 1 & 1 & 0.49 & 37,149 \\
Other amount in euro & 17,506 & 0 & 6,197 & 963,154 & 38,024 & 37,149 \\
Prud'hommes amount & 7,326 & 0 & 0 & 277,200 & 17,649 & 27,725 \\
Amount demanded by worker & 44,458 & 1 & 25,000 & 985,536 & 64,439 & 19,371 \\
Higher amount than prud'hommes & 0.38 & 0 & 0 & 1 & 0.49 & 27,725 \\
Lower amount than prud'hommes & 0.17 & 0 & 0 & 1 & 0.37 & 27,725 \\
Same amount as prud'hommes & 0.45 & 0 & 0 & 1 & 0.50 & 27,725 \\
\hline Worker who appealed & 0.61 & 0 & 1 & 1 & 0.49 & 33,767 \\
Economic dismissal & 0.16 & 0 & 0 & 1 & 0.36 & 37,149 \\
Worker's seniority in months & 81,66 & 0 & 50.00 & 538 & 87.20 & 27,147 \\
\hline \hline
\end{tabular}

Note: This table displays the mean, the minimum, the median, the maximum, the standard deviation and the number of observations for several important characteristics of the cases used to estimate judge bias. Source: Appeal court rulings database.

Table 3 - Correlation between judge bias and dismissal qualification

\begin{tabular}{rcc}
\hline & Dismissal qualification & Dismissal qualification \\
\cline { 2 - 3 } & $(1)$ & $(2)$ \\
\hline Judge pro-worker bias & $0.508^{* * *}$ & $0.493^{* * *}$ \\
wrt dismissal qualification & $(0.141)$ & $(0.133)$ \\
\hline Year FE & Yes & Yes \\
Court FE & Yes & Yes \\
Case controls & No & Yes \\
\hline F test & 12.91 & 13.82 \\
$\#$ obs & 9,138 & 9,138 \\
\hline
\end{tabular}

Note: Each column corresponds to one regression. The dependent variable is an indicator variable equal to one if the dismissal is deemed wrongful. Court and year fixed effects are included. Control variables included in column (2): indicator variable for economic dismissal, worker's wage, worker's seniority. The top fifth percentiles of judge pro-worker bias are trimmed to account for the non-linearity of the relation between the pro-worker bias and the qualification of dismissal displayed on Figure 11. Standard errors, displayed in parentheses, are clustered at the judge level. *, **, and *** denote statistical significance at 10,5 and $1 \%$. Source: Appeal court rulings database. 
Table 4 - Share of the variance of compensations explained by judge bias

\begin{tabular}{lcccccccc}
\hline & $(1)$ & $(2)$ & $(3)$ & $(4)$ & $(5)$ & $(6)$ & $(7)$ & $(8)$ \\
& \multicolumn{2}{c}{ Qualification of dismissal } & \multicolumn{4}{c}{ Compensation } & in months of salary \\
\cline { 2 - 10 } Pro-worker bias & No & Yes & No & Yes & No & Yes & No & Yes \\
Case controls & No & No & Yes & Yes & No & No & Yes & Yes \\
Year FE & Yes & Yes & Yes & Yes & Yes & Yes & Yes & Yes \\
Court FE & Yes & Yes & Yes & Yes & Yes & Yes & Yes & Yes \\
\hline$R^{2}$ & 0.020 & 0.024 & 0.033 & 0.037 & 0.019 & 0.022 & 0.114 & 0.117 \\
Adj. $R^{2}$ & 0.014 & 0.018 & 0.027 & 0.030 & 0.013 & 0.016 & 0.108 & 0.111 \\
$\#$ obs & 9,138 & 9,138 & 9,138 & 9,138 & 9,138 & 9,138 & 9,138 & 9,138
\end{tabular}

Note: Columns (1) to (4) report the $R^{2}$ and adjusted $R^{2}$ of the regression of the qualification of the dismissal - i.e dummy indicating whether the dismissal was deemed wrongful - on judge bias and case controls (dummy indicating whether the firm has more than 11 workers at the time of the dismissal, Prud'hommes compensation, salary, seniority), while columns (5) to (8) display similar results for the regression of the compensation in monthly salaries. Columns (1) and (5) display the $R^{2}$ when adding fixed effects only, columns (2) and (6) when controlling for the judge's pro-worker bias, columns (3) and (7) when controlling case characteristics, column (4) and (8) when controlling for both case characteristics and judge bias. Court and year fixed effects are included in all regressions. Source: Appeal court rulings database. 
Table 5 - Randomization test for judge bias with respect to dismissal qualification: case-level characteristics

\begin{tabular}{lcc}
\hline & $\begin{array}{c}\text { Dismissal deemed } \\
\text { wrongful }\end{array}$ & Judge's pro-worker bias \\
\hline \hline Amount at Prud'hommes (in months) & $4.594^{* * *}$ & 0.0983 \\
& $(0.537)$ & $(0.106)$ \\
Legislation threshold applied & $-0.022^{* * *}$ & 0.001 \\
& $(0.007)$ & $(0.001)$ \\
Seniority & -0.0125 & 0.0006 \\
& $(0.039)$ & $(0.005)$ \\
Number of employees & $-0.001^{*}$ & -0.000 \\
& $(0.001)$ & $(0.000)$ \\
Worker's salary & 0.000 & $0.000^{*}$ \\
& $(0.000)$ & $(0.000)$ \\
Economic dismissal & $0.061^{* * *}$ & -0.001 \\
& $(0.008)$ & $(0.001)$ \\
Time between dismissal and Appeal Court & -0.005 & -0.002 \\
& $(0.007)$ & $(0.001)$ \\
\hline \hline Joint F-Test & 0.0000 & 0.2291 \\
Observations & 9,128 & 9,128 \\
\hline \hline
\end{tabular}

Note: The dependent variable is an indicator variable equal to one if the dismissal is deemed wrongful in Column (1) and the judge pro-worker bias in Column (2). Court and year fixed effects are included. Standard errors are clustered at the judge level. Standard errors are displayed in parentheses. *, **, and *** denote statistical significance at 10,5 and $1 \%$. Source: Appeal court rulings database. All independent variables except for 'Legislation threshold applies' and 'Economic dismissal' are transformed to increase clarity of the table: variables are divided by 1000 . 
Table 6 - Randomization test for judge bias with respect to dismissal qualification: firm-level characteristics

\begin{tabular}{lcc}
\hline & $\begin{array}{c}\text { Dismissal deemed } \\
\text { wrongful }\end{array}$ & Judge's pro-worker bias \\
\hline \hline Number of workers in t-1 & -0.153 & 0.032 \\
& $(0.131)$ & $(0.023)$ \\
Sales in t-1 & 0.000 & -0.000 \\
& $(0.001)$ & $(0.000)$ \\
Total wages in t-1 & -0.009 & -0.002 \\
& $(0.010)$ & $(0.002)$ \\
Value added in t-1 & 0.007 & 0.001 \\
Net income in t-1 & $(0.007)$ & $(0.001)$ \\
& 0.011 & 0.000 \\
Debt in t-1 & $(0.012)$ & $(0.002)$ \\
& 0.002 & 0.000 \\
Cash in t-1 & $(0.003)$ & $(0.000)$ \\
& $-0.014^{* *}$ & -0.000 \\
Joint F-Test & $(0.007)$ & $(0.001)$ \\
Observations & 0.2313 & 0.8956 \\
\hline The & 4,847 & 4,847 \\
\hline
\end{tabular}

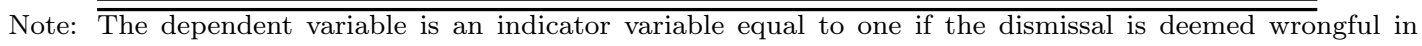
Column (1) and judge pro-worker bias in Column (2). Court and year fixed effects are included. Standard errors clustered at the judge level. Standard errors are displayed in parentheses. *, **, and *** denote statistical significance at 10,5 and 1\%. Source: Appeal court rulings database. All independent variables are transformed to increase clarity of the table: variables are divided by 1000 . 
Table 7 - Correlation between judge bias and compensation for wrongful dismissal

\begin{tabular}{rcc}
\hline & Compensation & Compensation \\
\cline { 2 - 3 } & $(1)$ & $(2)$ \\
\hline Judge pro-worker bias & $0.852^{* * *}$ & $0.838^{* * *}$ \\
wrt compensation & $(0.241)$ & $(0.241)$ \\
\hline Year FE & Yes & Yes \\
Court FE & Yes & Yes \\
Case controls & No & Yes \\
\hline F test & 12.47 & 12.10 \\
$\#$ obs & 9,138 & 9,138
\end{tabular}

Note: Each cell corresponds to one regression where the dependent variable is the total compensation for wrongful dismissal. Control variables included in column (2): indicator variable for economic dismissal,wage, seniority. The bottom and top fifth percentiles of judge bias are trimmed to account for the non-linearity of the relation between judge bias and the qualification of dismissal displayed on Figure 12. Court and year $\mathrm{x}$ sector fixed effects are used. Standard errors, clustered at the judge level, are in parenthesis.*, **, and ${ }^{* * *}$ denote statistical significance at 10,5 and 1\%. Source: Appeal court rulings database. 
Table 8 - Randomization test for judge bias on total compensation for wrongful dismissal: case-level characteristics

\begin{tabular}{|c|c|c|}
\hline & $\begin{array}{l}\text { Compensation } \\
\text { in monthly wages }\end{array}$ & $\begin{array}{c}\text { Judge pro-worker bias } \\
\text { in monthly wages }\end{array}$ \\
\hline \multirow[t]{2}{*}{ Amount at Prud'hommes (in months) } & $0.536^{* * *}$ & -0.002 \\
\hline & $(0.083)$ & $(0.002)$ \\
\hline \multirow[t]{2}{*}{ Legislation threshold applied } & 0.116 & 0.013 \\
\hline & $(0.386)$ & $(0.027)$ \\
\hline \multirow[t]{2}{*}{ Seniority } & $0.019^{* * *}$ & 0.000 \\
\hline & $(0.004)$ & $(0.000)$ \\
\hline \multirow[t]{2}{*}{ Number of employees } & -0.000 & -0.000 \\
\hline & $(0.000)$ & $(0.000)$ \\
\hline \multirow[t]{2}{*}{ Worker's salary } & $-0.000^{* * *}$ & 0.000 \\
\hline & $(0.000)$ & $(0.000)$ \\
\hline \multirow[t]{2}{*}{ Economic dismissal } & 1.116 & -0.025 \\
\hline & $(0.683)$ & $(0.030)$ \\
\hline \multirow[t]{2}{*}{ Time between dismissal and Appeal Court } & 0.001 & -0.000 \\
\hline & $(0.001)$ & $(0.000)$ \\
\hline Joint F-Test & 0.0000 & 0.7458 \\
\hline Observations & 4,948 & 4,948 \\
\hline \multicolumn{3}{|c|}{$\begin{array}{l}\text { Note: The dependent variable in the first column is the total compensation for wrongful dismissal. The } \\
\text { dependent variable in the second column is the judge pro-worker bias computed as defined in section } 4.2 \text {. } \\
\text { Standard errors are displayed in parentheses. Covariates include Appeal court fixed effects, year fixed effects, } \\
\text { the leave-one-out average industry annual growth rate of sales, and an indicator variable for economic dismissals. } \\
\text { Standard errors clustered at the judge level. Standard errors, clustered at the judge level, are in parenthesis. } \\
\text { **, and }{ }^{* * *} \text { denote statistical significance at } 10,5 \text { and } 1 \% \text {. Source: Appeal court rulings database. }\end{array}$} \\
\hline
\end{tabular}


Table 9 - Randomization test for judge bias on compensation for wrongful dismissal: firm-level characteristics

\begin{tabular}{lcc}
\hline & $\begin{array}{c}\text { Compensation } \\
\text { in monthly wages }\end{array}$ & $\begin{array}{c}\text { Judge pro-worker bias } \\
\text { in monthly wages }\end{array}$ \\
\hline \hline Number of workers in t-1 & $11.120^{*}$ & 0.778 \\
Sales in t-1 & $(5.763)$ & $(0.537)$ \\
& 0.042 & $-0.003^{*}$ \\
Total wages in t-1 & $(0.033)$ & $(0.002)$ \\
& -0.586 & -0.066 \\
Value added in t-1 & $(0.497)$ & $(0.043)$ \\
& 0.315 & 0.024 \\
Net income in t-1 & $(0.277)$ & $(0.022)$ \\
& -0.713 & 0.009 \\
Debt in t-1 & $(0.676)$ & $(0.043)$ \\
& 0.055 & 0.011 \\
Cash in t-1 & $(0.140)$ & $(0.010)$ \\
& -0.161 & -0.017 \\
\hline \hline Joint F-Test & $(0.201)$ & $(0.013)$ \\
Observations & 0.1312 & 0.2241 \\
\hline \hline
\end{tabular}

Note: The dependent variable in the first column is an indicator variable equal to one if the dismissal is deemed wrongful. The dependent variable in the second column is the judge pro-worker bias computed as defined in section 4.2. Standard errors are displayed in parentheses. Covariates include Appeal court fixed effects, year fixed effects, the leave-one-out average industry annual growth rate of sales, and an indicator variable for economic dismissals. All independent variables are transformed to increase clarity of the table: variables are divided by 1000 . Standard errors are clustered at the judge level.*, ${ }^{* *}$, and ${ }^{* * *}$ denote statistical significance at 10, 5 and $1 \%$. Source: DADS, FICUS-FARE, SIREN, Appeal court rulings database. 
Table 10 - From the initial to the final number of observations used to estimate the effect of judge bias on firm performance

\begin{tabular}{|c|c|c|c|}
\hline & \# of obs. & \# of firms & \# of judges \\
\hline Sample with judge fixed effects & 82,320 & 13,995 & 159 \\
\hline Non-missing employment, wages, Roa & 40,280 & 5,035 & 129 \\
\hline Firms with less than 100 employees & 35,888 & 4,486 & 129 \\
\hline
\end{tabular}

Table 11 - Summary of main variables at firm-level - all firms ( $<100$ employees)

\begin{tabular}{lcccccc}
\hline \hline & & & & & & \\
& mean & min & med & max & sd & count \\
\hline Nb of workers & 20.08 & 1.00 & 12 & 99.00 & 20.55 & 4486 \\
Sales (in K euros) & 4788.61 & 0.00 & 1929.91 & $64,175.00$ & $7,429.92$ & 4428 \\
Share of firms in manufacturing & 0.17 & 0.00 & 0.00 & 1.00 & 0.38 & 4486 \\
Share of firms in construction & 0.11 & 0.00 & 0.00 & 1.00 & 0.31 & 4486 \\
Share of firms in services & 0.34 & 0.00 & 0.00 & 1.00 & 0.48 & 4486 \\
Share of firms $<10$ years & 0.24 & 0.00 & 0.00 & 1.00 & 0.43 & 4486 \\
Survival at t +1 & 0.99 & 0.00 & 1.00 & 1.00 & 0.11 & 4486 \\
Survival at t +2 & 0.96 & 0.00 & 1.00 & 1.00 & 0.18 & 4486 \\
Survival at t +3 & 0.92 & 0.00 & 1.00 & 1.00 & 0.26 & 4486 \\
Wrongful dismissal & 0.52 & 0.00 & 0.00 & 1.00 & 0.50 & 4486 \\
Amount in month of salary (when $>0$ ) & 11.07 & 0.01 & 8.08 & 197.47 & 12.25 & 3009 \\
Amount in payroll (\%) (when $>0$ ) & 10.75 & 0.00 & 4.06 & 149.75 & 18.56 & 3805 \\
Judge pro-worker bias & -0.03 & -2.76 & -0.01 & 2.22 & 0.76 & 4486 \\
\hline$\quad \begin{array}{l}\text { Note: "Nb of workers" corresponds to headcounts on 31 December before the judgment year. "Amount" stands } \\
\text { for the total amount of compensation. "Wrongful dismissal" is a dummy variable equal to one if the dismissal }\end{array}$ &
\end{tabular}


Table 12 - Summary of main variables at firm-level - small firms ( $<10$ employees)

\begin{tabular}{lcccccc}
\hline \hline & & & & & & \\
& mean & min & med & max & sd & count \\
\hline Nb of workers & 4.98 & 1.00 & 5.00 & 9.00 & 2.38 & 1902 \\
Sales (in K euros) & 1231.21 & 0.00 & 684.44 & $24,990.51$ & 2136.92 & 1902 \\
Share of firms in manufacturing & 0.11 & 0.00 & 0.00 & 1.00 & 0.32 & 1902 \\
Share of firms in construction & 0.10 & 0.00 & 0.00 & 1.00 & 0.30 & 1902 \\
Share of firms in services & 0.35 & 0.00 & 0.00 & 1.00 & 0.48 & 1902 \\
Share of firms $<$ 10 years & 0.35 & 0.00 & 0.00 & 1.00 & 0.48 & 1902 \\
Survival at t+1 & 0.98 & 0.00 & 1.00 & 1.00 & 0.15 & 1902 \\
Survival at t+2 & 0.95 & 0.00 & 1.00 & 1.00 & 0.22 & 1902 \\
Survival at t +3 & 0.89 & 0.00 & 1.00 & 1.00 & 0.31 & 1902 \\
Wrongful dismissal & 0.52 & 0.00 & 0.00 & 1.00 & 0.50 & 1902 \\
Amount in month of salary (when $>0$ ) & 9.75 & 0.01 & 7.23 & 78.15 & 9.78 & 1299 \\
Amount in annual payroll $(\%)$ (when $>0$ ) & 19.28 & 0.00 & 10.56 & 381.36 & 24.56 & 1620 \\
Judge pro-worker bias & 0.00 & -2.76 & -0.01 & 2.22 & 0.77 & 1902 \\
\hline$\quad$ Note: "Nb of workers" corresponds to headcounts on 31 December before the judgment year. "Amount" stands & \\
$\quad$ for the total amount of compensation. "Wrongful dismissal" is a dummy variable equal to one if the dismissal &
\end{tabular}


Table 13 - Judge pro-worker bias and firm performance 1 year after the judgment

\begin{tabular}{lcccccc}
\hline \hline & $(1)$ & $(2)$ & $(3)$ & $(4)$ & $(5)$ & $(6)$ \\
\hline & Survival & \multicolumn{5}{c}{ growth rate between $t-1$ and $t+1$} \\
\cline { 3 - 7 } & $\begin{array}{c}\text { within } \\
{[t, t+1]}\end{array}$ & Employment & $\begin{array}{c}\text { Employment } \\
c d i\end{array}$ & $\begin{array}{c}\text { Employment } \\
c d d\end{array}$ & $\begin{array}{c}\text { Share } \\
c d i\end{array}$ & Sales \\
\hline Pro-worker bias & -0.001 & -0.009 & -0.003 & 0.001 & -0.000 & -0.007 \\
& $(0.001)$ & $(0.006)$ & $(0.007)$ & $(0.017)$ & $(0.002)$ & $(0.005)$ \\
$\mathrm{R}^{2}$ & 0.025 & 0.037 & 0.037 & 0.030 & 0.032 & 0.036 \\
\hline Pro-worker bias & 0.000 & $-0.018^{* *}$ & -0.005 & -0.019 & 0.005 & $-0.014^{*}$ \\
$\times$ Low Roa & $(0.002)$ & $(0.008)$ & $(0.010)$ & $(0.022)$ & $(0.003)$ & $(0.007)$ \\
Pro-worker bias & -0.003 & -0.000 & -0.001 & 0.020 & -0.005 & -0.001 \\
$\times$ High Roa & $(0.002)$ & $(0.010)$ & $(0.010)$ & $(0.028)$ & $(0.004)$ & $(0.007)$ \\
$\mathrm{R}^{2}$ & 0.025 & 0.037 & 0.037 & 0.030 & 0.033 & 0.037 \\
$\#$ obs & 4486.000 & 4486.000 & 4112.000 & 4112.000 & 4112.000 & 4418.000
\end{tabular}

Note: This table displays the estimates of the correlation between the judge bias and indicators of firm performance. $t$ denotes the year of the Appeal court judgment. The dependent variable is in Column (1) an indicator variable equal to one if the firm survives 1 year after the judgment; in Column (2) the symmetric growth rate between $t-1$ and $t+1$ of firm's employment; in Column (3) the symmetric growth rate between $t-1$ and $t+1$ of firm's employment in permanent contract - $c d i$; in Column (4) the symmetric growth rate between $t-1$ and $t+1$ of firm's employment in temporary contract; in Column (5) the change between $t-1$ and $t+1$ in the share of permanent jobs; in Column (6) the symmetric growth rate between $t-1$ and $t+1$ of sales. The variable of interest is the judge pro-worker bias computed as defined in section 4.2. Low roa firms denote firms with a return on assets below the median the year before the judgment. Covariates include Appeal court fixed effects, year fixed effects, the leave-one-out average industry annual growth rate of sales and an indicator variable for economic dismissals. The upper part of the table displays coefficient $\alpha_{1}$ of equation (5) and the bottom part coefficients $\beta_{1}$ and $\beta_{2}$ of equation (6). Standard errors, displayed in parentheses, are clustered at the judge level. ${ }^{*},{ }^{* *}$, and ${ }^{* * *}$ denote statistical significance at 10,5 and $1 \%$. Source: DADS, FICUS-FARE, SIREN, Appeal court rulings database. 
Table 14 - Judge pro-worker bias and firm performance 2 years after the judgment

\begin{tabular}{|c|c|c|c|c|c|c|}
\hline & $(1)$ & $(2)$ & $(3)$ & $(4)$ & $(5)$ & $(6)$ \\
\hline & \multirow{2}{*}{$\begin{array}{c}\text { Survival } \\
\text { within } \\
{[t, t+2]}\end{array}$} & \multicolumn{5}{|c|}{ growth rate between $t-1$ and $t+2$} \\
\hline & & Employment & $\begin{array}{l}\text { Employment } \\
\qquad c d i\end{array}$ & $\begin{array}{l}\text { Employment } \\
\qquad d d\end{array}$ & $\begin{array}{l}\text { Share } \\
c d i\end{array}$ & Sales \\
\hline \multirow[t]{2}{*}{ Pro-worker bias } & -0.003 & $-0.015^{* *}$ & -0.014 & 0.008 & -0.004 & $-0.017^{* *}$ \\
\hline & $(0.003)$ & $(0.008)$ & $(0.009)$ & $(0.017)$ & $(0.004)$ & $(0.007)$ \\
\hline $\mathrm{R}^{2}$ & 0.035 & 0.043 & 0.037 & 0.026 & 0.033 & 0.030 \\
\hline Pro-worker bias & $-0.007^{*}$ & $-0.033^{* *}$ & $-0.024^{* *}$ & 0.000 & -0.004 & $-0.030^{* * *}$ \\
\hline$\times$ Low Roa & $(0.004)$ & $(0.011)$ & $(0.012)$ & $(0.024)$ & $(0.005)$ & $(0.009)$ \\
\hline Pro-worker bias & 0.001 & 0.001 & -0.005 & 0.015 & -0.005 & -0.005 \\
\hline × High Roa & $(0.004)$ & $(0.012)$ & $(0.014)$ & $(0.024)$ & $(0.006)$ & $(0.010)$ \\
\hline $\mathrm{R}^{2}$ & 0.035 & 0.044 & 0.037 & 0.026 & 0.033 & 0.031 \\
\hline \# obs & 4486.000 & 4486.000 & 4112.000 & 4112.000 & 4112.000 & 4395.000 \\
\hline \multicolumn{7}{|c|}{$\begin{array}{l}\text { Note: This table displays the estimates of the correlation between the judge bias and indicators of firms performance. } t \\
\text { denotes the year of the Appeal court judgment. The dependent variable is in Column (1) an indicator variable equal to } \\
\text { one if the firm survives } 2 \text { years after the judgment; in Column (2) the symmetric growth rate between } t-1 \text { and } t+2 \text { of } \\
\text { firm's employment; in Column (3) the symmetric growth rate between } t-1 \text { and } t+2 \text { of firm's employment in permanent } \\
\text { contract - } c d i \text {; in Column (4) the symmetric growth rate between } t-1 \text { and } t+2 \text { of firm's employment in temporary } \\
\text { contract; in Column (5) the change between } t-1 \text { and } t+2 \text { in the share of permanent jobs; in Column (6) the symmetric } \\
\text { growth rate between } t-1 \text { and } t+2 \text { of sales. The variable of interest is the judge pro-worker bias computed as defined in } \\
\text { section } 4.2 \text {. Low roa firms denote firms with a return on assets below the median the year before the judgment. Covariates } \\
\text { include Appeal court fixed effects, year fixed effects, the leave-one-out average industry annual growth rate of sales and } \\
\text { an indicator variable for economic dismissals. The upper part of the table displays coefficient } \alpha_{1} \text { of equation }(5) \text { and the } \\
\text { bottom part coefficients } \beta_{1} \text { and } \beta_{2} \text { of equation }(6) \text {. Standard errors, displayed in parentheses, are clustered at the judge } \\
\text { level. } *, * * \text {, and } * * * \text { denote statistical significance at } 10,5 \text { and } 1 \% \text {. Source: DADS, FICUS-FARE, SIREN, Appeal court } \\
\text { rulings database. }\end{array}$} \\
\hline
\end{tabular}


Table 15 - Judge pro-worker bias and firm performance 3 years after the judgment

\begin{tabular}{|c|c|c|c|c|c|c|}
\hline & $(1)$ & $(2)$ & $(3)$ & $(4)$ & $(5)$ & $(6)$ \\
\hline & Survival & \multicolumn{5}{|c|}{ growth rate between $t-1$ and $t+3$} \\
\hline & $\begin{array}{l}\text { within } \\
{[t, t+3]}\end{array}$ & Employment & $\begin{array}{l}\text { Employment } \\
\qquad d i\end{array}$ & $\begin{array}{l}\text { Employment } \\
\qquad d d\end{array}$ & $\begin{array}{l}\text { Share } \\
c d i\end{array}$ & Sales \\
\hline Pro-worker bias & $\begin{array}{c}-0.007^{* *} \\
(0.003)\end{array}$ & $\begin{array}{l}-0.015^{*} \\
(0.009)\end{array}$ & $\begin{array}{l}-0.018^{*} \\
(0.010)\end{array}$ & $\begin{array}{c}0.001 \\
(0.022)\end{array}$ & $\begin{array}{l}-0.008^{*} \\
(0.005)\end{array}$ & $\begin{array}{c}-0.023^{* *} \\
(0.008)\end{array}$ \\
\hline $\mathrm{R}^{2}$ & 0.044 & 0.046 & 0.046 & 0.031 & 0.039 & 0.028 \\
\hline $\begin{array}{l}\text { Pro-worker bias } \\
\times \text { Low Roa }\end{array}$ & $\begin{array}{l}-0.010^{* *} \\
(0.005)\end{array}$ & $\begin{array}{c}-0.035^{* * *} \\
(0.010)\end{array}$ & $\begin{array}{c}-0.031^{* *} \\
(0.012)\end{array}$ & $\begin{array}{l}-0.005 \\
(0.023)\end{array}$ & $\begin{array}{l}-0.009 \\
(0.006)\end{array}$ & $\begin{array}{c}-0.047^{* * *} \\
(0.011)\end{array}$ \\
\hline $\begin{array}{l}\text { Pro-worker bias } \\
\times \text { High Roa }\end{array}$ & $\begin{array}{l}-0.004 \\
(0.004)\end{array}$ & $\begin{array}{c}0.003 \\
(0.012)\end{array}$ & $\begin{array}{l}-0.006 \\
(0.014)\end{array}$ & $\begin{array}{c}0.006 \\
(0.033)\end{array}$ & $\begin{array}{l}-0.007 \\
(0.006)\end{array}$ & $\begin{array}{l}-0.001 \\
(0.012)\end{array}$ \\
\hline $\mathrm{R}^{2}$ & 0.044 & 0.047 & 0.046 & 0.031 & 0.039 & 0.030 \\
\hline \# obs & 4486.000 & 4486.000 & 4112.000 & 4112.000 & 4112.000 & 4398.000 \\
\hline $\begin{array}{l}\text { Note: This table displ } \\
\text { denotes the year of th } \\
\text { one if the firm survive } \\
\text { firm's employment; in } \\
\text { contract - cdi; in Col } \\
\text { contract; in Column ( } \\
\text { growth rate between } t \\
\text { section } 4.2 \text {. Low roa fir } \\
\text { include Appeal court } \\
\text { an indicator variable } \mathrm{f} \\
\text { bottom part coefficien } \\
\text { level. }{ }^{*}, * *, \text { and }{ }^{* * *} \text { d } \\
\text { rulings database. }\end{array}$ & $\begin{array}{l}\text { s the estime } \\
\text { Appeal cour } \\
3 \text { years after } \\
\text { olumn (3) tl } \\
\text { nn (4) the s } \\
\text { the change } \\
1 \text { and } t+3 \\
\text { as denote fir } \\
\text { zed effects, y } \\
\text { economic d } \\
\beta_{1} \text { and } \beta_{2} \\
\text { tote statistic }\end{array}$ & $\begin{array}{l}\text { ates of the correla } \\
\text { t judgment. The } \\
\text { the judgment; ir } \\
\text { he symmetric gro } \\
\text { ymmetric growth } \\
\text { between } t-1 \text { anc } \\
\text { of sales. The var } \\
\text { ms with a return } \\
\text { ear fixed effects, } \\
\text { ismissals. The up } \\
\text { of equation (6). } \\
\text { al significance at }\end{array}$ & $\begin{array}{l}\text { n between the } \mathrm{j} \\
\text { pendent variabl } \\
\text { olumn (2) the } \mathrm{s} \\
\text { rate between } t \\
\text { ate between } t- \\
+3 \text { in the share } \\
\text { le of interest is } \\
\text { assets below the } \\
\text { e leave-one-out } \\
\text { r part of the tab } \\
\text { ndard errors, dis } \\
, 5 \text { and } 1 \% \text {. Sou }\end{array}$ & $\begin{array}{l}\text { ge bias and in } \\
\text { in Column ( } \\
\text { metric growth } \\
\text { and } t+3 \text { of } f \\
\text { and } t+3 \text { of } f \\
\text { permanent job } \\
\text { judge pro-wor } \\
\text { dian the year } \\
\text { rage industry } \\
\text { displays coeffi } \\
\text { yed in parentl } \\
\text { DADS, FICt }\end{array}$ & $\begin{array}{l}\text { ors of firms } \\
\text { indicator v } \\
\text { between } t- \\
\text { employmer } \\
\text { employmen } \\
\text { Column (6) } \\
\text { oias comput } \\
\text { e the judgm } \\
\text { al growth } \mathrm{r} \\
\alpha_{1} \text { of equat } \\
\text { are cluster }\end{array}$ & $\begin{array}{l}\text { performance. } t \\
\text { ariable equal to } \\
-1 \text { and } t+3 \text { of } \\
\text { it in permanent } \\
\text { t in temporary } \\
\text { the symmetric } \\
\text { ed as defined in } \\
\text { ent. Covariates } \\
\text { ate of sales and } \\
\text { ion (5) and the } \\
\text { ed at the judge } \\
\mathrm{N} \text {, Appeal court }\end{array}$ \\
\hline
\end{tabular}


Table 16 - Judge pro-worker bias and firm performance 3 years after the judgment conditional on surviving

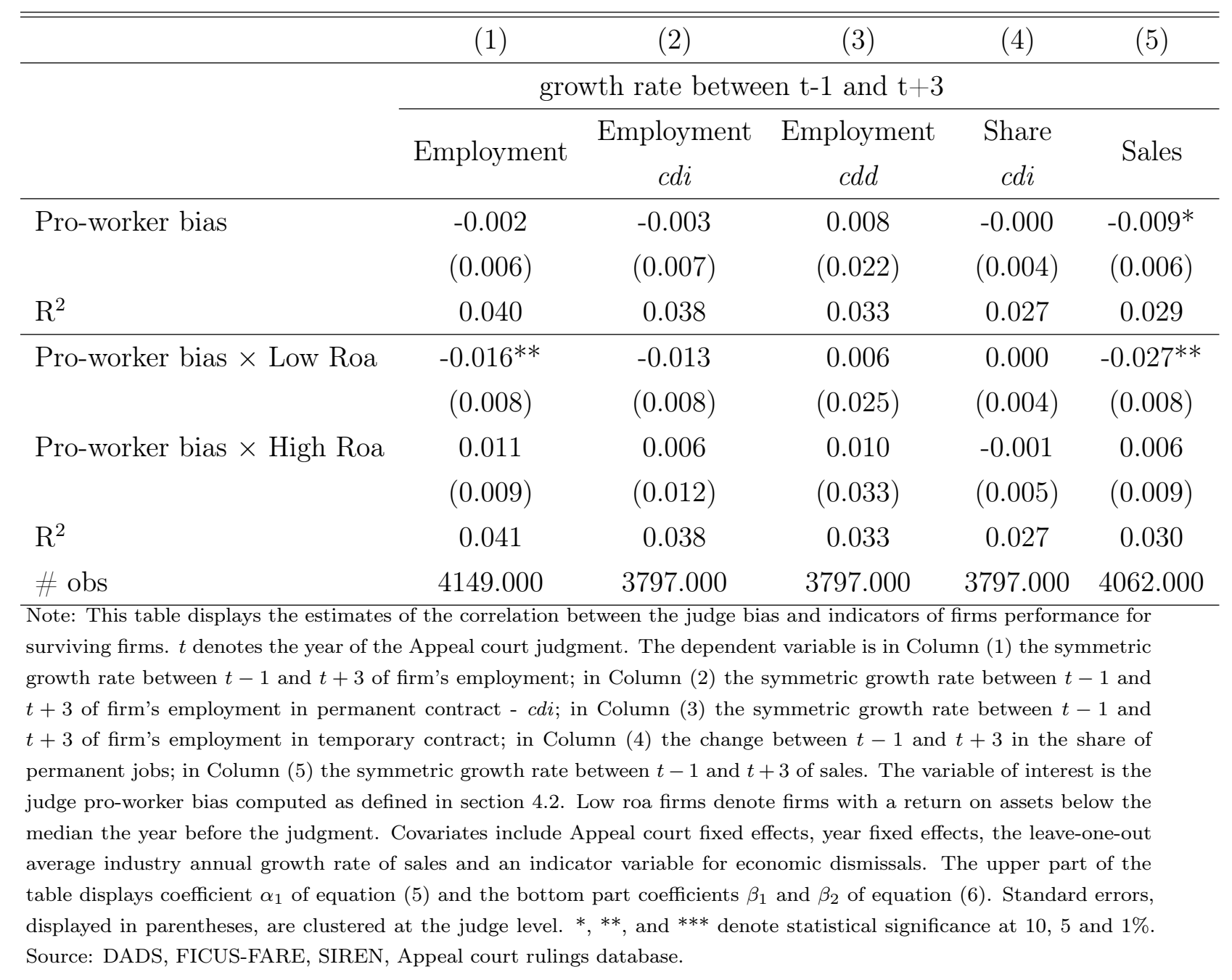


Table 17 - Judge pro-worker bias and firm performance 3 years after the judgment in small firms

\begin{tabular}{|c|c|c|c|c|c|c|}
\hline & $(1)$ & (2) & (3) & (4) & (5) & (6) \\
\hline & Survival & \multicolumn{5}{|c|}{ growth rate between $t-1$ and $t+3$} \\
\hline & $\begin{array}{c}\text { within } \\
{[t, t+3]}\end{array}$ & Employment & $\begin{array}{l}\text { Employment } \\
c d i\end{array}$ & $\begin{array}{c}\text { Employment } \\
c d d\end{array}$ & $\begin{array}{l}\text { Share } \\
c d i\end{array}$ & Sales \\
\hline Pro-worker bias & $\begin{array}{c}-0.016^{* *} \\
(0.007)\end{array}$ & $\begin{array}{l}-0.016 \\
(0.016)\end{array}$ & $\begin{array}{l}-0.027 \\
(0.018)\end{array}$ & $\begin{array}{l}-0.012 \\
(0.025)\end{array}$ & $\begin{array}{c}-0.017^{* *} \\
(0.007)\end{array}$ & $\begin{array}{l}-0.024 \\
(0.017)\end{array}$ \\
\hline $\mathrm{R}^{2}$ & 0.058 & 0.059 & 0.061 & 0.069 & 0.064 & 0.053 \\
\hline $\begin{array}{l}\text { Pro-worker bias } \\
\times \text { Low Roa }\end{array}$ & $\begin{array}{c}-0.027^{* *} \\
(0.011)\end{array}$ & $\begin{array}{c}-0.064^{* *} \\
(0.022)\end{array}$ & $\begin{array}{c}-0.058^{* *} \\
(0.024)\end{array}$ & $\begin{array}{l}-0.022 \\
(0.039)\end{array}$ & $\begin{array}{c}-0.023^{* *} \\
(0.011)\end{array}$ & $\begin{array}{c}-0.063^{* *} \\
(0.021)\end{array}$ \\
\hline $\begin{array}{l}\text { Pro-worker bias } \\
\times \text { High Roa }\end{array}$ & $\begin{array}{l}-0.005 \\
(0.007)\end{array}$ & $\begin{array}{c}0.030 \\
(0.020)\end{array}$ & $\begin{array}{c}0.004 \\
(0.025)\end{array}$ & $\begin{array}{l}-0.001 \\
(0.033)\end{array}$ & $\begin{array}{l}-0.011 \\
(0.010)\end{array}$ & $\begin{array}{c}0.012 \\
(0.024)\end{array}$ \\
\hline $\mathrm{R}^{2}$ & 0.060 & 0.063 & 0.062 & 0.069 & 0.064 & 0.057 \\
\hline$\#$ obs & 1902.000 & 1902.000 & 1750.000 & 1750.000 & 1750.000 & 1893.000 \\
\hline
\end{tabular}

Note: This table displays the estimates of the correlation between the judge bias and indicators of firms performance for the sample of small firms, below 10 employees the year before the judgment. $t$ denotes the year of the Appeal court judgment. The dependent variable is in Column (1) an indicator variable equal to one if the firm survives 3 years after the judgment; in Column (2) the symmetric growth rate between $t-1$ and $t+3$ of firm's employment; in Column (3) the symmetric growth rate between $t-1$ and $t+3$ of firm's employment in permanent contract - $c d i$; in Column (4) the symmetric growth rate between $t-1$ and $t+3$ of firm's employment in temporary contract; in Column (5) the change between $t-1$ and $t+3$ in the share of permanent jobs, in Column (6) the symmetric growth rate between $t-1$ and $t+3$ of sales. The variable of interest is the judge pro-worker bias computed as defined in section 4.2. Low roa firms denote firms with a return on assets below the median the year before the judgment. Covariates include Appeal court fixed effects, year fixed effects, the leave-one-out average industry annual growth rate of sales and an indicator variable for economic dismissals. The upper part of the table displays coefficient $\alpha_{1}$ of equation (5) and the bottom part coefficients $\beta_{1}$ and $\beta_{2}$ of equation (6). Standard errors, displayed in parentheses, are clustered at the judge level. *, **, and *** denote statistical significance at 10, 5 and 1\%. Source: DADS, FICUS-FARE, SIREN, Appeal court rulings database. 
Table 18 - Judge pro-worker bias and firm performance 3 years after the judgment in medium-sized firms

\begin{tabular}{lcccccc}
\hline \hline & $(1)$ & $(2)$ & $(3)$ & $(4)$ & $(5)$ & $(6)$ \\
\hline & \begin{tabular}{c} 
Survival \\
within \\
\cline { 3 - 7 }
\end{tabular} & \multicolumn{5}{c}{ growth rate between $t-1$ and $t+3$} \\
\cline { 3 - 7 } & $t, t+3]$ & Employment & $\begin{array}{c}\text { Employment } \\
c d i\end{array}$ & $\begin{array}{c}\text { Employment } \\
c d d\end{array}$ & $\begin{array}{c}\text { Share } \\
c d i\end{array}$ & Sales \\
\hline Pro-worker bias & 0.001 & -0.014 & -0.011 & 0.000 & 0.000 & $-0.020^{* *}$ \\
& $(0.003)$ & $(0.011)$ & $(0.010)$ & $(0.031)$ & $(0.005)$ & $(0.009))$ \\
$\mathrm{R}^{2}$ & 0.065 & 0.082 & 0.079 & 0.051 & 0.060 & 0.054 \\
\hline Pro-worker bias & 0.002 & -0.017 & -0.014 & -0.001 & 0.002 & $-0.036^{* *}$ \\
$\times$ Low Roa & $(0.006)$ & $(0.015)$ & $(0.015)$ & $(0.033)$ & $(0.007)$ & $(0.015)$ \\
Pro-worker bias & -0.001 & -0.011 & -0.007 & 0.001 & -0.001 & -0.004 \\
$\times$ High Roa & $(0.004)$ & $(0.013)$ & $(0.014)$ & $(0.046)$ & $(0.005)$ & $(0.010)$ \\
$\mathrm{R}^{2}$ & 0.065 & 0.082 & 0.079 & 0.051 & 0.060 & 0.055 \\
$\#$ obs & 2581.000 & 2581.000 & 2359.000 & 2359.000 & 2359.000 & 2502.000 \\
\hline
\end{tabular}

Note: This table displays the estimates of the correlation between the judge bias and indicators of firms performance for the sample of medium-sized firms, with 10 to 100 employees the year before the judgment. $t$ denotes the year of the Appeal court judgment. The dependent variable is in Column (1) an indicator variable equal to one if the firm survives 3 years after the judgment; in Column (2) the symmetric growth rate between $t-1$ and $t+3$ of firm's employment; in Column (3) the symmetric growth rate between $t-1$ and $t+3$ of firm's employment in permanent contract $-c d i$; in Column (4) the symmetric growth rate between $t-1$ and $t+3$ of firm's employment in temporary contract; in Column (5) the change between $t-1$ and $t+3$ in the share of permanent jobs; in Column (6) the symmetric growth rate between $t-1$ and $t+3$ of sales. The variable of interest is the judge pro-worker bias computed as defined in section 4.2. Low roa firms denote firms with a return on assets below the median the year before the judgment. Covariates include Appeal court fixed effects, year fixed effects, the leave-one-out average industry annual growth rate of sales and an indicator variable for economic dismissals. The upper part of the table displays coefficient $\alpha_{1}$ of equation (5) and the bottom part coefficients $\beta_{1}$ and $\beta_{2}$ of equation (6). Standard errors, displayed in parentheses, are clustered at the judge level. *, **, and *** denote statistical significance at 10,5 and 1\%. Source: DADS, FICUS-FARE, SIREN, Appeal court rulings database. 
Table 19 - First-stage IV estimates

\begin{tabular}{lcccc}
\hline \hline & $(1)$ & $(2)$ & $(3)$ & $(4)$ \\
\hline & All size & All size & Small firms & Small firms \\
\hline All Roa & $\begin{array}{c}1.910^{* * *} \\
(0.262)\end{array}$ & & $2.267^{* * *}$ & \\
& & $(0.500)$ & \\
Low Roa & & $1.595^{* * *}$ & & $2.393^{* * *}$ \\
& & $(0.385)$ & & $(0.866)$ \\
High Roa & & $2.208^{* * *}$ & & $2.924^{* * *}$ \\
& & $(0.457)$ & & $(0.928)$ \\
\hline $\mathrm{R}^{2}$ & 0.064 & 0.064 & 0.075 & 0.075 \\
$\mathrm{~F}$ & 15.79 & 13.17 & 6.01 & 5.05 \\
\# obs & 4486 & 4486 & 1902 & 1902 \\
\hline
\end{tabular}

Note: This table presents the first-stage estimates of the IV regression where the share of total compensation for wrongful dismissal in the payroll of the year preceding the judgment is instrumented by the judge fixed-effect. Each cell corresponds to one regression where the dependent variable is the share of total compensation for wrongful dismissal in the payroll of the year preceding the judgment. Column (1) displays the results for all firms with less than 100 employees on 31 December before the judgment year; Column (2) for firms with less than 100 employees on 31 December before the judgment year with either low (below the median) or high return on assets; Column (3) and (4) display similar results for firms with less than 10 employees on 31 December before the judgment year. Covariates include Appeal court fixed effects, year fixed effects, the leave-one-out average industry annual growth rate of sales and an indicator variable for economic dismissals. Standard errors, displayed in parentheses, are clustered at the judge level. *, **, and ${ }^{* * *}$ denote statistical significance at 10,5 and $1 \%$ s, are clustered at the judge level. Source: DADS, FICUS-FARE, SIREN, Appeal court rulings database. 
Table 20 - Second-stage IV estimates of the effects of total compensations for wrongful dismissal on firm performance 3 years after the judgment

\begin{tabular}{lcccccc}
\hline \hline & $(1)$ & $(2)$ & $(3)$ & $(4)$ & $(5)$ & $(6)$ \\
\hline & Survival & \multicolumn{5}{c}{ growth rate between $t-1$ and $t+3$} \\
\cline { 3 - 7 } & within \\
\cline { 3 - 7 } & {$[t, t+3]$} & Employment & Employment & Employment & Share & Sales \\
& & $c d i$ & $c d d$ & $c d i$ & \\
\hline Total amount & $-0.005^{* *}$ & $-0.011^{*}$ & $-0.013^{*}$ & 0.000 & $-0.006^{*}$ & $-0.016^{* *}$ \\
& $(0.002)$ & $(0.006)$ & $(0.007)$ & $(0.015)$ & $(0.003)$ & $(0.005$ \\
\hline Total amount & -0.008 & $-0.031^{* *}$ & $-0.031^{* *}$ & 0.011 & -0.009 & $-0.041^{* *}$ \\
$\times$ Low Roa & $(0.005)$ & $(0.013)$ & $(0.015)$ & $(0.023)$ & $(0.007)$ & $(0.014)$ \\
Total amount & -0.003 & 0.002 & -0.004 & -0.001 & -0.004 & 0.000 \\
$\times$ High Roa & $(0.002)$ & $(0.007)$ & $(0.007)$ & $(0.017)$ & $(0.003)$ & $(0.006)$ \\
$\#$ obs & 4486.000 & 4486.000 & 4112.000 & 4112.000 & 4112.000 & 4398.000 \\
\hline
\end{tabular}

Note: This table displays the second stage of the IV estimates where Total amount, which corresponds to the share of total compensation for wrongful dismissal in the total payroll of the year preceding the judgment, is instrumented by the judge bias. $t$ denotes the year of the Appeal court judgment. The dependent variable is in Column (1) an indicator variable equal to one if the firm survives 3 years after the judgment; in Column (2) the symmetric growth rate between $t-1$ and $t+3$ of firm's employment; in Column (3) the symmetric growth rate between $t-1$ and $t+3$ of firm's employment in permanent contract - $c d i$; in Column (4) the symmetric growth rate between $t-1$ and $t+3$ of firm's employment in temporary contract; in Column (5) the change between $t-1$ and $t+3$ in the share of permanent jobs; in Column (6) the symmetric growth rate between $t-1$ and $t+3$ of sales. The variable of interest is the judge pro-worker bias computed as defined in section 4.2. Low roa firms denote firms with a return on assets below the median the year before the judgment. Covariates include Appeal court fixed effects, year fixed effects, the leave-one-out average industry annual growth rate of sales and an indicator variable for economic dismissals. Standard errors, displayed in parentheses, are clustered at the judge level. * ${ }^{* *}$, and ${ }^{* * *}$ denote statistical significance at 10,5 and $1 \%$. Source: DADS, FICUS-FARE, SIREN, Appeal court rulings database. 
Table 21 - Second-stage IV estimates of the effects of total compensations for wrongful dismissal on performance of firms below 10 employees 3 years after the judgment

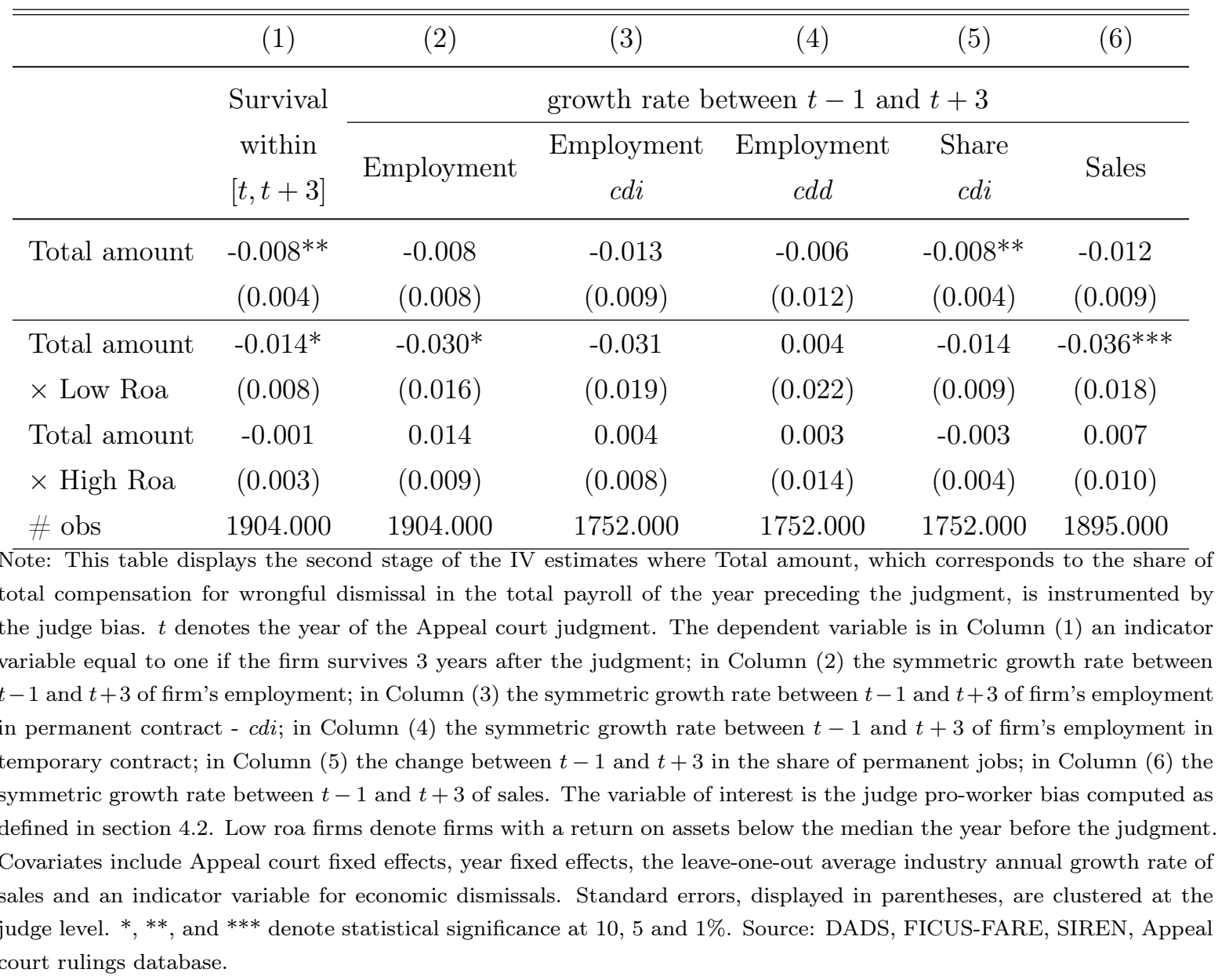


Table 22 - Judge pro-worker bias and small low-performing firm performance 3 years after the judgment, with quadratic terms

\begin{tabular}{|c|c|c|c|c|c|c|}
\hline & (1) & $(2)$ & $(3)$ & $(4)$ & $(5)$ & (6) \\
\hline & Survival & \multicolumn{5}{|c|}{ growth rate between $t-1$ and $t+3$} \\
\hline & $\begin{array}{l}\text { within } \\
{[t, t+3]}\end{array}$ & Employment & $\begin{array}{l}\text { Employment } \\
\qquad c d i\end{array}$ & $\begin{array}{c}\text { Employment } \\
c d d\end{array}$ & $\begin{array}{c}\text { Share } \\
c d i\end{array}$ & Sales \\
\hline Pro-worker bias & $\begin{array}{c}-0.026^{* *} \\
(0.012)\end{array}$ & $\begin{array}{c}-0.058^{* *} \\
(0.024)\end{array}$ & $\begin{array}{c}-0.055^{* *} \\
(0.026)\end{array}$ & $\begin{array}{c}0.005 \\
(0.041)\end{array}$ & $\begin{array}{c}-0.025^{* *} \\
(0.012)\end{array}$ & $\begin{array}{c}-0.066^{* *} \\
(0.023)\end{array}$ \\
\hline Pro-worker bias ${ }^{2}$ & $\begin{array}{l}-0.004 \\
(0.006)\end{array}$ & $\begin{array}{c}0.009 \\
(0.014)\end{array}$ & $\begin{array}{c}0.004 \\
(0.015)\end{array}$ & $\begin{array}{c}0.008 \\
(0.029)\end{array}$ & $\begin{array}{l}-0.004 \\
(0.008)\end{array}$ & $\begin{array}{c}0.006 \\
(0.015)\end{array}$ \\
\hline $\mathrm{R}^{2}$ & 0.134 & 0.111 & 0.113 & 0.109 & 0.135 & 0.104 \\
\hline \# obs & 973.000 & 973.000 & 911.000 & 911.000 & 911.000 & 966.000 \\
\hline $\begin{array}{l}\text { Note: This table displa } \\
\text { below } 10 \text { employees wh } \\
\text { Appeal court judgment } \\
3 \text { years after the judgm } \\
\text { Column (3) the symme } \\
\text { Column (4) the symme } \\
\text { (5) the change between } \\
t-1 \text { and } t+3 \text { of sales. } \\
\text { include Appeal court fi } \\
\text { an indicator variable fo } \\
*, * * \text {, and } * * * \text { denote st } \\
\text { database. }\end{array}$ & $\begin{array}{l}\text { s estimates o } \\
\text { se return on } \\
\text { The depend } \\
\text { ent; in Colum } \\
\text { tric growth } r \\
\text { ric growth ra } \\
t-1 \text { and } t+ \\
\text { Che variable o } \\
\text { red effects, ye } \\
\text { economic di } \\
\text { tistical signif }\end{array}$ & $\begin{array}{l}\text { the correlation be } \\
\text { ssets is below the } \\
\text { ent variable is in } \\
\text { n (2) the symmet } \\
\text { te between } t-1 \\
\text { te between } t-1 \text { a } \\
\text { in the share of p } \\
\text { f interest is the juc } \\
\text { ar fixed effects, th } \\
\text { missals. Standarc } \\
\text { cance at } 10,5 \text { and }\end{array}$ & $\begin{array}{l}\text { tween the judge bi } \\
\text { nedian the year pr } \\
\text { olumn ( } 1 \text { ) an indi } \\
\text { ic growth rate bet } \\
\text { and } t+3 \text { of firm' } \\
\text { nd } t+3 \text { of firm's } \\
\text { rmanent jobs; in C } \\
\text { ge pro-worker bias } \\
\text { e leave-one-out ave } \\
\text { errors, displayed } \\
1 \% \text {. Source: DAD }\end{array}$ & $\begin{array}{l}\text { s and indicators o } \\
\text { ceding the judgm } \\
\text { ator variable equ } \\
\text { ween } t-1 \text { and } t- \\
\text { employment in } \\
\text { mployment in ten } \\
\text { olumn (6) the syn } \\
\text { computed as defin } \\
\text { rage industry ann } \\
\text { n parentheses, are } \\
\text {, FICUS-FARE, }\end{array}$ & $\begin{array}{l}\text { firms perfor } \\
\text { nt. } t \text { denotes } \\
\text { to one if th } \\
3 \text { of firm's } \\
\text { ermanent co } \\
\text { porary contr } \\
\text { metric growt } \\
\text { ed in section } \\
\text { al growth ra } \\
\text { clustered at } \\
\text { IREN, Appe }\end{array}$ & $\begin{array}{l}\text { nance for firms } \\
\text { the year of the } \\
\text { e firm survives } \\
\text { mployment; in } \\
\text { tract - } c d i \text {; in } \\
\text { act; in Column } \\
\text { h rate between } \\
4.2 \text {. Covariates } \\
\text { te of sales and } \\
\text { the judge level. } \\
\text { al court rulings }\end{array}$ \\
\hline
\end{tabular}


Table 23 - Placebo tests: Judge pro-worker bias and firm performance before the judgment

\begin{tabular}{|c|c|c|c|c|c|}
\hline & (1) & $(2)$ & $(3)$ & $(4)$ & $(5)$ \\
\hline & \multicolumn{4}{|c|}{ growth rate between $\mathrm{t}-2$ and $\mathrm{t}-1$} & \multirow[b]{2}{*}{ Sales } \\
\hline & Employment & $\begin{array}{c}\text { Employment } \\
c d i\end{array}$ & $\begin{array}{c}\text { Employment } \\
c d d\end{array}$ & $\begin{array}{c}\text { Share } \\
\text { cdi }\end{array}$ & \\
\hline \multirow{3}{*}{ Pro-worker bias $\times$ Low Roa } & \multicolumn{4}{|c|}{ All firms } & \\
\hline & -0.005 & -0.001 & -0.004 & 0.002 & -0.001 \\
\hline & $(0.007)$ & $(0.008)$ & $(0.021)$ & $(0.005)$ & $(0.006)$ \\
\hline \multirow[t]{2}{*}{ Pro-worker bias $\times$ High Roa } & -0.005 & -0.002 & 0.036 & 0.003 & 0.006 \\
\hline & $(0.005)$ & $(0.010)$ & $(0.023)$ & $(0.009)$ & $(0.005)$ \\
\hline $\mathrm{R}^{2}$ & 0.039 & 0.047 & 0.034 & 0.042 & 0.035 \\
\hline \multirow[t]{2}{*}{$\#$ obs } & 4282 & 3420 & 3420 & 3420 & 4224 \\
\hline & \multicolumn{4}{|c|}{ Small firms } & \\
\hline \multirow[t]{2}{*}{ Pro-worker bias $\times$ Low Roa } & -0.001 & -0.008 & -0.040 & -0.005 & 0.000 \\
\hline & $(0.011)$ & $(0.013)$ & $(0.028)$ & $(0.009)$ & $(0.008)$ \\
\hline \multirow[t]{2}{*}{ Pro-worker bias $\times$ High Roa } & -0.005 & -0.0028 & 0.050 & -0.014 & 0.009 \\
\hline & $(0.010)$ & $(0.020)$ & $(0.034)$ & $(0.017)$ & $(0.010)$ \\
\hline $\mathrm{R}^{2}$ & 0.083 & 0.089 & 0.067 & 0.068 & 0.075 \\
\hline$\#$ obs & 1843 & 1477 & 1477 & 1477 & 1829 \\
\hline
\end{tabular}

Note: This table displays the estimates of the correlation between the judge bias and indicators of firm performance. $t$ denotes the year of the Appeal court judgment. The dependent variable is in Column (1) the symmetric growth rate between $t-2$ and $t-1$ of firm's employment; in Column (2) the symmetric growth rate between $t-2$ and $t-1$ of firm's employment in permanent contract - $c d i$; in Column (3) the symmetric growth rate between $t-2$ and $t-1$ of firm's employment in temporary contract; in Column (4) the change between $t-2$ and $t-1$ in the share of permanent jobs; in Column (5) the symmetric growth rate between $t-2$ and $t-1$ of sales. The variable of interest is the judge pro-worker bias computed as defined in section 4.2. Low roa firms denote firms with a return on assets below the median the year before the judgment. Covariates include Appeal court fixed effects, year fixed effects, the leave-one-out average industry annual growth rate of sales and an indicator variable for economic dismissals. The table displays coefficient coefficients $\beta_{1}$ and $\beta_{2}$ of equation (6) for all firms in the top panel and for firms with less than 10 employees the year before the judgment. Standard errors, displayed in parentheses, are clustered at the judge level. *,**, and *** denote statistical significance at 10, 5 and $1 \%$. Source: DADS, FICUS-FARE, SIREN, Appeal court rulings database. 
Table 24 - Judge pro-worker bias and firm performance 3 years after the judgment according to return on equity

\begin{tabular}{|c|c|c|c|c|c|c|}
\hline & (1) & (2) & (3) & (4) & (5) & (6) \\
\hline & Survival & \multicolumn{5}{|c|}{ growth rate between $t-1$ and $t+3$} \\
\hline & $\begin{array}{l}\text { within } \\
{[t, t+3]}\end{array}$ & Employment & $\begin{array}{l}\text { Employment } \\
\qquad d i\end{array}$ & $\begin{array}{c}\text { Employment } \\
c d d\end{array}$ & $\begin{array}{l}\text { Share } \\
c d i\end{array}$ & Sales \\
\hline \multicolumn{7}{|c|}{ All firms } \\
\hline Pro-worker bias & $-0.011^{* *}$ & $-0.037 * *$ & $-0.043^{* * *}$ & -0.005 & $-0.013^{* *}$ & $-0.047^{* * *}$ \\
\hline$\times$ Low Roe & $(0.004)$ & $(0.011)$ & $(0.012)$ & $(0.029)$ & $(0.006)$ & $(0.011)$ \\
\hline Pro-worker bias & -0.003 & 0.010 & 0.010 & 0.008 & -0.001 & -0.002 \\
\hline$\times$ High Roe & $(0.005)$ & $(0.012)$ & $(0.015)$ & $(0.028)$ & $(0.007)$ & $(0.011)$ \\
\hline $\mathrm{R}^{2}$ & 0.044 & 0.047 & 0.046 & 0.031 & 0.039 & 0.030 \\
\hline$\#$ obs & 4447 & 4447 & 4084 & 4084 & 4084 & 4369 \\
\hline \multicolumn{7}{|c|}{ Small firms } \\
\hline Pro-worker bias & $-0.025^{* * *}$ & $-0.062^{* *}$ & $-0.087^{* * *}$ & -0.036 & $-0.028^{* *}$ & $-0.063^{* * *}$ \\
\hline$\times$ Low Roe & $(0.007)$ & $(0.021)$ & $(0.020)$ & $(0.038)$ & $(0.010)$ & $(0.017)$ \\
\hline Pro-worker bias & -0.003 & 0.036 & 0.038 & 0.014 & -0.002 & 0.019 \\
\hline$\times$ High Roe & $(0.010)$ & $(0.023)$ & $(0.032)$ & $(0.030)$ & $(0.013)$ & $(0.023)$ \\
\hline $\mathrm{R}^{2}$ & 0.054 & 0.057 & 0.061 & 0.069 & 0.061 & 0.058 \\
\hline$\#$ obs & 1887 & 1887 & 1735 & 1735 & 1735 & 1878 \\
\hline \multicolumn{7}{|c|}{$\begin{array}{l}\text { Note: This table displays the estimates of the correlation between the judge bias and indicators of firm performance. } t \\
\text { denotes the year of the Appeal court judgment. The dependent variable is in Column (1) an indicator variable equal to } \\
\text { one if the firm survives } 3 \text { years after the judgment; in Column (2) the symmetric growth rate between } t-1 \text { and } t+3 \text { of } \\
\text { firm's employment; in Column (3) the symmetric growth rate between } t-1 \text { and } t+3 \text { of firm's employment in permanent } \\
\text { contract - } c d i \text {; in Column (4) the symmetric growth rate between } t-1 \text { and } t+3 \text { of firm's employment in temporary } \\
\text { contract; in Column (5) the change between } t-1 \text { and } t+3 \text { in the share of permanent jobs; in Column (6) the symmetric } \\
\text { growth rate between } t-1 \text { and } t+3 \text { of sales. The variable of interest is the judge pro-worker bias computed as defined in } \\
\text { section } 4.2 \text {. Low roe firms denote firms with a return on equity below the median the year before the judgment. Covariates } \\
\text { include Appeal court fixed effects, year fixed effects, the leave-one-out average industry annual growth rate of sales and } \\
\text { an indicator variable for economic dismissals. The upper part of the table displays coefficient } \alpha_{1} \text { of equation (5) and the } \\
\text { bottom part coefficients } \beta_{1} \text { and } \beta_{2} \text { of equation (6). Standard errors, displayed in parentheses, are clustered at the judge } \\
\text { level. } *, * * \text {, and }{ }^{* * *} \text { denote statistical significance at } 10,5 \text { and } 1 \% \text {. Source: DADS, FICUS-FARE, SIREN, Appeal court } \\
\text { rulings database. }\end{array}$} \\
\hline
\end{tabular}


Table 25 - Judge pro-worker bias and firm performance 3 years after the judgment - Large Appeal courts

\begin{tabular}{lcccccc}
\hline \hline & $(1)$ & $(2)$ & $(3)$ & $(4)$ & $(5)$ & $(6)$ \\
\hline & Survival & \multicolumn{5}{c}{ growth rate between $t-1$ and $t+3$} \\
\cline { 3 - 7 } & within & Employment & $\begin{array}{c}\text { Employment } \\
\text { [ }\end{array}$ Employment & Share & \\
& $t, t+3]$ & & $c d i$ & $c d d$ & $c d i$ & Sales \\
\hline Pro-worker bias & $-0.012^{* *}$ & $-0.035^{* * *}$ & $-0.030^{* *}$ & $-0.039^{*}$ & -0.006 & $-0.028^{* *}$ \\
& 0.050 & 0.058 & 0.060 & 0.050 & 0.053 & 0.044 \\
$\mathrm{R}^{2}$ & 0.050 & 0.058 & 0.060 & 0.050 & 0.053 & 0.044 \\
\hline Pro-worker bias & -0.010 & $-0.038^{* * *}$ & $-0.029^{* *}$ & 0.007 & -0.005 & $-0.024^{*}$ \\
$\times$ Low Roa. & $(0.007)$ & $(0.010)$ & $(0.013)$ & $(0.026)$ & $(0.009)$ & $(0.012)$ \\
Pro-worker bias & $-0.014^{* * *}$ & $-0.032^{* *}$ & $-0.030^{*}$ & $-0.084^{* *}$ & -0.006 & $-0.032^{*}$ \\
$\times$ High Roa & $(0.004)$ & $(0.013)$ & $(0.015)$ & $(0.025)$ & $(0.008)$ & $(0.018)$ \\
$\mathrm{R}^{2}$ & 0.050 & 0.058 & 0.060 & 0.052 & 0.053 & 0.044 \\
$\#$ obs & 2074.000 & 2074.000 & 1907.000 & 1907.000 & 1907.000 & 2022.000 \\
\hline
\end{tabular}

Note: This table displays the estimates of the correlation between the judge bias and indicators of firm performance in large Appeal courts which comprise several social chambers. $t$ denotes the year of the Appeal court judgment. The dependent variable is in Column (1) an indicator variable equal to one if the firm survives 3 years after the judgment; in Column (2) the symmetric growth rate between $t-1$ and $t+3$ of firm's employment; in Column (3) the symmetric growth rate between $t-1$ and $t+3$ of firm's employment in permanent contract - $c d i$; in Column (4) the symmetric growth rate between $t-1$ and $t+3$ of firm's employment in temporary contract; in Column (5) the change between $t-1$ and $t+3$ in the share of permanent jobs; in Column (6) the symmetric growth rate between $t-1$ and $t+3$ of sales. The variable of interest is the judge pro-worker bias computed as defined in section 4.2. Low roe firms denote firms with a return on equity below the median the year before the judgment. Covariates include Appeal court fixed effects, year fixed effects, the leave-one-out average industry annual growth rate of sales and an indicator variable for economic dismissals. The upper part of the table displays coefficient $\alpha_{1}$ of equation (5) and the bottom part coefficients $\beta_{1}$ and $\beta_{2}$ of equation (6). Standard errors, displayed in parentheses, are clustered at the judge level. ${ }^{*},{ }^{* *}$, and ${ }^{* * *}$ denote statistical significance at 10, 5 and 1\%. Source: DADS, FICUS-FARE, SIREN, Appeal court rulings database. 


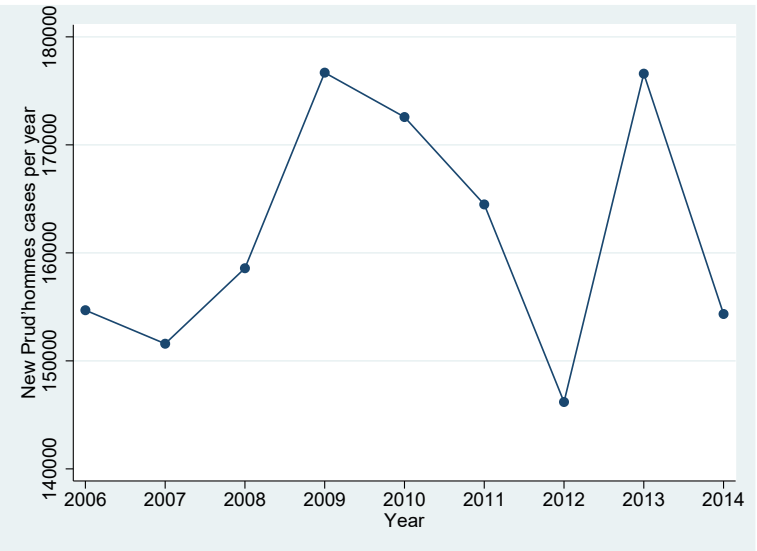

(a) New Prud'hommes cases

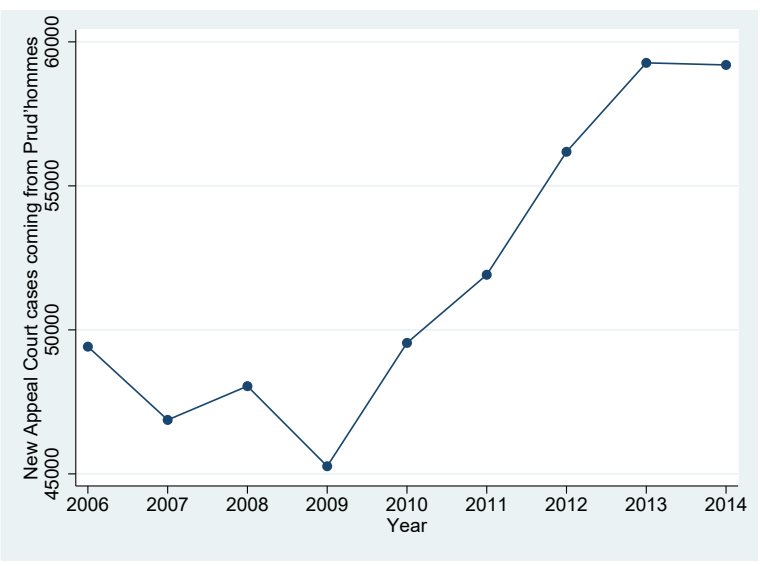

(b) New Appeal court cases coming from Prud'hommes

Figure 1 - Number of new Prud'hommes cases per year and new Appeal court cases coming from Prud'hommes per year in France

Note: Figure (a) on the left displays the numbers of new cases opened per year for all French Employment Tribunals (including non-metropolitan France). Figure (b) on the right displays the numbers of new Appeal court cases coming from Prud'hommes opened per year. Figures were constructed using datasets on Prud'hommes and Appeal court activity available on the website of the French Ministry of Justice. Numbers displayed do not include requests for interim measures (demande en référé). Source: Appeal court rulings database.

Figure 2 - Example of end of Appeal court ruling

\section{PAR CES MOTIFS}

\section{LACOUR,}

Statuant par arrêt contradictoire,

INFIRME PARTIELLEMENT le jugement déféré et statuant à nouveau,

CONDAMNE la Société cause réelle et sérieuse;

à verser à Monsieur B. $30.000 €$ (TRENTE MLLE EUROS) à titre díndemnité pour liœnciement sans

ORDONNE le remboursement par la Société à l'organisme concerné des indemnités de chômage effectivement versées à Mbnsieur B. par suite de son licenciement et $œ$ dans la limite de trois mois :

DÉBOUTE Mbnsieur B. de sa demande au titre de dommages et intérêts pour manquement auxobligations œnventionnelles ;

CONFRME pour le surplus le jugement déféré;

Yajoutant,

CONDAMNE la Société

Proøédure Civile;

à verser à Monsieur B. la somme de $1.000 €$ (MLLE EUROS) au titre de lartide 700 du Code de

DÉBOUTE la Société ___ de sa demande au titre de l'article 700 du Code de Procédure Civile ;

CONDAMNE la Société auxentiers dépens.

Prononcé publiquement par mise à disposition de l'arrêt au greffe de la Cour, les parties en ayant été préalablement avisées dans les conditions prévies au deuxième alinéa de l'article 450 du Code de Procédure Civile,

Et signé par Madame a grésident, et par Madame @ grefier, auquel la minute de la décision a été remise par le magistrat signataire.

\section{LE GREFFIER LE PRÉSIDENT}

Mnute en sept pages.

Composition de la juridiction :

Décision attaquée : C. Prud. Longwy, Nancy 2011-02-25 
Figure 3 - Histogram of compensation amounts in monthly wage

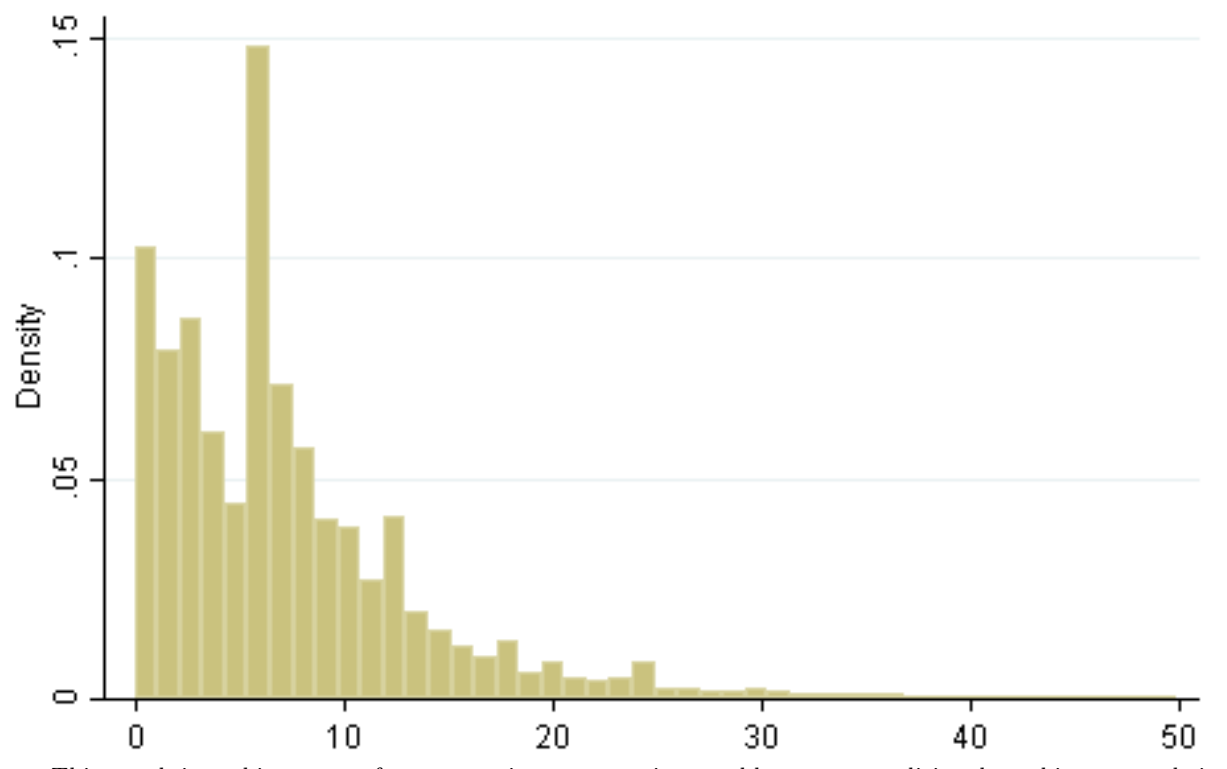

Note: This graph is an histogram of compensation amounts in monthly wages, conditional on this amount being positive. Only amounts lower than 50 months of salary are displayed. Source: Appeal court rulings database.

Figure 4 - Compensations for wrongful dismissals and seniority
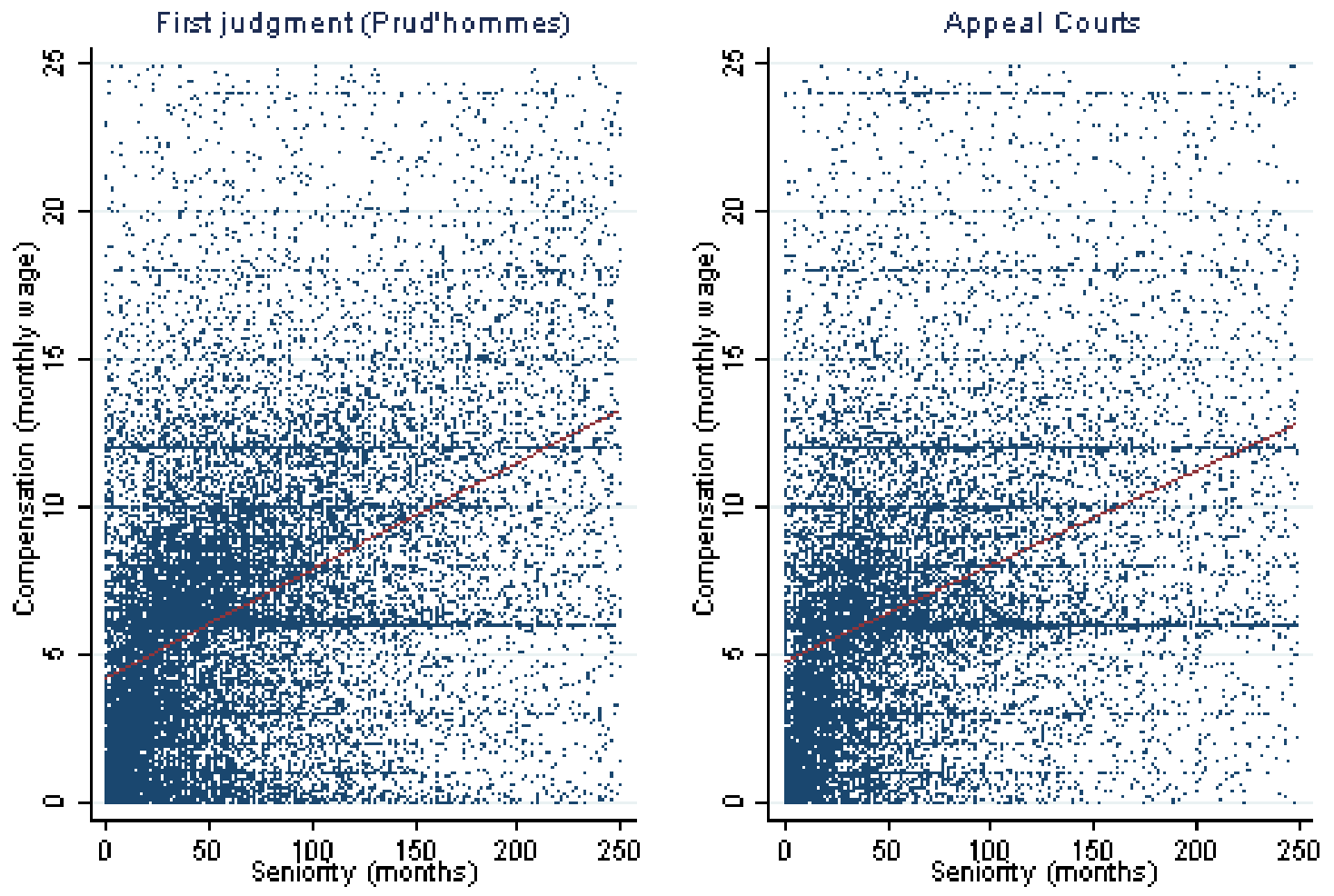

Mot: $\log 1$ s chenelore immed

Note: These graphs are scatter plots of compensations for wrongful dismissals depending on seniority. Compensations are expressed in monthly wage. The left panel displays compensations set by prud'hommes and the right panel displays compensations set by Appeal courts. Source: Appeal court rulings database. 
Figure 5 - Relation between compensations for wrongful dismissals set by Appeal courts and by prud'hommes

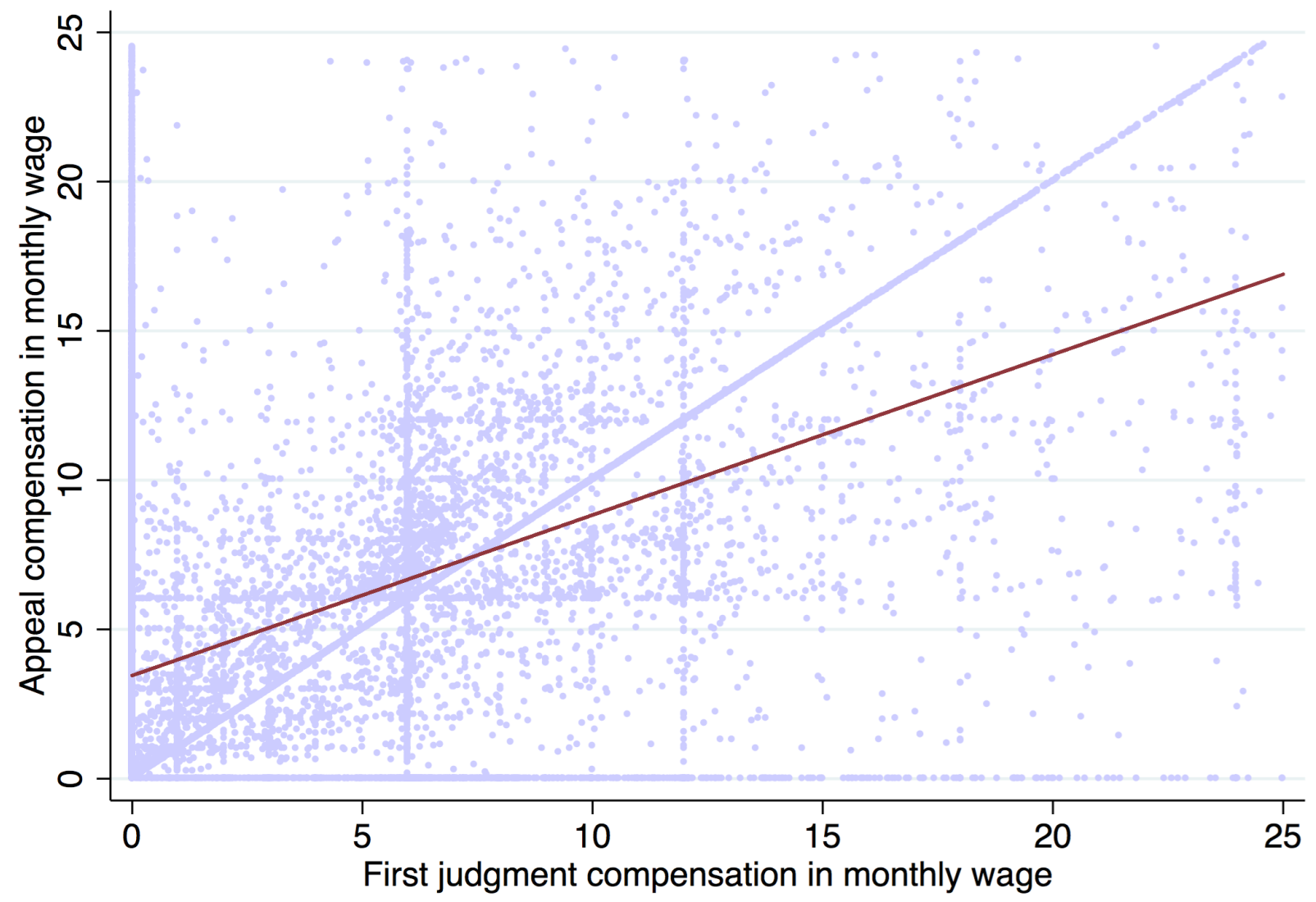

Note: This graph is a scatter plot of the compensations for wrongful dismissals set by Appeal courts and by prud'hommes. Compensations are expressed in monthly wage. Source: Appeal court rulings database. 
Figure 6 - Histogram of frequency of dismissals deemed unfair per judge

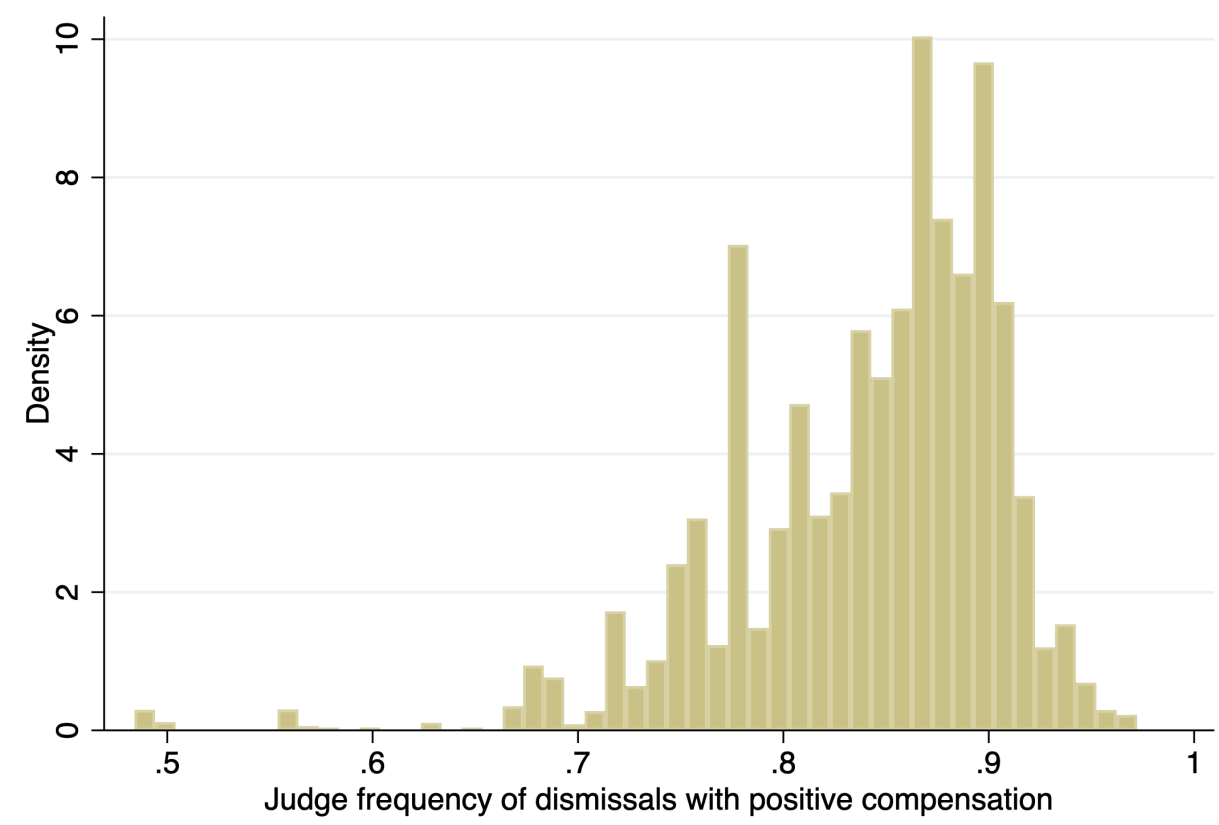

Note: This Figure exhibits the histogram of frequency of dismissals deemed unfair per judge. Caselevel data are used, therefore the number of observations used is the number of different cases for which we are able to compute the pro-worker bias. Source: Appeal court rulings database. 
Figure 7 - Relation between mean compensation per judge for unfair dismissal and mean compensation granted for other reasons

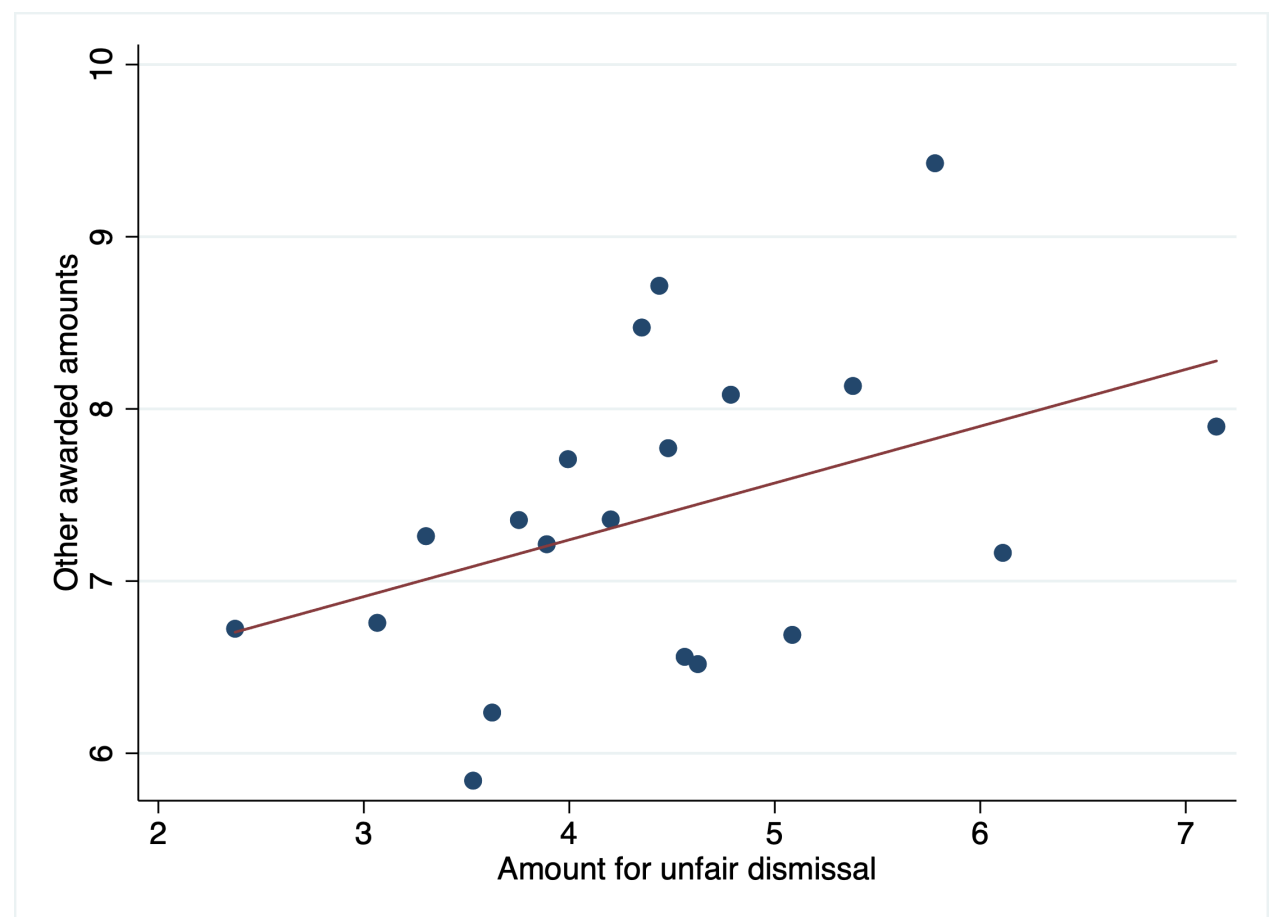

Note: This figure exhibits the scatter plot of mean compensation in month of salary for unfair dismissal per judge, grouped in 20 equal-sized bins, against the mean compensation for other reasons. Case-level data are used, therefore the number of observations used is the number of different cases for which we are able to compute the pro-worker bias. Source: Appeal court rulings database. 
Figure 8 - Histogram of mean compensation per judge

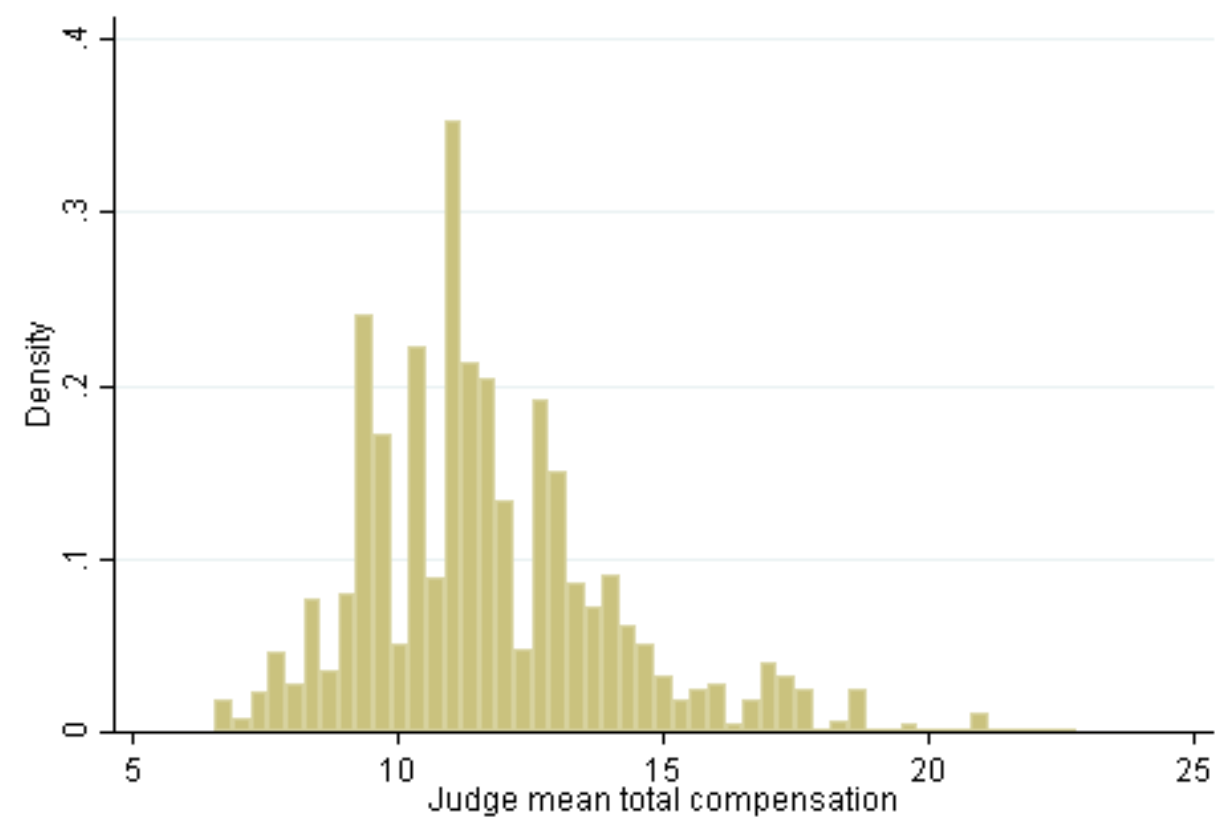

Note: This figure exhibits the histogram of mean compensation in month of salary per judge. Caselevel data are used, therefore the number of observations used is the number of different cases for which we are able to compute the pro-worker bias. Source: Appeal court rulings database.

Figure 9 - Allocation of cases exploited for identification

\begin{tabular}{|c|c|c|}
\multicolumn{5}{c|}{ Court of Paris } \\
& \multicolumn{2}{c|}{ Social chamber 1 } \\
\hline \\
\hline
\end{tabular}

Note: This figure displays the allocation of cases to judges used for identification. Within an Appeal court, there may be several social chambers. Within each social chamber, there is, at an instant $t$, one chamber president who judges the cases. When judges change assignments in the course of a year, for instance in 2014, one can identify the allocation to president A or president B. 
Figure 10 - Network of judges

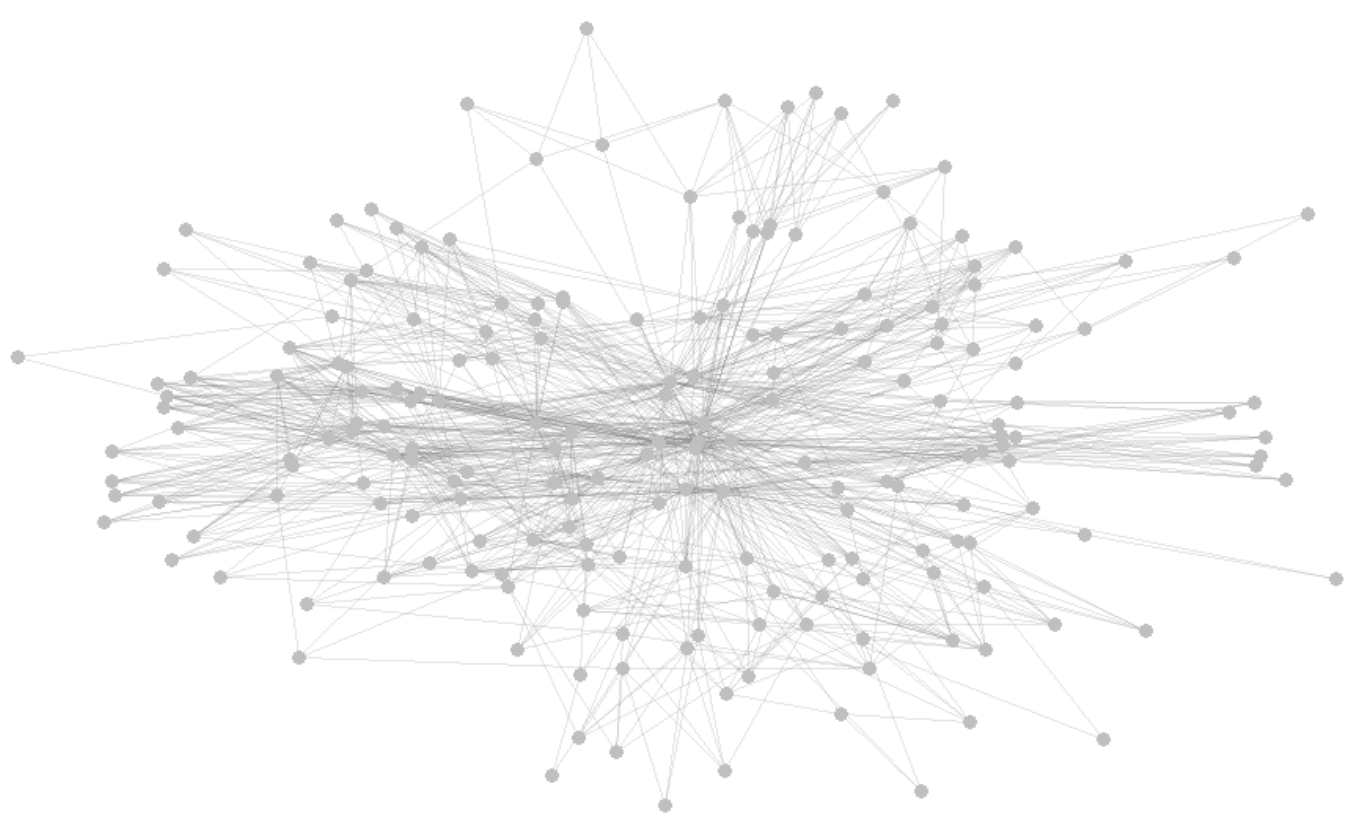

Note: Each dot represents a judge. Two dots are connected if the two judges shared the same social chamber at least once. The higher the network density, the higher the mobility of judges across social chambers. If judges were not mobile whatsoever, one would observe perfectly distinct judge clusters, each cluster representing one social chamber. Source: Appeal court rulings database.

Figure 11 - Judge pro-worker bias with respect to the dismissal qualification

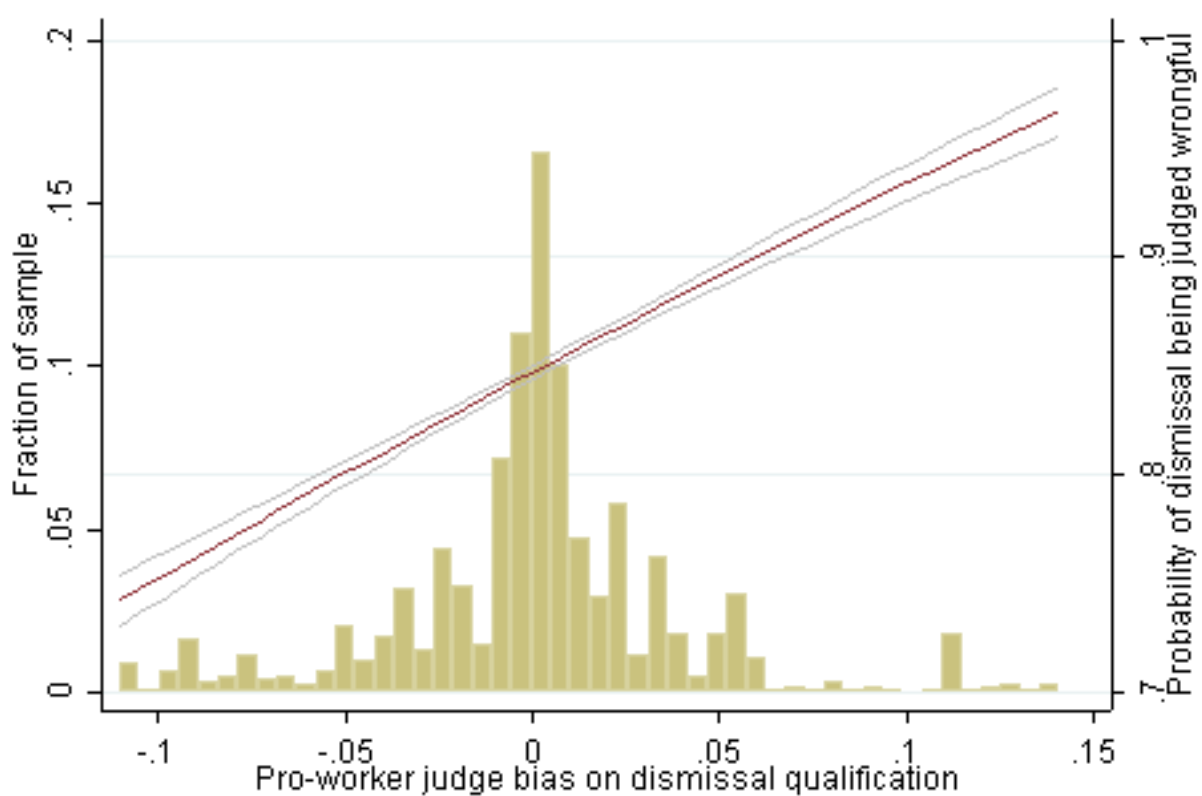

Note: This figure displays the histogram of pro-worker biases of judges with respect to the qualification of dismissals in background and a local polynomial fit of the indicator variable equal to one if the dismissal is deemed wrongful, represented by the red line. The grey lines display the frontiers of the $95 \%$ confidence interval of the local polynomial fit. Case-level data are used, therefore the number of observations is the number of different cases for which we are able to compute the pro-worker bias reported in Table 2. The pro-worker bias is computed as defined in Section 4.2. Source: Appeal court rulings database. 
Figure 12 - Judges pro-worker biases with respect to the compensation in months of salary

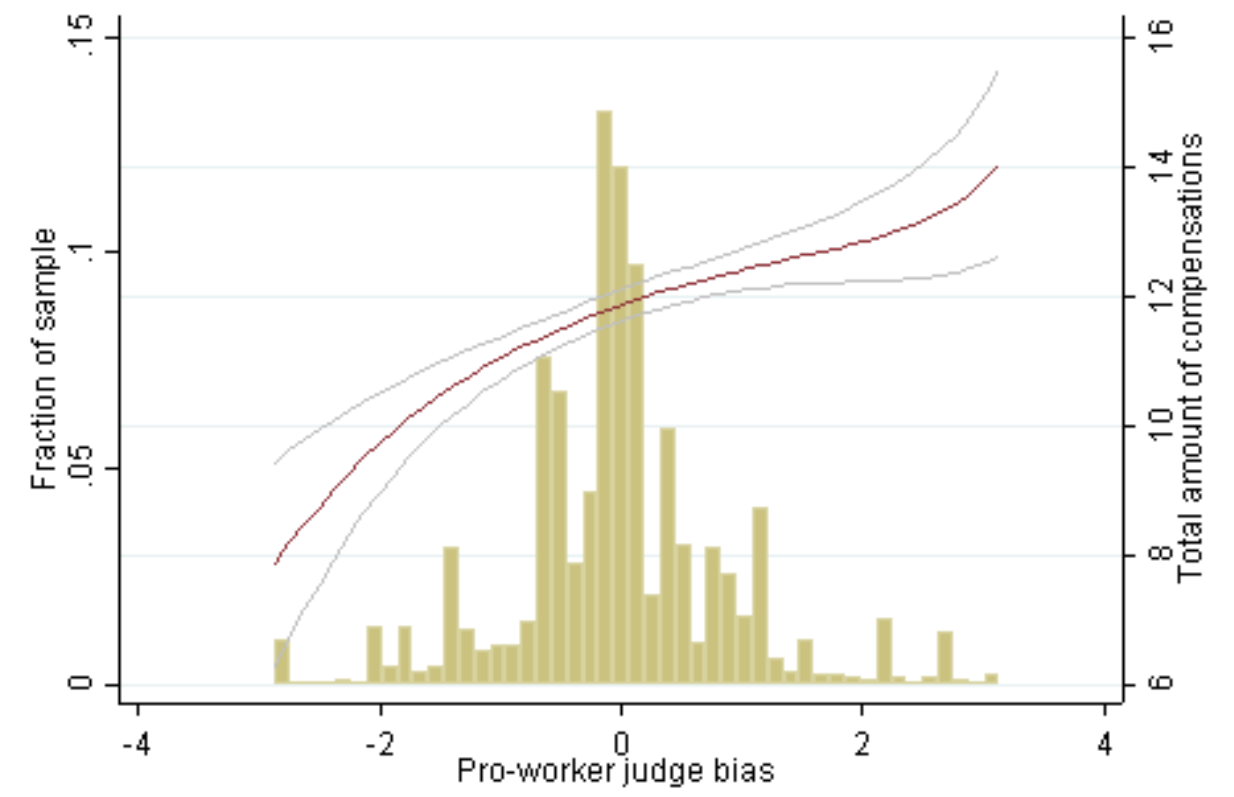

Note : This figure displays the histogram of the pro-worker biases of judges with respect to the total amount of compensation for wrongful dismissal and a local polynomial fit of the total amount of compensation, represented by the red line. The grey lines display the frontiers of the $95 \%$ confidence interval of the local polynomial fit. Case-level data are used, therefore the number of observations is the number of different cases for which we are able to compute the pro-worker bias reported in Table 2. The pro-worker bias is computed as defined in Section 4.2. Source: Appeal court rulings database.

Figure 13 - Correlation between the two indices of pro-worker biases

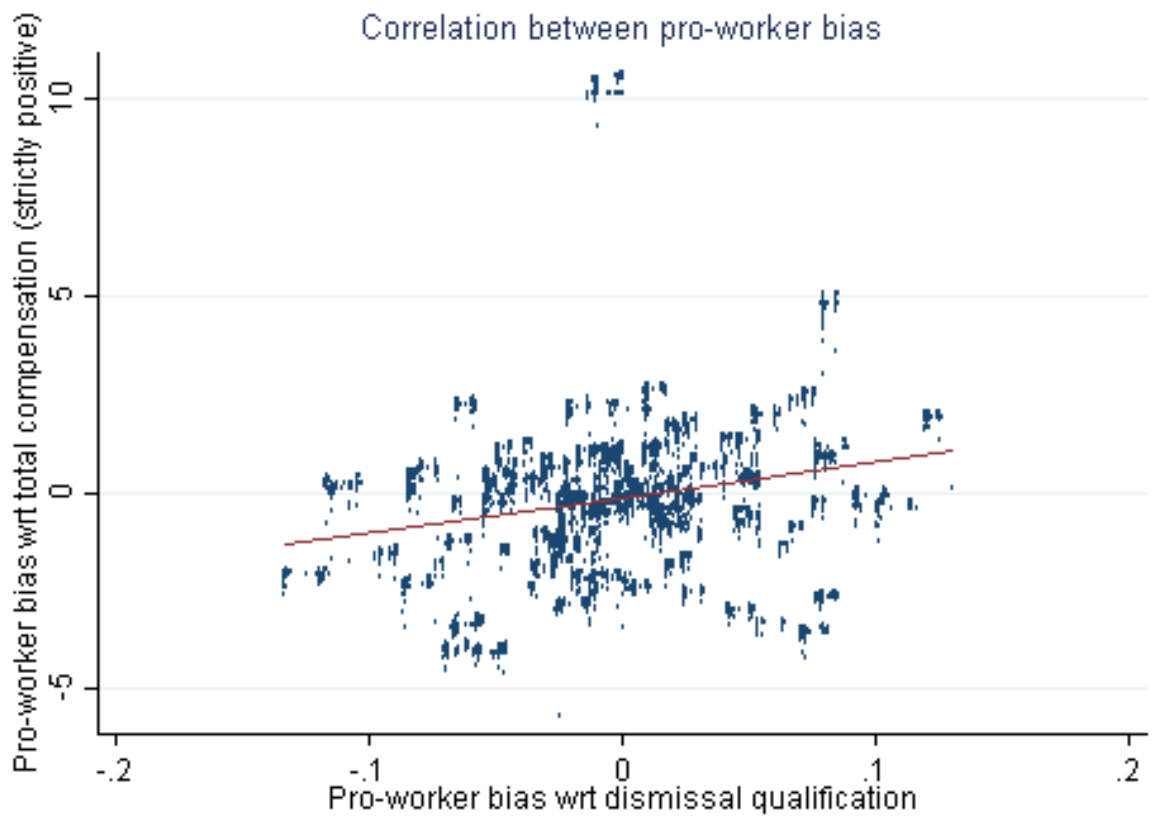

Note: This figure is a scatter plot of the pro-worker bias measure computed from the dismissal qualification and the proworker bias computed from the compensation amount, conditional on being positive. Pro-worker biases are computed as defined in Section 4.2. Source: Appeal court rulings database. 
Figure 14 - Augmented component-plus-residual plot

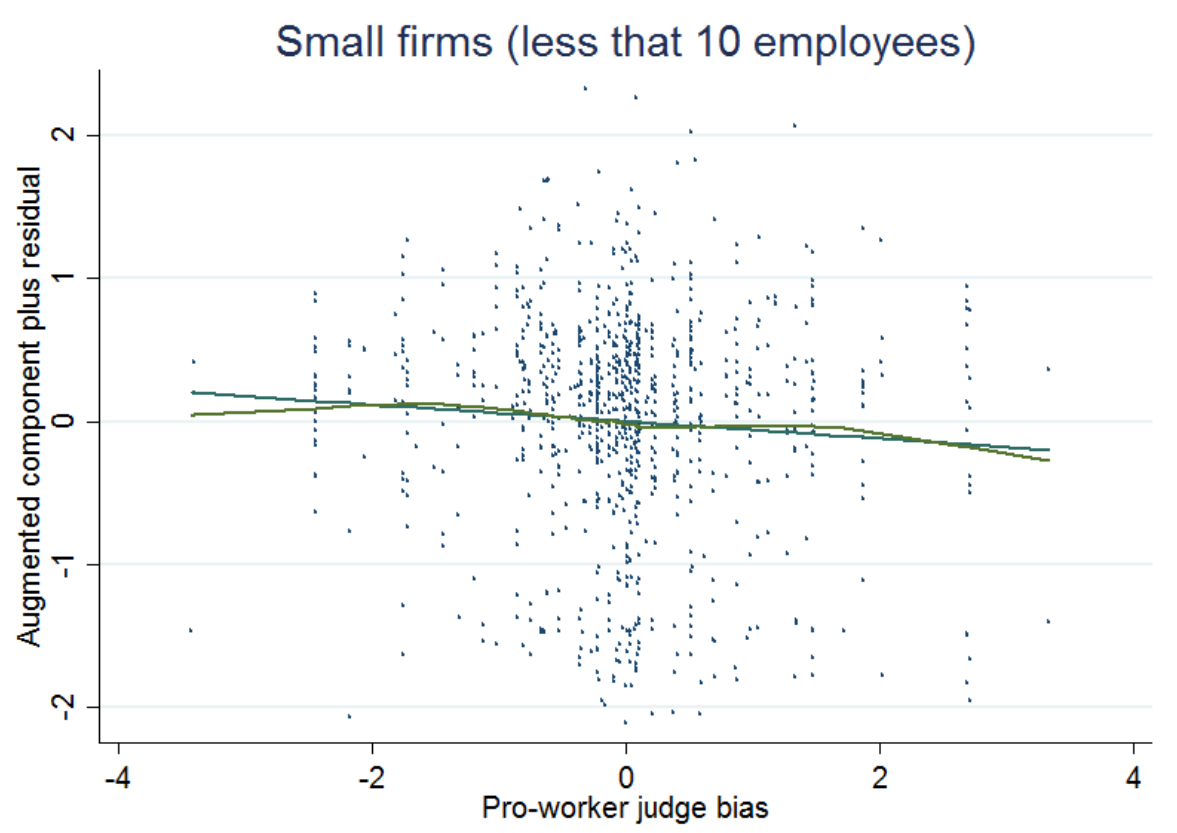

Note: This figure is an augmented component-plus-residual plot of the reduced form estimation of the correlation between the judge bias and the employment growth of firms with fewer than 10 employees and whose return on assets is below the median at 3-year horizon displayed in Table 17. The non-linear line is a lowess smooth of the plotted points. Source: DADS, FICUS-FARE, SIREN, Appeal court rulings database. 
Figure 15 - Counter factual exercises
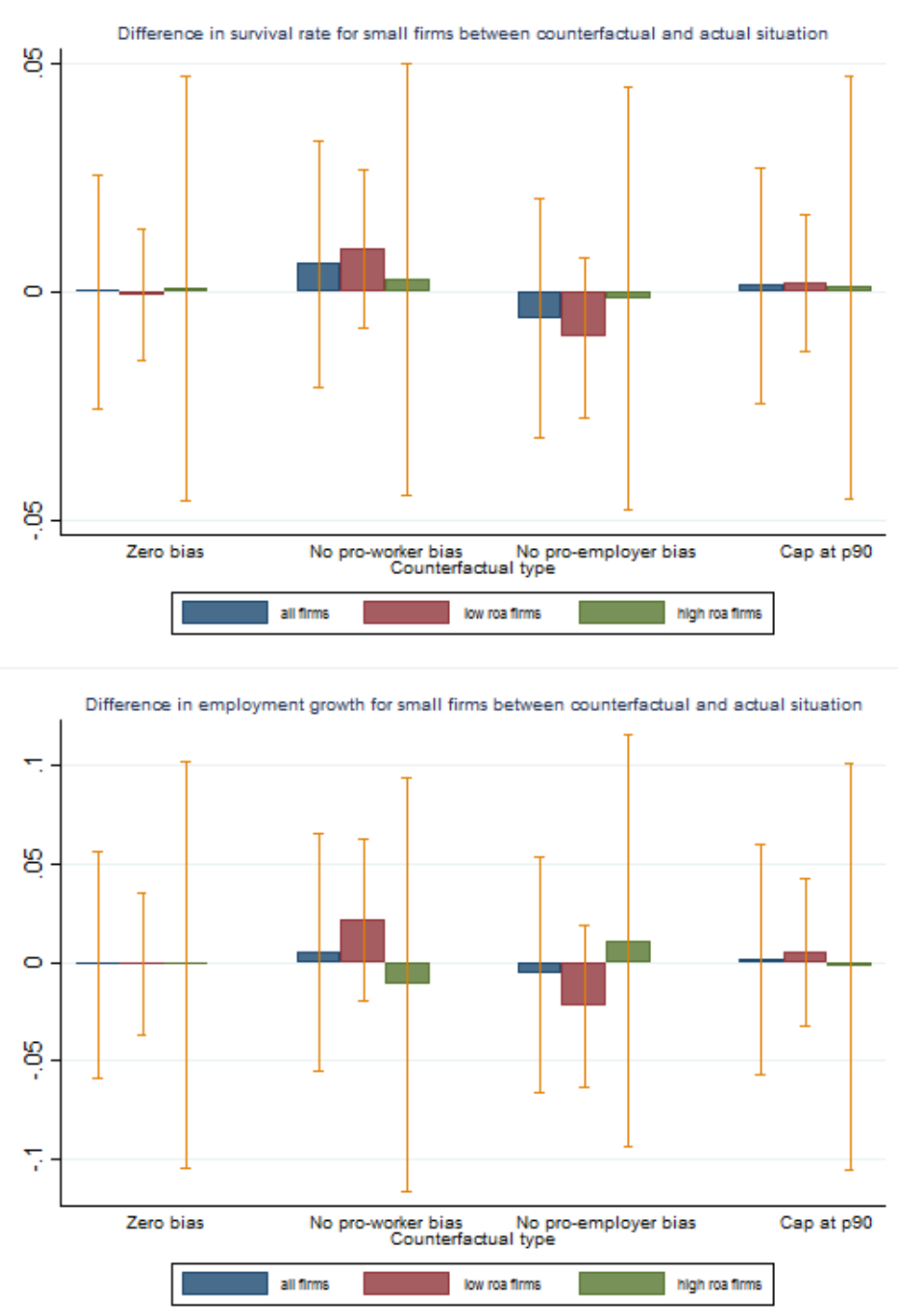

Note: This figure reports the results of counterfactual exercises in which we cap judge bias at several percentiles of the distribution of bias. To do so, we first estimate the predicted outcomes of firms from the estimation of equation (5) applied to our initial sample with 1,000 bootstrap replications. This yields a distribution of predicted outcomes with the actual distribution of judge bias. Then, we repeat the same exercise for the samples with counterfactual distributions of the judge bias to obtain the distributions of predicted outcomes with counterfactual distributions of judge bias. The top panel and the bottom panel respectively report the mean and the $95 \%$ confidence interval of the differences between those predicted outcomes three years after the judgments for the survival rate and the employment growth rate at 3 year-horizon for firms with fewer than 10 employees whose return on assets is below the median the year preceding the judgment. Source: DADS, FICUS-FARE, SIREN, Appeal court rulings database. 


\section{A Caps on dismissal compensation in European coun- tries}

A majority of European countries have set rules that limit the amounts granted by judges in case of unfair dismissal (excluding cases of discrimination or harassment):

- In Italy, a fixed amount compensating an unfair dismissal was introduced in 2014 by the so-called (Jobs $\boldsymbol{A} \boldsymbol{c t}$ ) for the new indefinite-duration contract with progressive employment protection, which depends on seniority: from 4 months for less than 2 years of seniority to 24 months for 12 years of seniority. From these amounts one must deduce the compensation received at the time of dismissal. In 2018 the Italian Constitutional Court overruled this regulation, stating that the amount of compensation to the worker cannot be based only on her seniority.

- In Germany the schedule depends on seniority and reaches 12 months of salary (and even 15 months if the worker is more than 50 years old with more than 15 years of seniority, and 18 months if more than 55 years olds with more than 20 years of service).

- In Austria, the schedule depends on seniority: for those with less than 2 years the amount is 6 weeks of salary; between 2 and 5 years it is 2 months; between 5 and 15 years, 3 months; between 15 and 25 months, 4 months; beyond that: 5 months of salary.

- In Belgium, the minimum compensation is 3 weeks and the maximum 17 weeks of salary.

- In Denmark, worker compensation is capped at 1 year of salary for blue-collar; for whitecollar workers, compensation goes up to half of the wages received during the notice period, capped at 3 months for those under 30, at 4 months if more than 10 years of service and 6 months if they have more than 15 years of service.

- In Spain, the indemnity is set at 33 days per year of seniority with a maximum of 24 months of salary, for contracts signed since the 2012 labor market reform.

- In Finland, the allowance is between 3 (minimum) and 24 (maximum) months of salary, depending on several factors including seniority, the age of the employee, the length of unemployment period, or the loss of income.

- In the Netherlands, the schedule depends above all on the age of the employee $(1 / 2$ month of salary per year of seniority up to 35 years old, 1 month per year of seniority between 35 and 45 years old, 1.5 month per year of seniority between 45 and 55 years old, 2 months per year of seniority beyond 55), to which a correction factor can be added depending on the exact situation. From these amounts one must deduce the compensation received at the time of dismissal.

- In Portugal, the court may grant between 15 (minimum) and 45 (maximum) days of salary per year of seniority with a minimum of 3 months.

- In the United Kingdom, for employees with more than two years of seniority the allowance consists of two components (i) a basic allowance which depends on seniority and capped at $£ 14,250$ and (ii) a compensatory allowance capped at one year of salary and limited to $£ 78,335$.

- In Sweden, the allowance is 16 months of salary for employees with less than 5 years of seniority, 24 months between 5 and 10 years, and 32 months for more than 10 years. 
- In France since 2017 (Ordonnances), compensation for unfair dismissal is capped by an amount that depends on seniority varying from 1 month to 20 months for employees with 30 year or more of tenure, and cannot be less that 3 months of salary for employees with at least 2 years of seniority (at least 11 years for those working in firms with fewer than 11 employees).

\section{B Computation of judge bias}

To compute the bias of judges, we can estimate

$$
y_{i j k t}=\eta_{k t}+\nu_{i j k t}
$$

assuming $\mathbb{E}\left(\nu_{i j k t} \mid \eta_{k t}\right)=0$, meaning that the compensation awarded in case $i$ is assumed to be equal to a term common to all cases judged in the same chamber and year as case $i$ plus a random term. This implies that the chamber $\times$ year fixed effect in chamber $k$ in year $t$ is defined by the expectation of the compensation $y_{i j k t}$ in chamber $k$ in year $t$ :

$$
\eta_{k t}=\mathbb{E}\left(y_{i j k t} \mid k, t\right)
$$

the sample counterpart of which is

$$
\hat{\eta}_{k t}=\frac{1}{n_{k t}} \sum_{i \in(k, t)} y_{i}
$$

where $i \in(k, t)$ stands for all the cases judged in chamber $k$ at date $\mathrm{t}$ and $n_{k t}$ is the number of cases judged in chamber $k$ in year $t$. The chamber $k$ fixed effect in year $t$ is equal to the average of all compensations in chamber $k$ in year $t$.

By definition, the estimator of the judge fixed effect, conditional on the chamber $\times$ year fixed effect is

$$
\hat{\varepsilon}_{j}=\frac{1}{n_{j}} \sum_{i \in j} \hat{\nu}_{i}
$$

where $i \in j$ stands for all cases $i$ judges by judge $j$. Let us denote by $(K, T)(j)$ the set of all chamber $\times$ year pairs $(k, t)$ observed for judge $j$. From equations (B1) and (B4), we can write

$$
\hat{\varepsilon}_{j}=\frac{1}{n_{j}} \sum_{i \in j} y_{i}-\frac{1}{n_{j}} \sum_{(k, t) \in(K, T)(j)} \frac{n_{j k t}}{n_{k t}} \hat{\eta}_{k t}
$$

Equation (B5) shows, together with equation (B3), that $\hat{\varepsilon}_{j}$ is equal to $\bar{\varepsilon}_{j}$ defined in equation $(2)$.

\section{Judge mobility and judge ranking}

To illustrate the relation between the mobility of judges and their ranking according to their bias, suppose a simple situation with one period only and four judges, $A, B, C, D$, ranked from the least to the most (unknown) pro-worker bias. Suppose that $A$ and $D$ belong to the same social chamber and that $C$ and $B$ belong to another social chamber during the whole period. Our measure of the bias relies on the difference in the share of dismissals deemed wrongful by different judges belonging to the same social chamber with respect to the average share of dismissals deemed wrongful in that social chamber. It allows us to conclude that $D$ is more pro-worker 
than $A$ and that $C$ is more pro-worker than $B$. But it yields information neither about the comparison of $B$ and $A$ nor about the comparison of $D$ and $C$ because the average share of dismissals deemed wrongful in the social chamber is different, and depends, among other factors, on the true bias of judges allocated to the social chamber. Depending on the selection of judges in social chambers according to their bias, we may conclude that the ranking is (by increasing order of pro-worker bias) $B, A, C, D$, or $B, C, A, D$ or $A, D, B, C$ instead of the true ranking $A, B, C, D$. In our approach, this problem is mitigated insofar as judges are mobile across social chambers. In the previous example, $A$ might, during the period of interest, share the same social chamber as both $D$ and $B$, which may enable us to rank $A, B$ and $A, D$. Such judge mobility thus may help us to exclude the erroneous rankings $B, A, C, D$ and $B, C, A, D$. Hence, the higher the degree of judge mobility, the higher the probability to achieve a perfect ranking.

\section{Risk premium associated with the bias of judges}

This appendix presents the computation of the approximation of the risk premium associated with the bias of judges following standard treatment of the computation of risk premium (see e.g. Eeckhoudt et al. (2005)).

Let us consider a lottery which yields $w(1+e)$, where $w$ is a fixed amount and $e$ is a random variable, whose expected value is $\mathbb{E}(e)=0$. Let us denote by $u$ the von Neumann and Morgenstern utility function. The relative risk premium $\pi$ associated with the random term $e$ is defined by

$$
\mathbb{E}(u[w(1+e)])=u[w(1-\pi)]
$$

First order approximation of $u[w(1-\pi)]$ in the neighborhood of $\pi=0$ yields:

$$
u[w(1-\pi)] \simeq u(w)-\pi w u^{\prime}(w)
$$

Second order approximation of $\mathbb{E}[w(1+e)]$ in the neighborhood of $e=0$ yields:

$$
\begin{aligned}
\mathbb{E}(u[w(1+e)]) & \simeq \mathbb{E}\left[u(w)+w e u^{\prime}(w)+\frac{1}{2}(w e)^{2} u^{\prime \prime}(w)\right] \\
& =u(w)+w \mathbb{E}(e) u^{\prime}(w)+\frac{1}{2} \mathbb{E}\left((w e)^{2}\right) u^{\prime \prime}(w) \\
& =u(w)+\frac{w^{2}}{2} \mathbb{E}\left(e^{2}\right) u^{\prime \prime}(w)
\end{aligned}
$$

Substituting these two approximations into equation (D6), we get

$$
\pi \simeq \frac{1}{2} \mathbb{E}\left(e^{2}\right) \rho(w)
$$

where $\rho(w)=-\frac{w u^{\prime \prime}(w)}{u^{\prime}(w)}$ is the Arrow Prat coefficient of relative risk aversion.

Now, if we consider another lottery, which yields $w\left(1+e_{1}\right)$, where $w$ is the same fixed amount as in the first lottery and $e_{1}$ is a random variable, with $\mathbb{E}\left(e_{1}\right)=0$, we can compute the risk premium in the same way and get

$$
\pi_{1} \simeq \frac{1}{2} \mathbb{E}\left(e_{1}^{2}\right) \rho(w)
$$

The two last equations imply that

$$
\pi_{1}-\pi \simeq \frac{1}{2}\left[\mathbb{E}\left(e_{1}^{2}\right)-\mathbb{E}\left(e^{2}\right)\right] \rho(w)
$$


In our setup, $e_{1}$ can be defined as the random variable including judge bias and $e$ as the random variable without judge bias. Therefore, $\pi_{1}-\pi$ can be interpreted as the risk premium associated with the judge bias.

The variance of total compensation is equal to

$$
\mathbb{E}\left[\left(w\left(1+e_{1}\right)\right)^{2}\right]-\left[\mathbb{E}\left(w\left(1+e_{1}\right)\right)\right]^{2}=w^{2} \mathbb{E}\left(e_{1}^{2}\right)
$$

Now, let us assume that the judge biases explain the share $\lambda$ of the variance of total compensation, i.e.

$$
\lambda=\frac{w^{2} \mathbb{E}\left(e_{1}^{2}\right)-w^{2} \mathbb{E}\left(e^{2}\right)}{w^{2} \mathbb{E}\left(e_{1}^{2}\right)}=\frac{\mathbb{E}\left(e_{1}^{2}\right)-\mathbb{E}\left(e^{2}\right)}{\mathbb{E}\left(e_{1}^{2}\right)}
$$

Substituting in (D7) we get:

$$
\pi_{1}-\pi \simeq \lambda \frac{1}{2} \rho(w) \mathbb{E}\left(e_{1}^{2}\right)
$$

or, using the expression of $\mathbb{E}\left(e_{1}^{2}\right)$ given in equation (D8):

$$
\pi_{1}-\pi \simeq \lambda \frac{1}{2} \rho(w) \frac{\mathbb{V}\left[w\left(1+e_{1}\right)\right]}{w^{2}}
$$

According to Table 2, the standard deviation of compensations for wrongful dismissal is equal to 56,385 euros and the mean compensation amounts to 31,461 euros. Table 4 shows that the dispersion of judges biases explains $0.3 \%$ of the variance of compensations for wrongful dismissals. This implies that the risk premium is equal to $(0.003)(1 / 2)(56385 / 31461)^{2} \approx 0.0048$ times the coefficient of relative risk aversion, whose estimation is between 1 and 3 for workers (Chetty (2006); Hendren (2017)) and smaller for firms which have more possibility of risk diversification.

\section{E Extraction of compensation amounts and other vari- ables of Appeal court rulings}

This section provides additional details on the construction of our novel database of anonymized Appeal court rulings. We use the universe of Appeal court ruling over ten years. The latter are available and digitized on a systematic basis, contrary, to first instance rulings, which are collected locally at the court level and are not compiled in a common legal database. We use Natural Language Techniques (NLP) to extract the information from close to 145,000 text documents. Each of these rulings is a few pages long, with some spreading over a dozen pages. Extracting information accurately from textual documents that contain many digressions and qualitative arguments is not a straightforward exercise. In order to reduce the complexity of the problem, we exploit the structure of these legal documents, which follow a well-established template.

\section{Structure and recognizable information within rulings}

Each ruling can naturally be divided into roughly five blocks as follows i) a brief header with the case number, the date of the audience, identities of the parties, etc.; ii) a description of the history of the contractual relationship between the employee and the employer with the parties' claims iii) a restatement of the decision appealed; iv) the main arguments behind the rulings containing the reassessment by the Appeal Court of factual elements and the legal groundings of the first-instance decision; and v) the conclusion ruling whether the dismissal is deemed wrongful, and assigning monetary awards, if any. We split these main blocks by tagging the text with specific legal keywords used to mark the boundaries of the different sections. For instance, the 
conclusion is generally introduced by the expression "Par ces motifs" (For these reasons) or variants thereof.

We then extract the information from each block and generate up to several hundred variables for any given text. This is because there is a wide array of potential damages that can be sought by the parties and/or awarded. Besides compensation for wrongful dismissal (indemnité pour licenciement sans cause réelle et sérieuse), the following compensations may also be awarded by Appeal court judges: compensation for non-respect of the dismissal procedure; compensation for unpaid wages (indemnité pour rappel de salaire); compensation for moral and financial damages (indemnité pour préjudice moral et financier); compensation in lieu of notice period (indemnité compensatrice de préavis) when the notice period was not respected; compensation under article 700 of the French Code of Civil Procedure, which covers the legal costs of the wining party; compensation for unpaid annual leave (indemnité compensatrice de congés payés) ; allowance for overtime hours (heures supplémentaires). An employee may receive these different compensations concurrently.

It is important to track compensations along all these dimensions because the amounts granted by judges under these various motives are not fully independent, even though in principle the legal bases for granting them are distinct. In other words, it is possible that in a judge's assessment of the case the amounts become correlated. To detect substitution between the different types of monetary awards, we keep track of all of them using initially more than twenty categories before aggregating them. Because of the length of legal proceedings, some amounts, still expressed in French francs before the adoption of the Euro in 2001, also need be appropriately converted.

It turns out that judges often award these other types of compensation. They are awarded alongside compensations for wrongful dismissal to workers, but not only that, as rightful dismissal can also be marred by procedural irregularities. In total, out of 145,000 cases in our original sample of court decisions, a positive amount is awarded to workers in $60 \%$ of the cases, whatever the motive. Out of these cases receiving a positive amount, the dismissal is deemed unfair $61 \%$ of the time. But workers also receive compensation for other reasons, such as paid leave $(47 \%$ of cases), advance notice (40\%), salaries $(13 \%)$ or overtime hours $(7 \%)$ when these amounts were due but had not been fully paid by the employer prior to the dismissal. More rarely do judges award compensation for moral damage $(2 \%)$, harassment $(2 \%)$ or discrimination $(0.3 \%)$. One or several of these other types of compensation are awarded in $93 \%$ of the cases with a positive amount paid to the worker at the end of the trial.

The data include a wide array of variables related to the case (compensations for wrongful dismissals, worker seniority, wage, Appeal court, city of the Prud'hommes council, whether it was the worker who appealed, etc.), as well as the firm's name and address. Using the firm's name and address we are able to retrieve the firm identifier (SIREN), and then link the compensation dataset to matched employer-employee data as well as financial variables. The stages for the construction of this dataset are the following.

Extracting wages and tenure requires paying close attention to the wording of rulings as there is substantial heterogeneity in how they are reported. For instance tenure information is sometimes not explicitly stated as a duration but can to be recovered from the mentions of when the employee was hired. We therefore use multiple approaches to revover the information. Recovering wages is crucial in order to express the compensation in terms of months of salary. Again, we target a large number of keywords to detect mentions of annual, monthly, weekly, or even hourly wages. Despite our best efforts, for some court rulings the information could not be fully extracted, thus creating missing observations. 


\section{Variable selection and sample attrition}

Heterogeneity in the writing of the rulings across jurisdictions and over time means that an automatic extraction can generate mistakes and approximations. Therefore we conducted a series of manual checks on a subsample of 2,560 observations, selected at random. The manual dataset creation was undertaken as part of a project of Pierre Cahuc and Stéphane Carcillo, and funded by the Chaire sécurisation des parcours professionnels. To examine the Appeal court rulings published by the Minister of Justice, ten research assistants were hired, each of them being in charge of a given year. These assistants carried out the research with the following key words: 'licenciement sans cause réelle et sérieuse' (unfair dismissal) and 'indemnités' (compensation). Even though the research assistants were asked to select randomly Appeal court rulings within the year, some of them selected only rulings from particular months: the assistants in charge of studying the 2009, 2010 and 2012 years mostly selected court rulings of September and October, and marginally court rulings from November and December. We find that the correlation between the compensation amount of the manually-filled and the automatically-filled datasets is equal to $94 \%$, which is in the upper range of seminal papers using this type of approach (Baker et al. (2016)). 